\title{
Soil Geosynthetic Interaction: Design Parameters from Experimental and Theoretical Analysis
}

\author{
Nicola Moraci • Giuseppe Cardile • \\ Domenico Gioffrè • Maria Clorinda Mandaglio • \\ Lidia Sarah Calvarano • Laura Carbone
}

Accepted: 26 March 2014 / Published online: 2 May 2014

(C) Springer New York 2014

\begin{abstract}
The main objective of this paper is to discuss the experimental and theoretical approaches developed by different researchers in order to understand and to evaluate the soil geosynthetic interaction under different loading conditions. In the paper, the soil-geosynthetic interaction in pullout, direct shear, and inclined plane tests under both static and cyclic loading is analyzed based on the different theoretical and experimental results carried out by the authors and also available in literature. For each type of test, the factors affecting test results and soil-geosynthetic interface behavior, the theoretical model developed to predict the interface resistance and mobilized friction, and the relevance of the interface parameters obtained through the different tests in the design and performance of geosynthetic reinforced earth structures are discussed in detail.
\end{abstract}

Keywords Geosynthetic $\cdot$ Interaction $\cdot$ Design $\cdot$ Laboratory tests $\cdot$ Modeling

\footnotetext{
N. Moraci $(\bowtie) \cdot$ G. Cardile $\cdot$ D. Gioffrè $\cdot$ M. C. Mandaglio $\cdot$ L. S. Calvarano $・$ L. Carbone Civil, Energy, Environmental and Materials Engineering Department, Mediterranea University of Reggio Calabria, DICEAM, Via Graziella, Località Feo di Vito, 89060 Reggio Calabria, Italy e-mail: nicola.moraci@unirc.it

G. Cardile

e-mail: giuseppe.cardile@unirc.it

D. Gioffrè

e-mail: domenico.gioffre@unirc.it

M. C. Mandaglio

e-mail: linda.mandaglio@unirc.it

L. S. Calvarano

e-mail: lidia.calvarano@unirc.it

L. Carbone

e-mail: laura.carbone@unirc.it
} 


\section{Abbreviations}

$A_{b} \quad$ Area of each rib element of geogrid $\left(\mathrm{mm}^{2}\right)$

$a_{b o x} \quad$ Upper box acceleration $\left(\mathrm{m} / \mathrm{s}^{2}\right)$

$a_{\text {const }} \quad$ Constant acceleration of the upper box during the slide $\left(\mathrm{m} / \mathrm{s}^{2}\right)$

$A_{r} \quad$ Node embossment area $\left(\mathrm{mm}^{2}\right)$

$A_{t} \quad$ Bar portion between two nodes area $\left(\mathrm{mm}^{2}\right)$

$B \quad$ Bearing member thickness (mm)

$B_{L} \quad$ Lower support minimum width (m)

$B_{U} \quad$ Upper box minimum width (m)

CRD Constant rate of displacement $(\mathrm{mm} / \mathrm{min})$

$C_{\alpha S} \quad$ Reduction coefficient of geogrid area where skin friction develops

D Damping ratio (\%)

DI Degree of interference

$D_{50} \quad$ Average grain size (mm)

$D_{85} \quad$ Grain size corresponding to $85 \%$ in weight of passing soil (mm)

$D_{\max } \quad$ Maximum grain size $(\mathrm{mm})$

$\mathrm{Dr} \quad$ Relative density (\%)

$f \quad$ Cyclic tensile load frequency $(\mathrm{Hz})$

$F(\beta) \quad$ Force required to hold back the upper box $(\mathrm{kN})$

F1 Scale effect coefficient

F2 Shape effect coefficient

$f_{b} \quad$ Soil-geosynthetic pullout interaction coefficient

$f_{d s} \quad$ Soil-geosynthetic interface coefficient of direct sliding

$K \quad$ Geogrid shear stiffness $(\mathrm{kN} / \mathrm{m})$

$L_{L} \quad$ Lower support minimum length along the displacement direction (m)

$L_{R} \quad$ Reinforcement length in the anchorage zone (m)

$L_{U} \quad$ Upper box minimum length along the displacement direction (m)

$n_{t} \quad$ Number of geogrid bearing members

$n_{t b} \quad$ Number of nodes in a transversal element

$P_{b 1} \quad$ Maximum pullout bearing force of a single isolated transverse member $(\mathrm{kN} / \mathrm{m})$

$P_{b n} \quad$ Maximum pullout bearing force $(\mathrm{kN} / \mathrm{m})$

$P_{\text {max }}^{C} \quad$ Maximum applied cyclic tensile load $(\mathrm{kN} / \mathrm{m})$

$P_{i} \quad$ Initial pullout load $(\mathrm{kN} / \mathrm{m})$

$P_{R} \quad$ Pullout resistance (per unit of width) $(\mathrm{kN} / \mathrm{m})$

$P_{R}{ }^{C} \quad$ Post-cyclic pullout resistance $(\mathrm{kN} / \mathrm{m})$

$P_{R}^{S} \quad$ Static pullout resistance $(\mathrm{kN} / \mathrm{m})$

$\mathrm{P}_{R B} \quad$ Bearing component of pullout resistance $(\mathrm{kN} / \mathrm{m})$

$P_{R S} \quad$ Skin friction component of pullout resistance $(\mathrm{kN} / \mathrm{m})$

$S \quad$ Spacing between geogrid bearing members ( $\mathrm{mm}$ )

$\mathrm{T}_{\mathrm{d}} \quad$ long-term tensile strength $(\mathrm{kN} / \mathrm{m})$

$u \quad$ Upper box displacement (mm)

$u_{\text {lim }} \quad$ Maximum upper box displacement (mm)

$W_{R} \quad$ Geogrid specimen width (m)

$\alpha \quad$ Ratio between soil-geosynthetic interface shear strength and soil internal shear strength

$\alpha_{\mathrm{B}} \quad$ Fraction of total frontal area of geogrid available for bearing resistance 


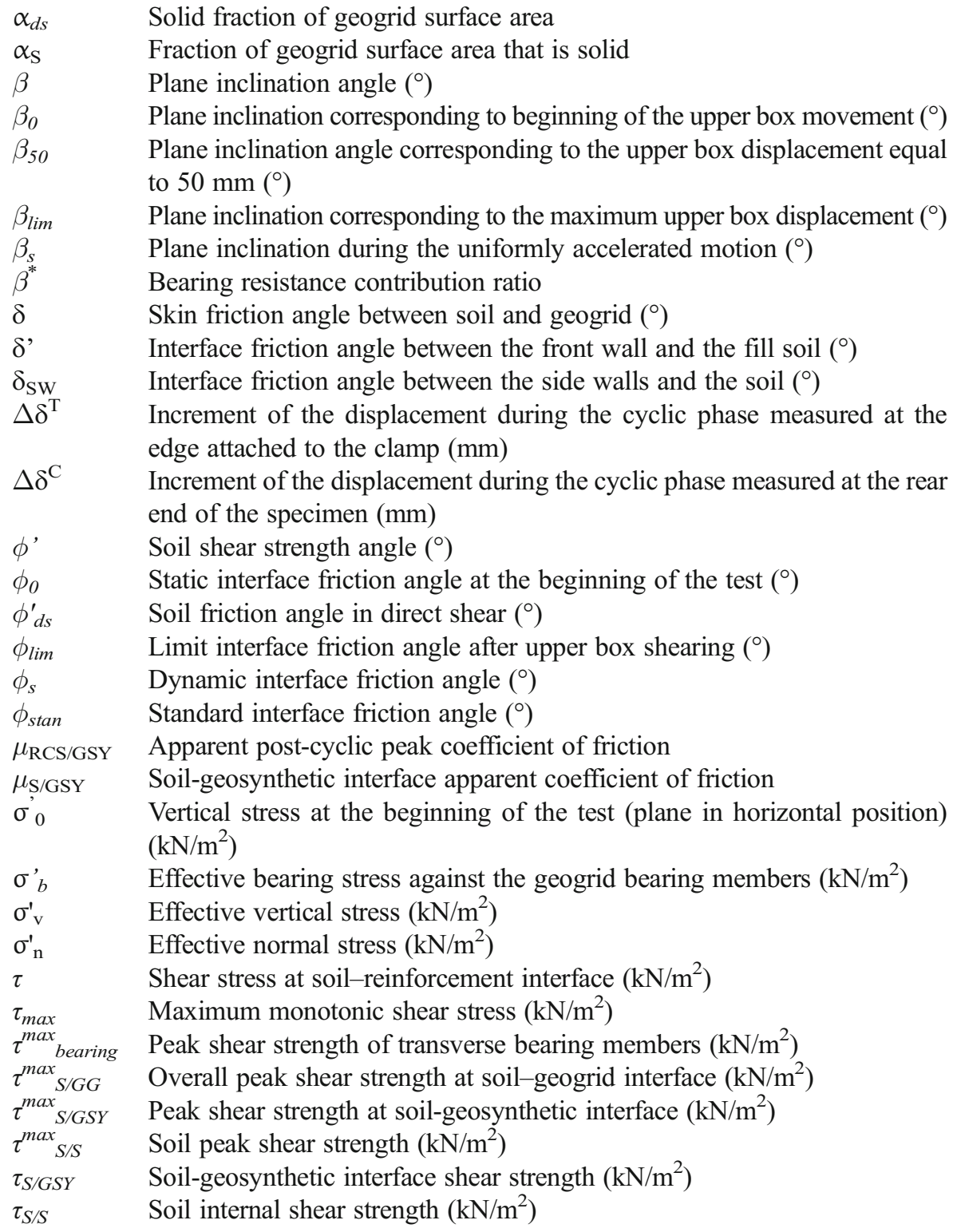

\section{Introduction}

The knowledge of soil-reinforcement interaction parameters, and their evolution over time, also linked to the variation of the applied loads, is particularly important in the design of geosynthetic reinforced soil structures. In fact, the reinforcement length and, consequently, the size of the reinforced block depend on the assumed interface apparent coefficient of friction.

The soil geosynthetic interaction can be very complex because it is affected by structural, geometrical, and mechanical characteristics of the geosynthetic by the 
mechanical properties of soil and by boundaries and loading conditions. In particular, the skin friction is the only mechanism that develops at soil-geotextile interface, while for geogrid, due to its open structure, the interaction becomes more complex.

In particular, for geogrid, three different elementary interaction mechanisms could be mobilized at interface as follows: the friction between soil and solid reinforcement surface, the passive resistance mobilized against the bearing members, and the friction between the soil enclosed within the openings of the reinforcement and the surrounding one [1]. Depending on the considered failure mechanism and on the geometrical structure of the reinforced element (continuous or open mesh type), one or more of the above elementary interaction mechanisms can be mobilized.

The complex behavior at soil-geosynthetic interface is generally approximated by introducing an equivalent frictional shear stress that allows evaluating an overall resistance, referred to the whole reinforcement surface. In order to study the soil-geosynthetic interaction, different tests and theoretical analyses have been developed during the last decades.

Figure 1 shows possible failure mechanisms of geosynthetic reinforced soil wall. In the blue mechanism, sliding of the soil mass on reinforcement surface is considered; in this case, direct shear tests can be performed to quantify soil-reinforcement interaction. In the red mechanism, the reinforcement is pulled out, so pullout tests can be used.

Finally, the inclined plane test is suitable in order to investigate the interface properties under low vertical stresses as in the cases of inclined barrier and cover systems in landfills. In fact, in these cases, the interfaces can be critical surfaces where sliding may occur due to an improper assessment of the interface shear strength.

The main objective of this paper is to discuss the experimental and theoretical modeling for the understanding and evaluation of soil-geosynthetic interaction in order to emphasize the relevance of the interface parameters in the design and performance of geosynthetic reinforced earth structures.

\section{Soil-Geosynthetic Interaction in Pullout Loading Conditions}

Pullout tests are necessary in order to study the interaction behaviour between soil and geosynthetics in the anchorage zone; hence, these properties have direct implications in

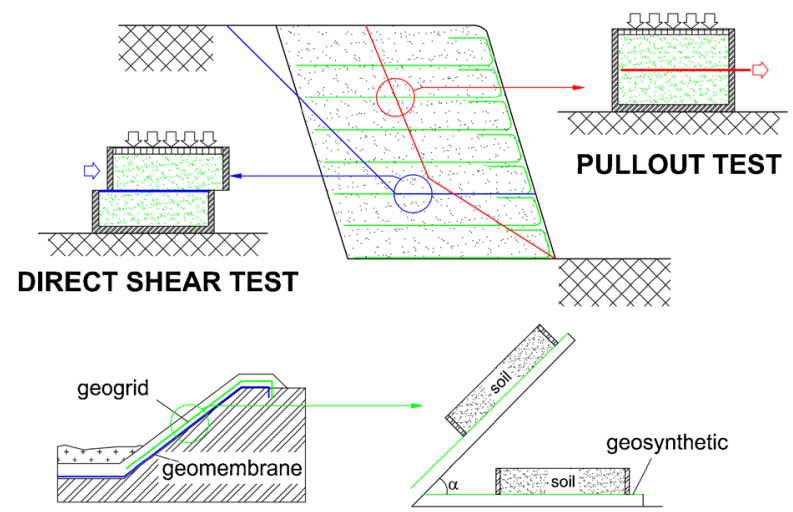

INCLINED PLANE TEST

Fig. 1 Example of soil-geosynthetic interaction mechanisms and test devices used to simulate the interface behavior 
the design of geosynthetic reinforced soil structures. The test method is intended to be a performance test conducted as closely as possible to replicate design or as built conditions [2].

The pullout resistance can be described by the following equation:

$$
P_{R}=2 \cdot L_{R} \cdot \sigma_{v}^{\prime} \cdot f_{b} \cdot \tan \phi^{\prime}=2 \cdot L_{R} \cdot \sigma_{v}^{\prime} \cdot \mu_{S / G S Y}
$$

Where $P_{R}$ is the pullout resistance (per unit of width), $L_{R}$ is the reinforcement length in the anchorage zone, $\sigma^{\prime}{ }_{v}$ is the effective vertical stress, $\phi^{\prime}$ is the soil shear strength angle, $f_{b}$ is the soil-geosynthetic pullout interaction coefficient, and $\mu_{S / G S Y}$ is the soilgeosynthetic interface apparent coefficient of friction.

The pullout interaction coefficient $f_{b}$ may be determined by means of theoretical expressions [1], whose limits have been investigated by different researchers [3-5], or by back-calculation from pullout test results. Previous experimental studies $[3,4,6]$ have shown that the values of $f_{b}$ are largely influenced by the choice of the value of the soil shear strength angle.

In the absence of a clear indication regarding the choice of the soil shear strength angle to be used for the determination of $f_{b}$, the problem of the assessment of the pullout resistance may be overcome by the use of the soil-geosynthetic interface apparent coefficient of friction determined by means of large-scale pullout tests, using the following equation:

$$
\mu_{S / S G Y}=f_{b} \cdot \tan \phi^{\prime}=\frac{P_{R}}{2 \cdot L_{R} \cdot \sigma_{v}^{\prime}}
$$

It is important to notice that the determination of $\mu_{S / G S Y}$, using Eq. 2, can be performed without any assumption about the values of the soil shear strength angle mobilized at the interface, since all the parameters of Eq. 2 can be easily determined from the pullout tests. Nevertheless, it is important to define the role of all the design and test parameters on the mobilization of the interaction mechanisms (frictional and passive) in pullout loading conditions.

\section{Factors Affecting Pullout Test Results}

Several pullout test devices were developed by different researchers. The pullout apparatus is basically composed of a rigid steel large pullout box, a vertical load application system, a horizontal force application device, a clamp system, and all the required control and data acquisition instruments $[3,7,8]$.

The pullout test procedure is generally conducted as follows: preparation of the internal walls in order to minimize the friction, filling and compaction of soil in the lower half of the box, placement of geosynthetic specimen and installation of test instrumentations, filling and compaction of soil in the upper half of the box, placement of the air bag used to apply the vertical load, closing of pullout box, connection of the top cover and of the clamp system with the load application devices, and connection of test instrumentation and start of the test.

The main factors affecting the pullout test results are showed in the Table 1 . These factors are related to the test apparatus and procedure, to the soil geotechnical properties, and to the reinforcement characteristics. 
Table 1 Main factors affecting pullout test results

\begin{tabular}{|c|c|c|c|}
\hline Test apparatus & Test procedure & Soil & Reinforcement \\
\hline $\begin{array}{l}\text { Vertical load application } \\
\text { system }\end{array}$ & Displacement rate & Type & Type \\
\hline Front wall effect & Soil specimen preparation & $\begin{array}{l}\text { Grain size } \\
\text { distribution }\end{array}$ & $\begin{array}{l}\text { Specimen width and } \\
\text { length }\end{array}$ \\
\hline $\begin{array}{l}\text { Friction between side wall } \\
\text { and soil }\end{array}$ & Applied vertical stress & $\begin{array}{l}\text { Degree of } \\
\text { compaction }\end{array}$ & Specimen tensile stiffness \\
\hline Pullout box dimensions & $\begin{array}{l}\text { Instrumentation characteristic and } \\
\text { installation }\end{array}$ & Shear strength & $\begin{array}{l}\text { Specimen geometry and } \\
\text { structure }\end{array}$ \\
\hline Clamping system & & & \\
\hline
\end{tabular}

The different pullout test devices differ in the box dimensions and in the methods used to minimize the effects of the boundary conditions on the test results. Moreover, different testing procedures are used.

\section{Influence of Boundary and Test Conditions}

For a better understanding of the effects that the boundary conditions and the apparatus scale effect have on the pullout results, different researchers [4, 8-16] performed pullout tests on prototype equipment properly instrumented.

The comparison between the results of these researches has allowed to identify the following factors affecting the pullout test results: the influence of the vertical load application system, the influence of the boundary conditions at the front wall, the efficiency of the methods used to minimize the friction between side walls and soil, the influence of the box sizes and in particular of the thickness of the soil (soil specimen height) below and above the geosynthetic specimen in order to avoid the boundary effects, the influence of geosynthetic specimen width, the influence of the clamping device, and the influence of the displacement rate used in the test.

\section{Influence of Vertical Load Application System}

The vertical confining stress is applied by means of a flexible membrane (usually rubber) filled with liquid or gas (air bag). The second system allows constant normal stresses and the possibility of free vertical displacement at every point of the soil surface contact area.

The influence of two different vertical load application systems was studied by Palmeira and Milligan [4] comparing the results of pullout tests performed with both rigid and flexible loading application systems. Pullout results showed that, if a flexible type load application system is used, the maximum pullout force is lower than the one obtained using a rigid load application plate. It is important to notice that the use of a flexible membrane allows a uniform load distribution on contact area. 


\section{Influence of Boundary Conditions at the Front Wall}

The influence of the boundary conditions at the front wall was studied by many authors by means of pressure cells placed at the front wall at different positions. These measurements have shown that the pressure applied on the front wall grows continuously as the test progresses $[9,13,17,18]$; the peak value is found in the vicinity of the geogrid and then the pressure on the front wall decreases symmetrically towards top and bottom boundaries.

By comparing pullout test results carried out with different roughness at the front wall (Fig. 2), Palmeira and Milligan [4] have demonstrated that the apparent friction angle mobilized at the interface increases with the interface friction angle $\delta$ ' between the front wall and the fill soil.

In order to study the influence of the stiffness of the front wall, Sugimoto et al. [9] performed pullout tests with a special equipment capable of providing both rigid and flexible boundary conditions (Fig. 3). In the case of the rigid boundary, no displacement at the front wall is allowed; vice versa, for the flexible boundary (obtained by means of two membranes filled with air in pressure and arranged between the soil and the front wall of the box), free movements at the front wall are possible.

It was found that the stiffness of the front wall influences the distribution of the displacements along the reinforcement length and therefore the mobilization of the interaction mechanisms. With a flexible front wall, there is an uniform distribution of the interaction mechanisms along the reinforcement, while with a rigid front wall, the interaction mechanisms (i.e., the skin friction between soil and reinforcement solid surface and the bearing resistance that develops against transversal elements) along the reinforcement are not uniform.

This effect was explained by Sugimoto et al. [9], as the consequence of the local increase of the relative density of the soil close to the front wall caused by an imposed discontinuity in the displacement field (rigid front wall), that in the case of flexible front wall is not significant.

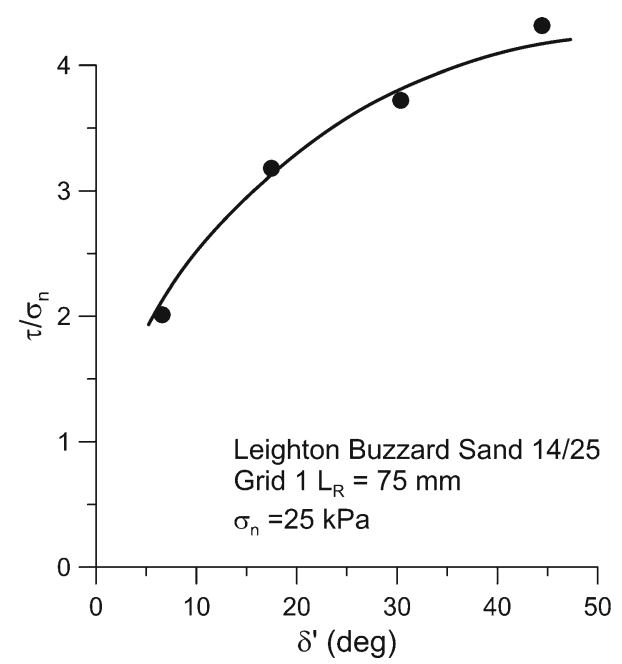

Fig. 2 Boundary effects on pullout tests: effect of front wall roughness [4] 

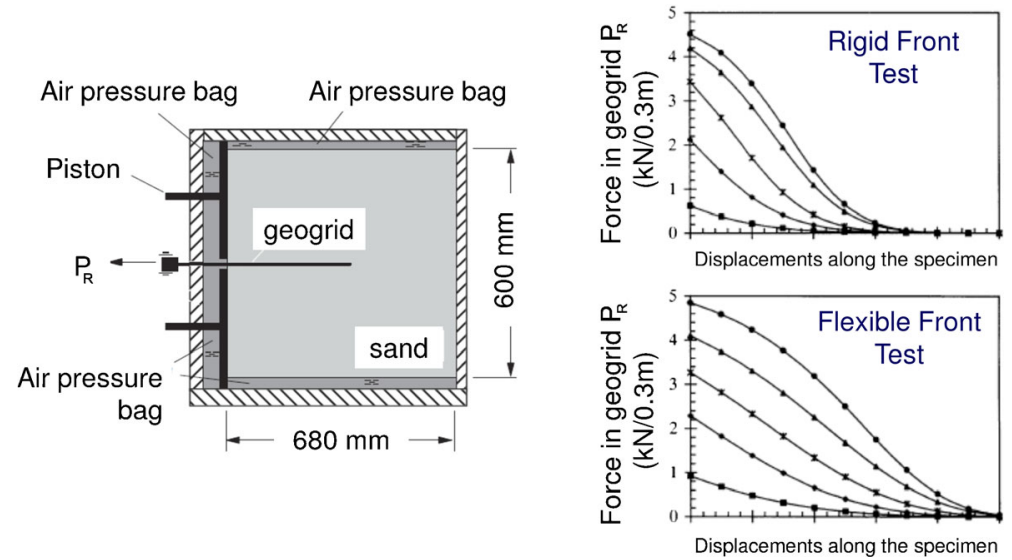

Fig. 3 Boundary effects on pullout tests: effect of front wall stiffness [9]

Generally, in order to minimise the friction effects at the front wall, low friction materials glued to the walls are used. In addition, to avoid front wall effects, the front confined section of the reinforcement specimen is moved to a suitable distance from the front wall by means of metal sleeves fixed to the front wall.

Moreover, the experimental results demonstrate that the influence of the stiffness of the front wall is lower for large pullout boxes and for boxes having a large distance between the first confined section of the geosynthetic specimen and the front wall (sleeves). Different researchers [19-22] have studied the influence of the sleeve length on pullout test results.

From the comparison of pullout tests carried out without sleeves and with different sleeve lengths, Farrag et al. [20] have observed that the increasing of the sleeve length causes a reduction of the pullout resistance and of the pressure exerted on the front wall. Based on test results performed with different sleeve lengths, the authors proposed to use sleeve length of $0.30 \mathrm{~m}$ in order to minimize front wall effects (Fig. 4).

\section{Efficiency of Methods Used to Minimize Friction Between Side Walls and Soil}

The boundary conditions on the side walls of the pullout box have a marked influence on test results. The effective vertical confining stress acting at the soil-reinforcement

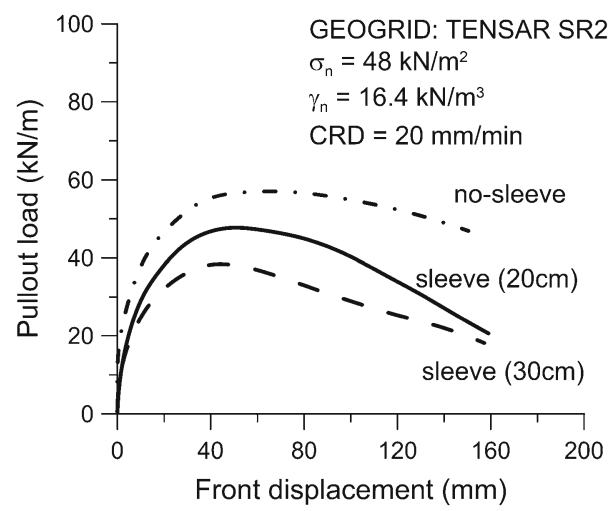

Fig. 4 Influence of the method used to minimize front wall friction: influence of sleeves length [20] 
interface is due to the normal stress applied on the top soil specimen and to the dead weight of the soil above the interface. Considering the thickness of the soil layer above the reinforcement, the friction developed along the lateral walls of the pullout box can lead to confining stresses lower than those expected [13, 17, 20].

Also in these cases, in order to minimize the friction effects at the side walls, low friction materials glued to the walls (Teflon, smooth aluminum, glass, and lubricated rubber membranes) must be used.

\section{Influence of Soil Specimen Height to Avoid Boundary Effects}

The rigid boundaries above and below the reinforcement plane can affect the interaction mechanisms between soil and geogrid. These boundaries can lead to an increase in the normal stresses acting on the geosynthetic specimen surface, especially when the soil thickness is small and the soil dilatancy is restrained.

An important indication on the choice of the proper height of the pullout box is given by tests carried out by Farrag et al. [20] for different soil layer height, $H$. It was found that a soil layer height of $30 \mathrm{~cm}$, above and below the reinforcement plane, is recommended in order to avoid the effect of the rigid boundary.

\section{Influence of Clamping System, of Specimen Width, and of Displacement Rate}

Another important topic is the configuration of the clamping system used to apply the pullout tensile force that can be either outside or inside the pullout box [3, 7]. In the second case, the clamping system is inserted at a given depth into the test box, embedded in the soil, in order to allow total confinement of the reinforcement during the test.

According to Farrag and Morvant [11] and Moraci and Montanelli [3], in the tests performed with an external clamping device, pullout curves should be plotted referring to the displacement of a point of the specimen that is as close as possible to the clamping device but that remains within the confining soil during the whole duration of the test. In fact, the first nodal displacement inside the soil is less than the displacement in correspondence of the pullout force application point. Moreover, the adoption of an external clamping system leads to a reduction of the specimen anchorage length as the test proceeds; this reduction must be considered in the interpretation of the test. The internal clamping device has three main advantages: the anchorage length is constant for the whole test duration; the displacement measured at the clamp is exactly the displacement of the first confined section of the geogrid; and it is possible to evaluate the geosynthetic confined tensile strength. This clamping system requires a series of preliminary calibration tests that have to be done, at the same boundary conditions, on the clamping system without any reinforcement, in order to evaluate the pullout resistance developed between the clamping system and the surrounding soil.

Theoretical and experimental studies carried out by Hayashi et al. [14] and by Moraci and Recalcati [8] have shown that for reinforcement specimens having a width smaller than the pullout box (narrow reinforcements), the tendency of soil dilatancy develops a three-dimensional effect (Fig. 5). In fact, the nondilating zone in the soil surrounding narrower geogrid specimens restrains soil dilatancy in the dilating zone. 


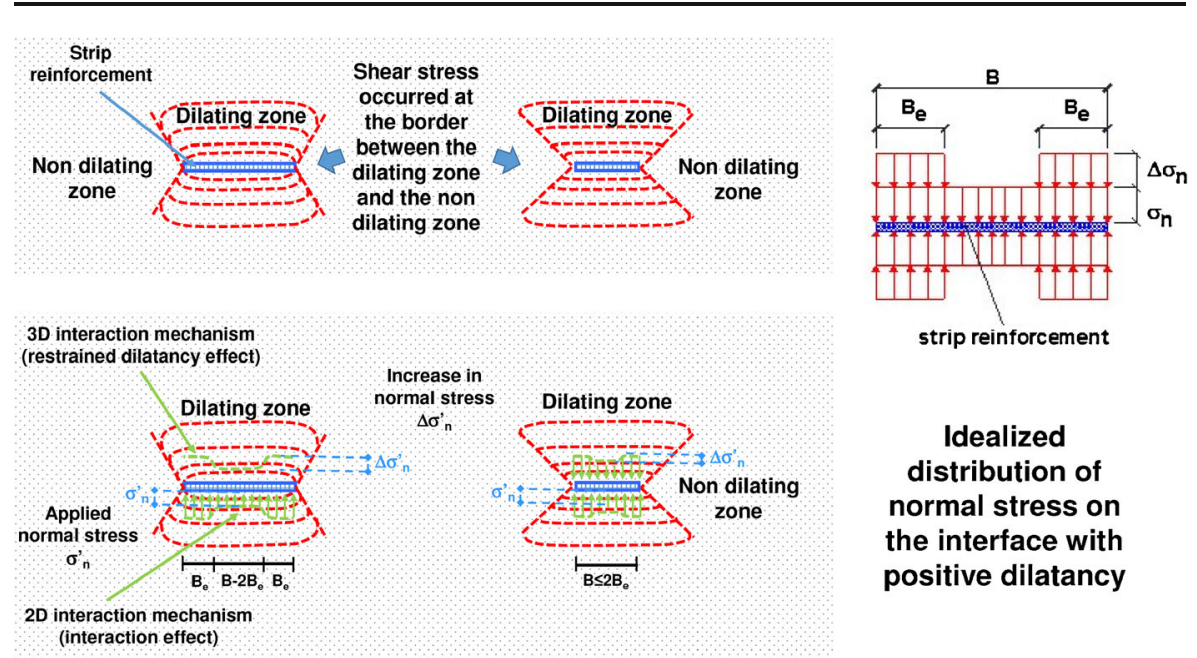

Fig. 5 Influence of specimen width: three-dimensional effect and idealized distribution of normal stress on interface [14]

This in turn generates shear stresses at the border between the two zones and produces an increase of the effective normal stress on the soil-geogrid interface and, consequently, an increase of pullout resistance. By increasing the specimen width, the aforementioned effect is reduced because the soil area that blocks the dilatancy decreases, and the shear stresses, due to the smoothness of the box walls lined with Teflon film, cannot be generated anymore (Fig. 6).

Measurements of the vertical stress obtained by means of small pressure cells distributed along the entire width of the reinforcement specimen and at a vertical small distance $(20 \mathrm{~mm})$ from the reinforcement [23] showed that, if proper techniques to reduce the friction between soil and the lateral walls are used, a uniform distribution of the initial confining stress can be obtained also for specimens having a width equal to the pullout box width.

Similar results were obtained by pullout tests performed by Chang et al. [13] on geogrid specimens having different width and varying the friction at the inner lateral wall interface by applying on the walls materials with different roughness.

From the analysis of these results, it can be concluded that the use of narrow reinforcement specimen, in order to reduce the influence of the friction between soil and lateral pullout box walls, can result in an overestimation of the interaction parameters obtained by laboratory tests. This overestimation is not conservative for design when the geosynthetic is used in reinforced soil, where the geosynthetic element works under plain strain conditions.

Finally, due to the physical-chemical properties of the constituent polymer (HDPE), the geogrids have a viscous-elastoplastic behavior when subjected to tensile load. Due to the viscous behavior, the geogrid mechanical properties depend on test temperature and test rate. Therefore, also pullout tests results depend on the displacement rate used. In order to compare the test results, the pullout tests performed on granular soils are generally carried out at a displacement rate equal to $1 \mathrm{~mm} / \mathrm{min}$. 


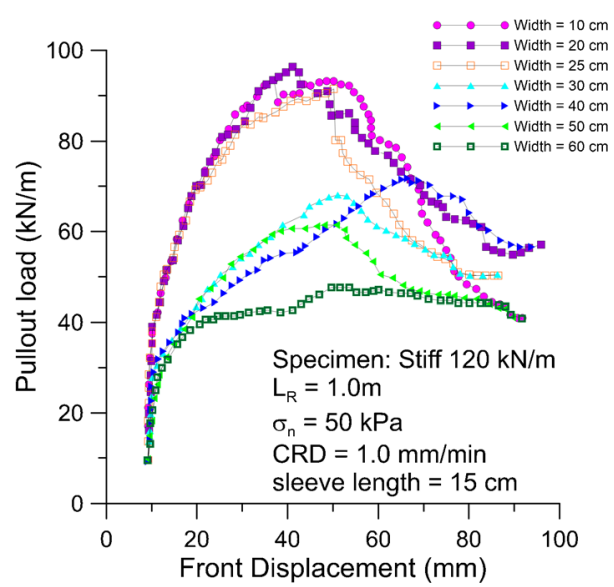

Fig. 6 Influence of specimen width on pullout test results (modified from Hayashi et al. [14])

Therefore, based on the considerations outlined in the previous paragraphs, an ideal large-scale pullout test device has to:

- Apply the vertical pressure by means of air bag

- Minimize the friction effects at the side walls, using low friction materials glued to the walls (Teflon, smooth aluminum, glass, and lubricated rubber membranes)

- Avoid the effects of the front wall using sleeves length at least of $20 \mathrm{~cm}$

- Maintain the GSY specimen always confined during the test using an internal clamping system

- Avoid the effects of bottom rigid boundary using a soil height in the box at least equal to $60 \mathrm{~cm}$

- Avoid tridimensional effect using GSY specimen width almost equal to the box width

Soil-Geosynthetic Interaction Under Monotonic Pullout Loading Conditions

Moraci and Recalcati [8] have proposed the use of a test procedure and a test apparatus that minimize all possible scale effects related to the boundary conditions, to the pullout box dimensions, and to the test procedure type.

Using the large pullout test apparatus developed by the authors [8] $(1,700 \mathrm{~mm} \times$ $680 \mathrm{~mm} \times 600 \mathrm{~mm}$ ), a wide experimental research was carried out in order to study the influence of different test parameters as follows: the applied vertical stress, the soil grain size distribution, the soil shear strength, the reinforcement width and length, the reinforcement stiffness, and the reinforcement geometry and structure.

The test results obtained by the authors in different researches [8, 24-28] clearly show the influence of the different parameters studied (reinforcement stiffness and structure, embedded length, and vertical effective stress) on the pullout behavior of extruded geogrids embedded in a granular soil. In particular, the main conclusions of the experimental research are discussed in the following.

The tensile strength in pullout conditions is very close to the tensile strength obtained by in air tests performed at the same rate of displacement of pullout tests. 
This means that the influence of soil confinement on reinforcement tensile strength is generally negligible.

The pullout behavior depends on reinforcement length and on the applied vertical stress. Generally, the tests performed with "long" specimens show a strain-hardening behavior. In this case, it is possible to observe that the pullout interaction mechanisms develop progressively along the reinforcement specimens; therefore, a progressive increase of the pullout resistance with the increase of the front displacement occurs. The tests performed on "short" specimens show a strain-softening behavior, with a progressive decrease of pullout resistance after peak value. In this case, the interaction mechanisms develop almost at the same time along the whole length of the specimen as showed by the displacements measured along the reinforcement specimen for different pullout resistance values (Fig. 7).

The phenomenon that has the largest influence on pullout strength and on the interface apparent coefficient of friction $\left(\mu_{S / G S Y}\right)$, both at peak and residual load conditions, is the dilatancy of the soil at the interface (Fig. 8). Due to dilatancy effects,
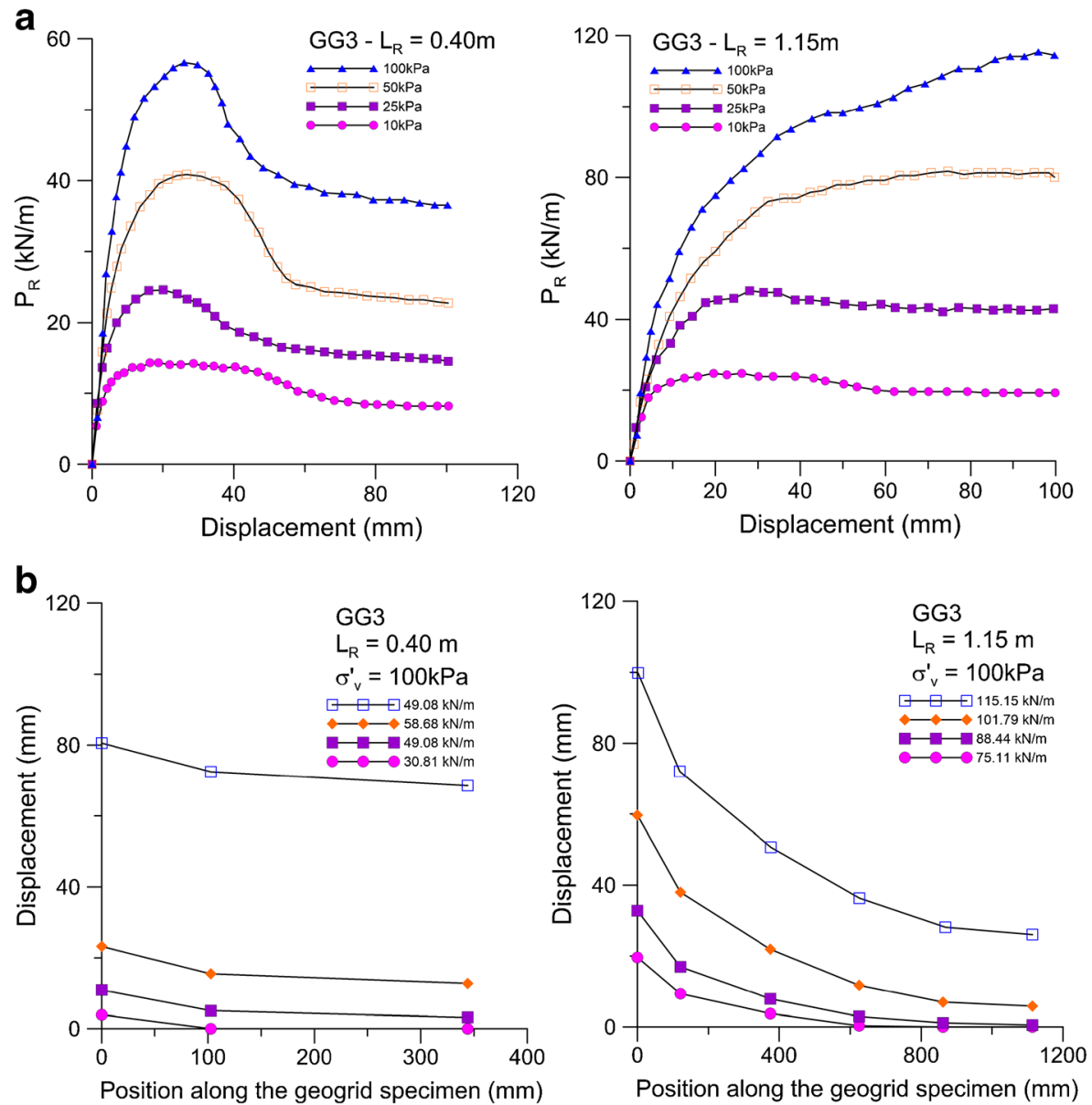

Fig. 7 Pullout test results for different specimen lengths and applied vertical stresses (a), and displacement along the specimen for different values of pullout resistance (b) [8] 

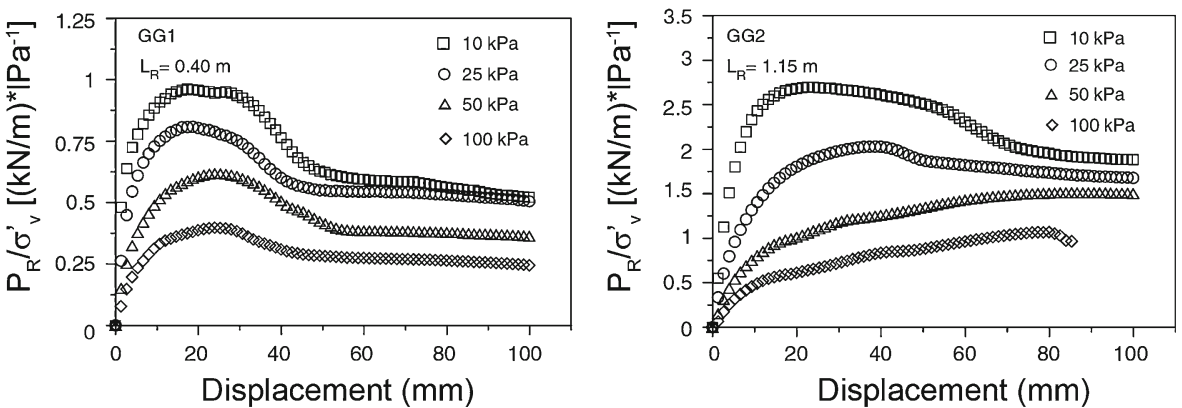

Fig. 8 Normalization of the pullout test results: the effect of soil dilatancy ( $L_{\mathrm{R}}=$ const.) [8]

the interface apparent coefficient of friction mobilized at low vertical effective confining pressure $(10 \mathrm{kPa})$ is higher than that at high confining pressure $(50$ or $100 \mathrm{kPa})$. The dilatancy phenomenon is related to the development of passive failure surfaces which are generated against the node embossments and the geogrid transversal bars.

The experimental results have also shown that the extensibility of reinforcement has an influence on peak pullout strength (Fig. 9). In particular, extensibility effects are more marked for long reinforcements and at high confining stresses (up to $50 \%$ ). On the other hand, under residual pullout load conditions, the extensibility effects are negligible.

The same considerations were obtained also in term of interface apparent coefficient of friction mobilized at the peak. In particular, a clear decrease of the apparent coefficient of friction, mobilized at the soil-geosynthetic interface under pullout conditions, from low to high effective vertical confined stresses, is showed. These results, mainly due to the soil dilatancy phenomena and secondly to the extensibility of the reinforcement, involve to consider in the design, values of the interface apparent coefficient of friction variables depending on the applied confinement stress and on the reinforcement anchorage length (Fig. 10).

Furthermore, for a determined soil-geosynthetic interface, it is possible to obtain the pullout resistance mobilized in the reinforcement for a given displacement of the point that separates the anchorage zone from the rigid block by performing pullout tests, in different boundary conditions $\left(\sigma^{\prime}, L_{R}\right)$. These results can be used in the design analysis based on the displacement methods [29].

Therefore, from the iso-displacement curves shown in Fig. 11, it is possible to obtain, for different anchorage lengths and confining stresses, the pullout forces
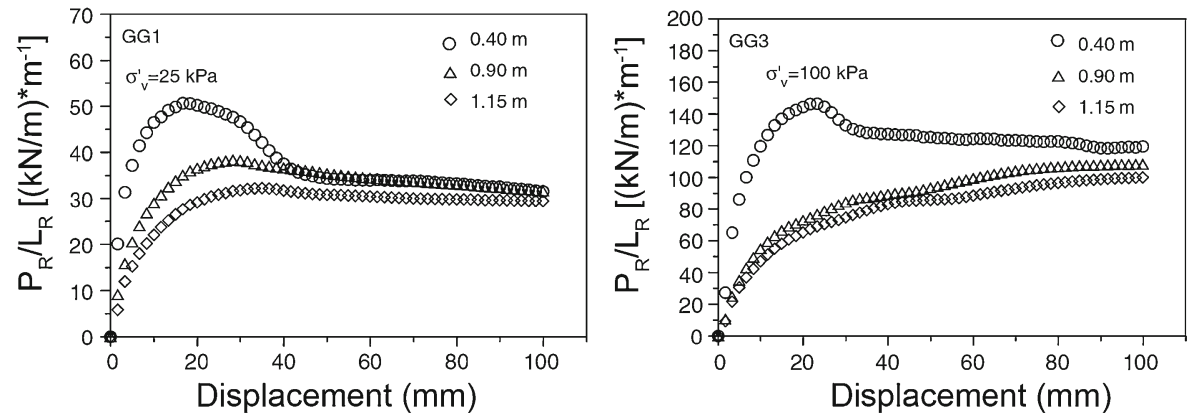

Fig. 9 Normalization of the pullout test results: effect of the reinforcement extensibility $\left(\sigma^{\prime}{ }_{v}=\right.$ const.) [8] 

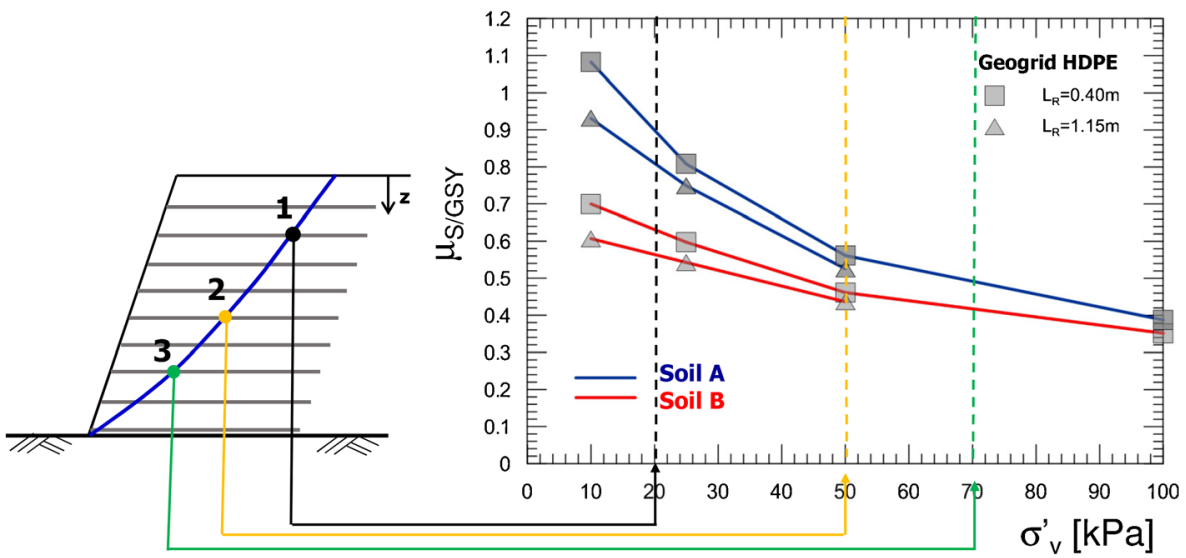

Fig. 10 Peak interface apparent coefficient of friction versus normal effective confining stress for different reinforcement lengths and soil types: soil $A$ uniform medium sand, soil B gravel with silty sand [24]

mobilized in the reinforcement for a given allowable displacement of the section that represents the boundary between the active and the anchorage zones [25].

\section{Soil-Geosynthetic Interaction Under Cyclic Pullout Loading Conditions}

Only a few researches about the soil-geosynthetic interface interaction under pullout cyclic and post-cyclic tensile loading conditions are available in literature [18, 30-36].

Recently, Moraci and Cardile [26, 27, 37] proposed a multistage pullout test procedure to evaluate the pullout behavior under cyclic and post-cyclic loading conditions composed of three different phases. In the first one, the pullout tests were performed under constant rate of displacement (CRD) equal to $1 \mathrm{~mm} / \mathrm{min}$. When a fixed pullout load was achieved, a sinusoidal cyclic tensile load of given frequency and amplitude was applied, at load control, for a fixed number of cycles. After this phase, the test was again carried out under CRD conditions at the same displacement rate used in the first stage of the test, until the pullout or the tensile failure was reached (Fig. 12). The comparison between the static pullout curves and multistage ones showed that the pullout cyclic loads produce a decrease of the post-cyclic pullout resistance.
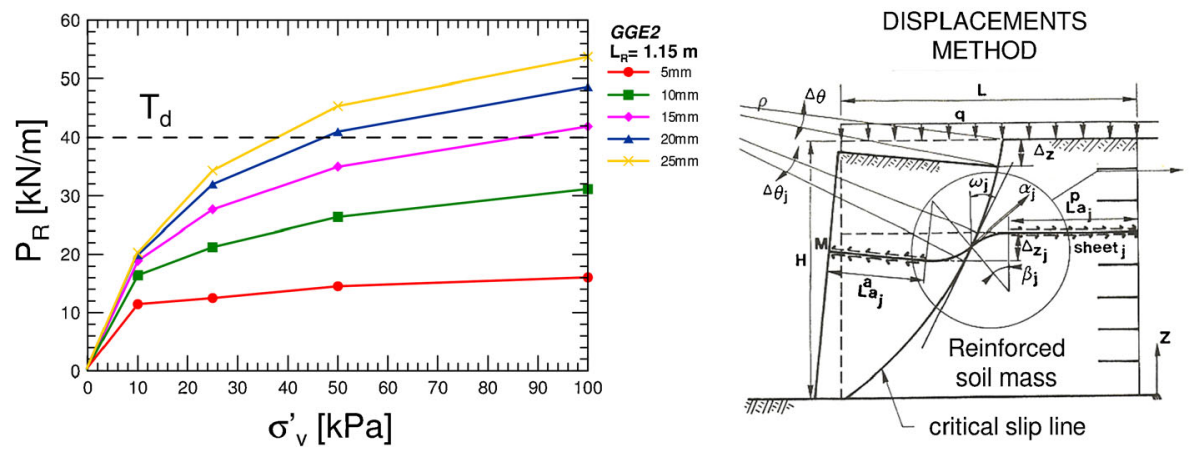

Fig. 11 Iso-displacement curves obtained through pullout tests [25] 

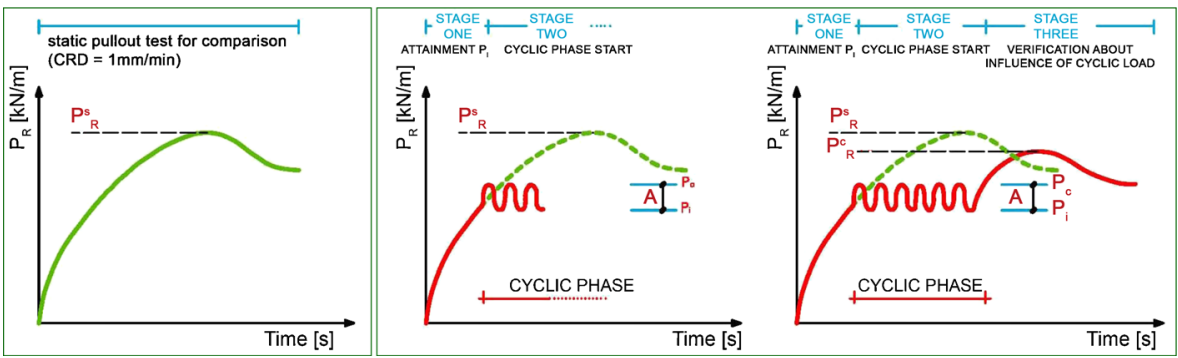

Fig. 12 Schematic representation of CRD and multistage pullout tests [26]

In particular, the pullout post-cyclic resistance reduction depended mainly on the amplitude of cyclic pullout loading and on the applied vertical confined stress (Fig. 13). The same results were clearly obtained also in terms of apparent post-cyclic peak coefficient of friction $\mu_{\mathrm{RCS} / \mathrm{GSY}}$ (Fig. 14).

The test results showed that the influence of the cyclic tensile load frequency, for the values studied in the research, seems to be negligible. During the cyclic phase, the increments of cyclic deformations were accumulated mainly in the first 10-15 load cycles increasing with the applied cyclic loading amplitude and effective vertical stress.

The pullout behaviour during the cyclic phase was also analyzed by the authors [27] using the double graph showed in Fig. 15 for different geogrids. In the upper part of the graph, the increment of the displacement during the cyclic phase measured at the edge attached to the clamp, $\Delta \delta^{T}$, is plotted versus the number of cycles; a stable behavior is characterized by a curve concave upward. In the lower part of the graph, $\Delta \delta^{T}$ is plotted
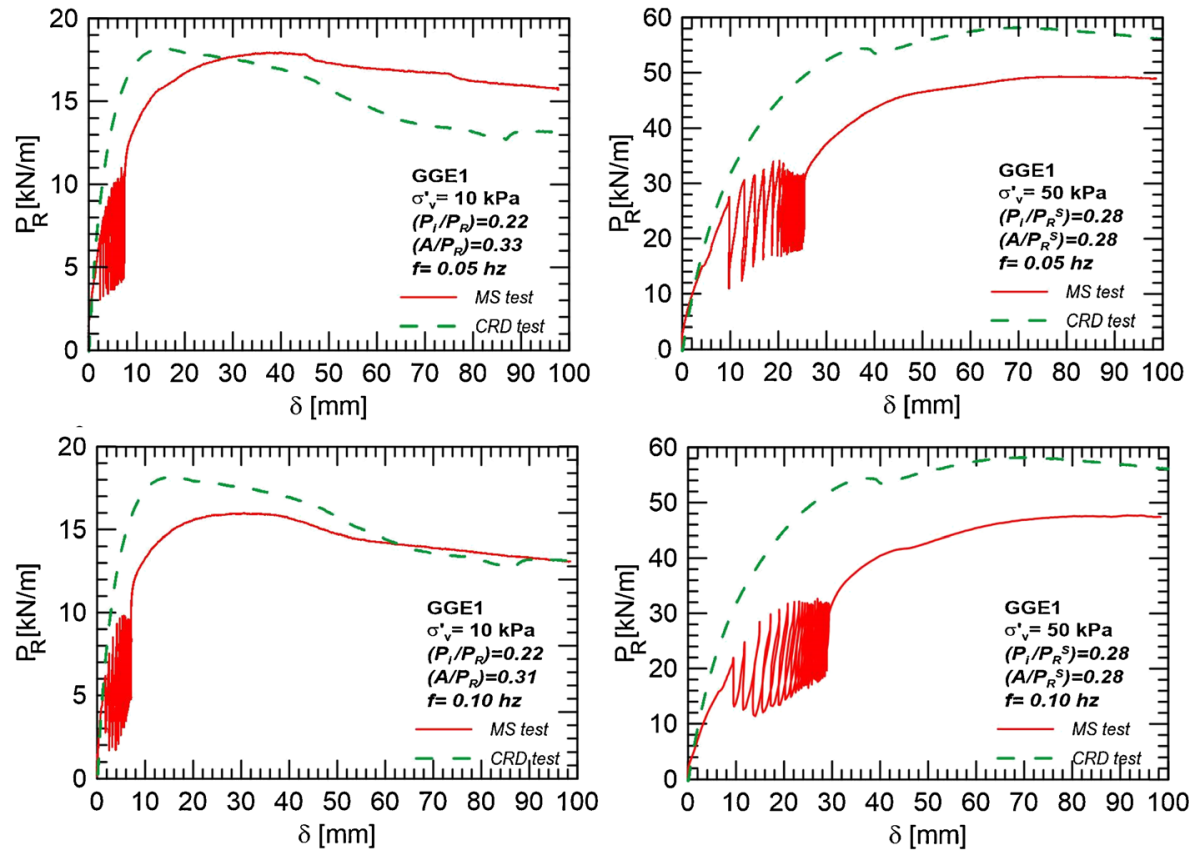

Fig. 13 Influence of cyclic loading on post-cyclic pullout resistance [26] 


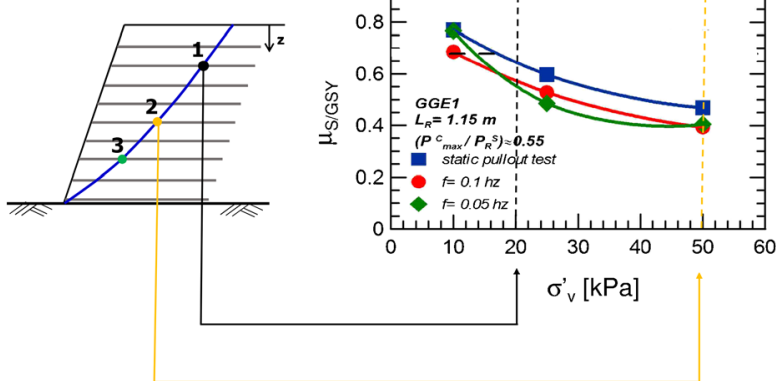

Fig. 14 Influence of cyclic loading on post-cyclic apparent coefficient of friction mobilized at the interface (modified from Moraci and Cardile [26])

versus the increment of the displacement during the cyclic phase measured at the rear end of the specimen, $\Delta \delta^{C}$.

The analysis of the pullout cyclic behavior showed, generally, a stable behavior for the studied interfaces. Only for the test carried out at the higher effective confinement pressure $(50 \mathrm{kPa})$ and at higher applied cyclic load amplitude, an unstable behavior, characterized by very large accumulated displacements and by pullout failure, occurred (Fig. 15).

These findings should be considered in seismic design of geosynthetic reinforced earth structure reducing properly the interface parameters generally determined by monotonic pullout tests conducted under controlled rates of displacement.

Therefore, the pullout behavior of geosynthetic, under cyclic loading conditions, depends on the same parameters discussed for static loading conditions, on frequency
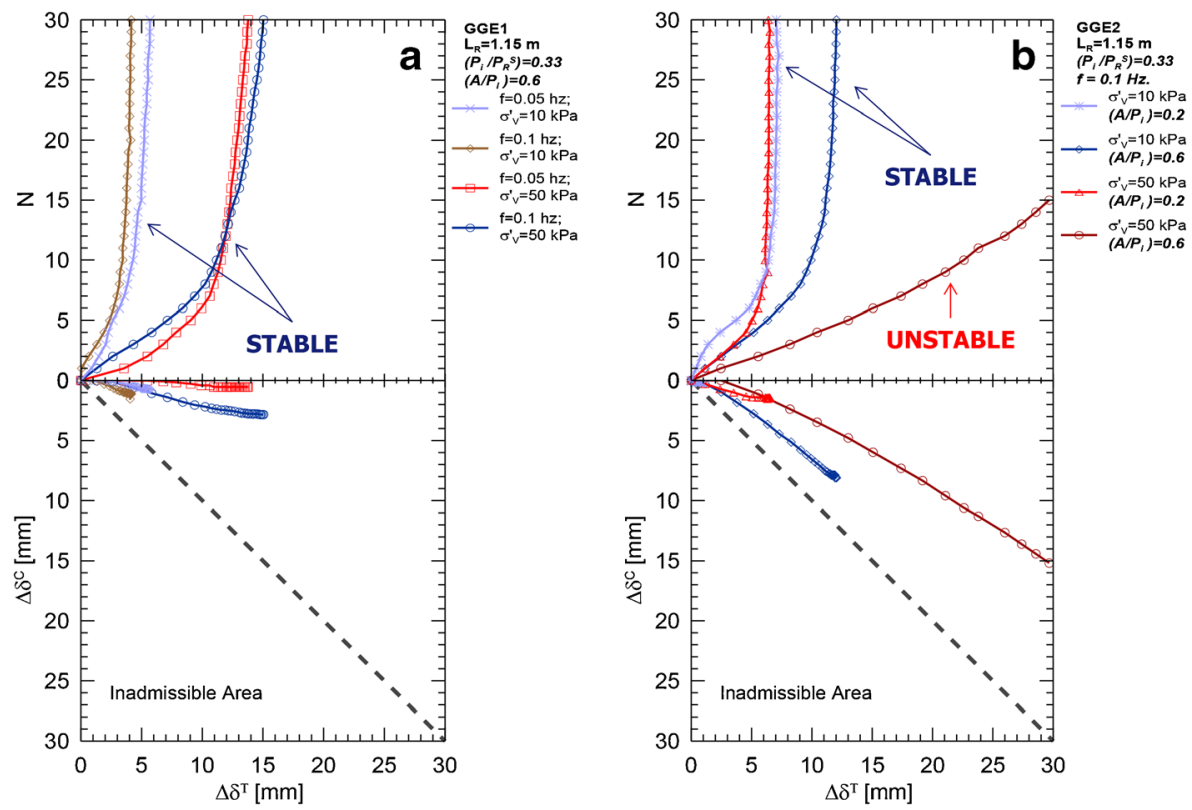

Fig. 15 Interface behavior during cycling phase of multistage pullout test on GGE1 and GGE2 geogrid [27] 
and amplitude of the applied cyclic loading, on the level of static tensile load already acting on the geosynthetic reinforcement, and on the number of load cycles.

Theoretical Interpretation of Soil-Geosynthetic Interaction in Pullout Loading Conditions

The main interaction mechanisms affecting the pullout resistance of geogrids are the skin friction, between soil and reinforcement solid surface, and the bearing resistance that develops against transversal elements. The pullout resistance of a geogrid, assuming that the different interaction mechanisms act at the same time with maximum value and that they are independent on each other, can be evaluated using the following equation:

$$
P_{R}=P_{R S}+P_{R B}
$$

Where $P_{R S}$ is the skin friction component of pullout resistance and $P_{R B}$ is the bearing component of pullout resistance.

The frictional component of pullout resistance, for a geogrid of length $L_{R}$ and unit of width $W_{R}$ (Fig. 16), may be evaluated by the following expression:

$$
P_{R S}=2 \cdot \alpha_{S} \cdot L_{R} \cdot \tau=2 \cdot \alpha_{S} \cdot L_{R} \cdot \sigma_{n}^{\prime} \cdot \tan \delta
$$

Where $\sigma_{n}$ ' is the normal effective stress, $\delta$ is the skin friction angle between soil and geogrid, $\tau$ is the shear stress acting at soil-reinforcement interface, and $\alpha_{S}$ is the fraction of geogrid surface area that is solid.

To evaluate the bearing component of pullout resistance, Jewell [38] proposed the following expression:

$$
P_{R B}=\left(\frac{L_{R}}{S}\right) \cdot \alpha_{B} \cdot \sigma_{b}^{\prime} \cdot B
$$

Where $S$ is the spacing between geogrid bearing members, $L_{R} / S$ is the number of geogrid bearing members, $\alpha_{B}$ is the fraction of total frontal area of geogrid available for

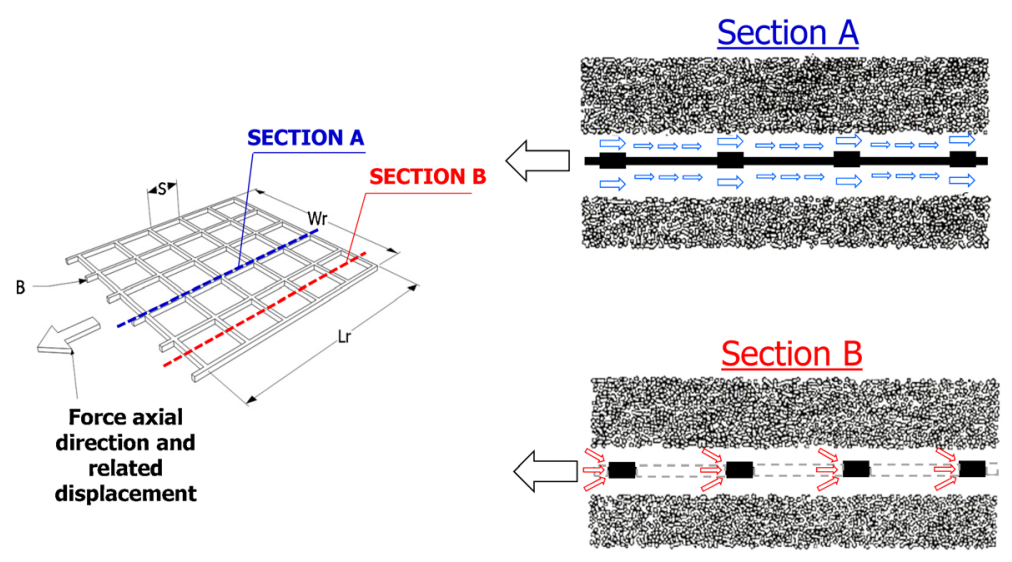

Fig. 16 Schematic representation of grid geometry [1] 
bearing resistance, $B$ is the bearing member thickness, and $\sigma_{b}{ }_{b}$ is the effective bearing stress against the geogrid bearing members.

Therefore, the pullout resistance of a geogrid can be obtained using the following equation:

$$
P_{R}=2 \cdot \alpha_{S} \cdot L_{R} \cdot \sigma_{n}^{\prime} \cdot \tan \delta+\left(\frac{L_{R}}{S}\right) \cdot \alpha_{B} \cdot B \cdot \sigma_{b}^{\prime}=2 \cdot f_{b} \cdot L_{R} \cdot \sigma_{n}^{\prime} \cdot \tan \phi^{\prime}
$$

Where $f_{b}$ is the interaction coefficient in pullout loading conditions.

The interaction coefficient under pullout loading condition $f_{b}$ can be obtained as a function of reinforcement geometrical parameters $\left(\alpha_{s}, \alpha_{b}, B\right.$, and $\left.S\right)$, of soil shear strength angle friction, $\phi$, of soil-geosynthetic skin friction angle, $\delta$, and of effective stresses acting at the interfaces $\left(\sigma_{n}^{\prime}\right.$ and $\left.\sigma_{b}^{\prime}\right)$ (Fig. 16) as follows:

$$
f_{b}=\alpha_{S} \cdot\left(\frac{\tan \delta}{\tan \phi^{\prime}}\right)+\left(\frac{\alpha_{b} \cdot B}{S}\right)^{\prime} \cdot\left(\frac{\sigma_{b}^{\prime}}{\sigma_{n}^{\prime}}\right) \cdot \frac{1}{2 \cdot \tan \phi^{\prime}}
$$

It is important to notice that in the theoretical equation used to evaluate the pullout interaction coefficient $f_{b}$, there are two components that represent the skin friction and the bearing resistance interaction.

The bearing stress $\sigma_{b}^{\prime}$ can be evaluated using different failure mechanisms.

In particular, Jewell et al. [1] proposed a solution based on a punching failure mechanism (lower bound), Peterson and Anderson [39] proposed a solution based on a general shear failure (upper bound), Bergado et al. [40] proposed a solution based on a modified punching mechanism, while Matsui et al. [41] proposed a solution based on a Prandtl failure mechanism.

For granular soils, the bearing stresses $\sigma_{b}^{\prime}$ acting on geogrid bearing members are linked to the soil shear strength angle, to the initial stress state, to the interface roughness, and to the reinforcement depth in relation to the sizes of the bearing members. In spite of this, in the equations proposed by the [1, 39-41], the ratio $\sigma_{b}^{\prime} /$ $\sigma_{n}^{\prime}$ depends only on soil shear angle.

Several authors tried to validate the different theoretical solutions proposed to evaluate the bearing stress. In particular, in the research carried out by Zhou et al. [42], the experimental results obtained on geogrid embedded in sands showed that the Matsui et al. [41] and Bergado et al. [40] solutions are in good agreement with the experimental results (Fig. 17).

During the test, sand motion around geogrid ribs was captured with microimages analysis system. The aim of this study was to clarify the interaction mechanism between sand and geogrid transversal ribs. Figure 18 shows particle motion around a transverse rib above and below the interface at various stages. The following phenomena were observed: sand particles in front of the transverse rib rotate during pullout. In particular, the particles on the upper of the reinforcement symmetrical axis rotate in clockwise while the particles on the lower of the reinforcement symmetrical axis rotate in anticlockwise. Particles on the top right side of the transverse rib fall into the voids created during the movement of the geogrid.

The microimage analysis confirms the macroscopic observations that the soil in front of the transverse rib is subjected to a passive state of stress while behind it an active state is reached, creating loose soil region. Additionally, it is worth noting that 


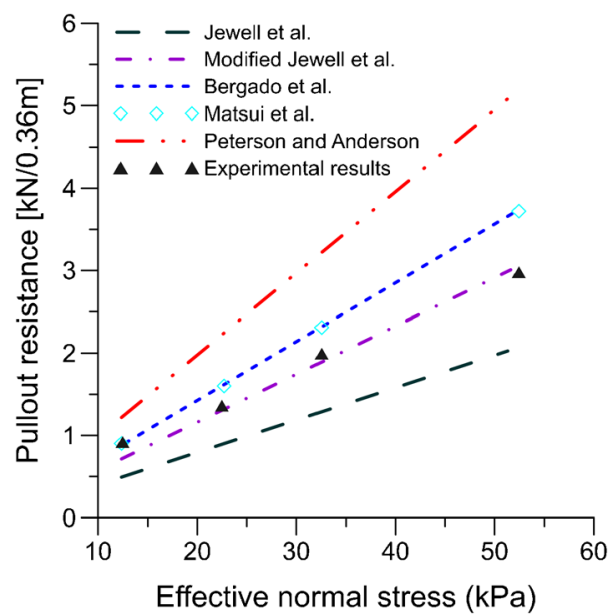

Fig. 17 Comparison between different solutions proposed to evaluate the bearing stress and experimental results [42]

the sand particles do not move symmetrically along the interface due to the different boundary conditions. Finally, it was possible to observe that the average thickness of the shear band was approximately six times the rib thickness and that the length subjected to the bearing stress was about ten times the rib thickness (Fig. 19).

Some researchers $[4,10,43-47]$ found that the bearing resistance depends on the ratio between the thickness of transverse bar and the average soil particle diameter (scale effect) and on the shape of the transverse bar. The results presented in Fig. 20 were obtained by tests on isolated rigid smooth transverse members with different cross-sections embedded in dense sands or crushed glass [10].

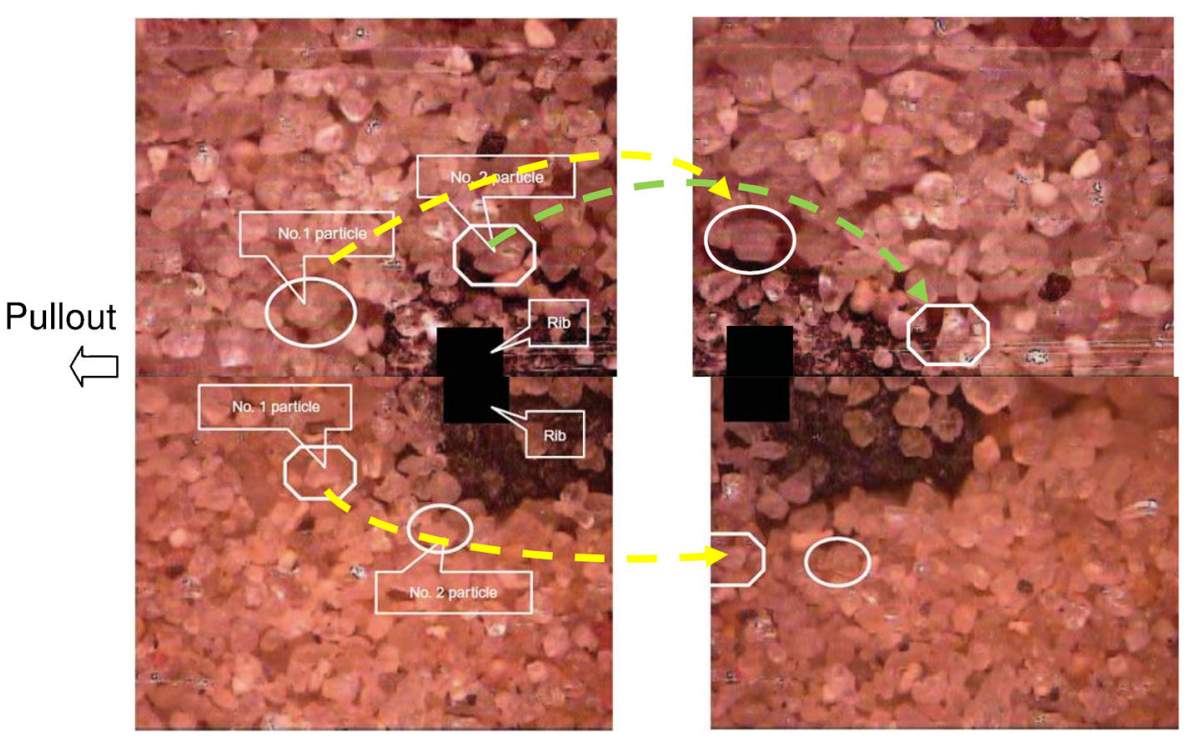

Fig. 18 Particles motion around transverse rib (modified from Zhou et al. [42]) 

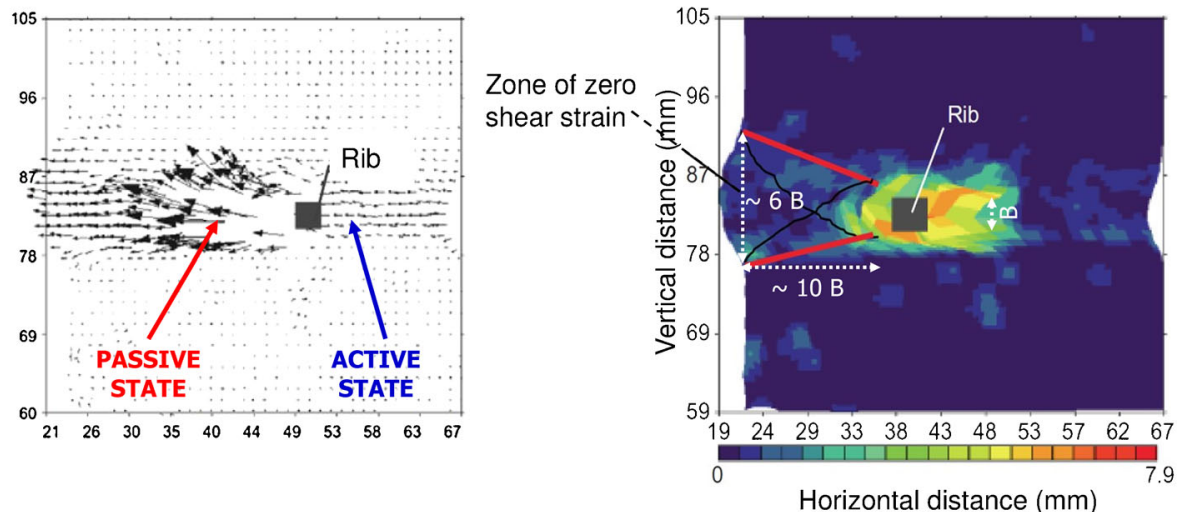

Fig. 19 Microimage analysis of interaction mechanisms (modified from Zhou et al. [42])

The results showed that bearing stress depends on the transverse member shape and on scale effects. In fact, the normalized bearing stress becomes independent on the soil particle size only for ratios between member thickness $B$ and average particle size $D_{50}$ greater than 10 .

For values of $B / D_{50} \leq 10$, bearing stresses greater than those evaluated using the theoretical expressions were measured (Fig. 20). To take into account scale effect, Jewell [38] proposed the following expression:

$$
\left(\frac{\sigma_{b}^{\prime}}{\sigma_{n}^{\prime}}\right)_{S}=\left(\frac{20-B / D_{50}}{10}\right) \cdot\left(\frac{\sigma_{b}^{\prime}}{\sigma_{n}^{\prime}}\right)=F_{1} \cdot\left(\frac{\sigma_{b}^{\prime}}{\sigma_{n}^{\prime}}\right)
$$

Where $F_{1}$ is the scale effect coefficient.

The shape effects are related to the geometry of the reinforcement transverse elements. In order to take into account shape effects, Jewell [43] suggested to use a shape coefficient $F_{2}$ equal to 1.0 for circular shape and equal to 1.2 for rectangular shape.

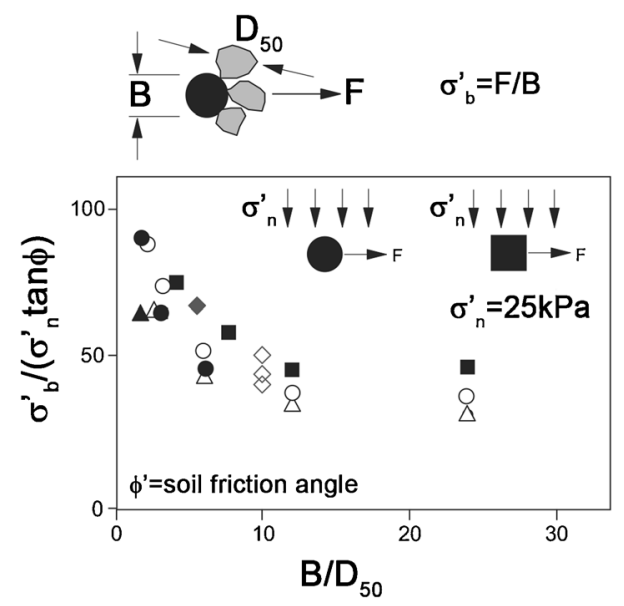

Fig. 20 Scale and shape effects: results of pullout tests on isolated transverse members with different crosssections [10] 
Other studies, Palmeira and Milligan [4] and Bergado et al. [45], have shown the existence of interference effects between the transverse elements that can lead to a reduction of passive resistance acting on them. This result was, also, verified qualitatively by photoelastic analysis conducted during pullout tests [46, 47]. These effects are due to the dimensions of the transverse bars, to the average particle size $D_{50}$ within the openings of the geogrid mesh, and to the spacing between the transverse elements.

Due to interference between transverse elements, passive surfaces cannot develop completely due to the closeness of the transverse element in front of them Dyer [46].

As the ratio between $S / B$ increases, the interference between transverse members decreases. In particular, according to experimental results obtained by Palmeira $[10,44]$ on metal grids embedded in dense sand, for $S / B$ ratios above 40 , there are not interference effects (Fig. 21).

Suksiripattanapong et al. [48] performed pullout tests on steel grids embedded in coarse-grained soils. Figure 22 shows the relationship obtained by the authors between the maximum pullout bearing force, $P_{b n}$, and transverse member spacing ratio, $S / B$, compared with maximum pullout bearing force of a single isolated transverse member $P_{b 1}$, for all tested soils. The results indicate that the failure mechanism in correspondence of the transverse elements could be classified into three zones, depending on the $S / B$ value. Zone 1 is defined as block failure (maximum interference effects), zone 2 as transition failure zone where the interference effects decrease as $S / B$ increases, and zone 3 as individual failure, for $S / B$ ratios of above 25 , where the interference effects disappear and in each transverse member, the bearing stress is fully mobilized individually (Fig. 22).

In order to study the interference phenomena, which could occur when the distance between the bearing members decreases, Cazzuffi et al. [28] performed a series of

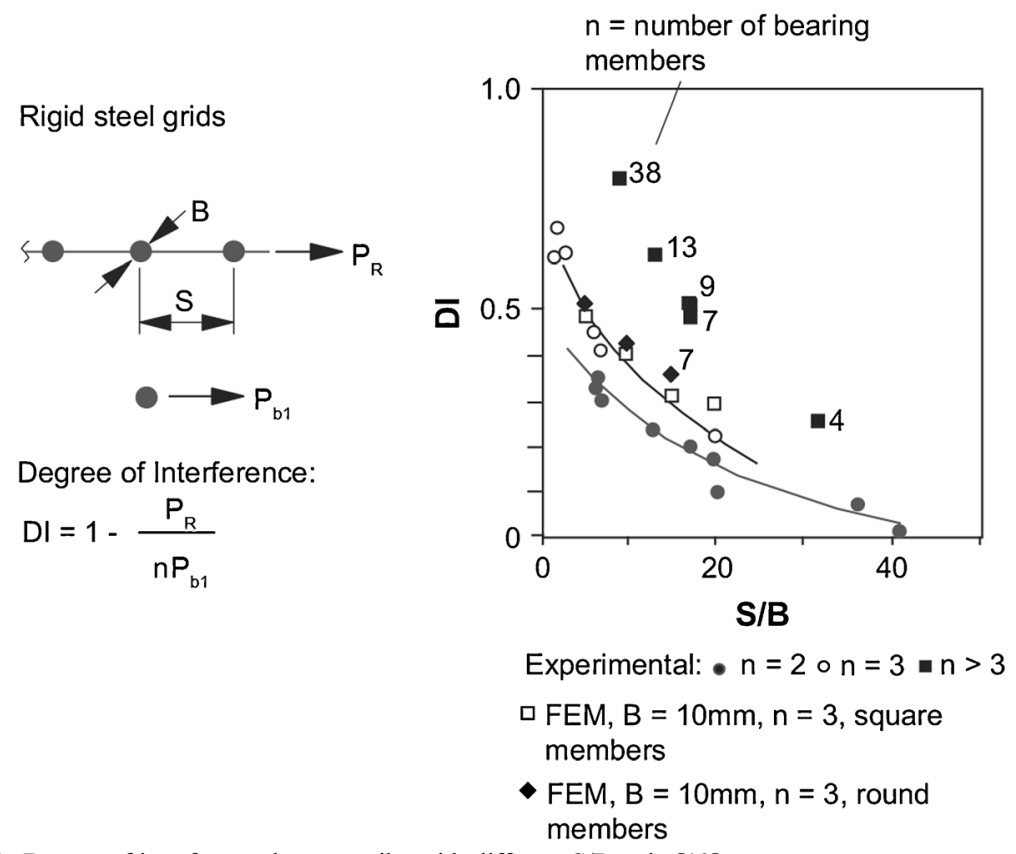

Fig. 21 Degree of interference between ribs with different $\mathrm{S} / \mathrm{B}$ ratio [10] 


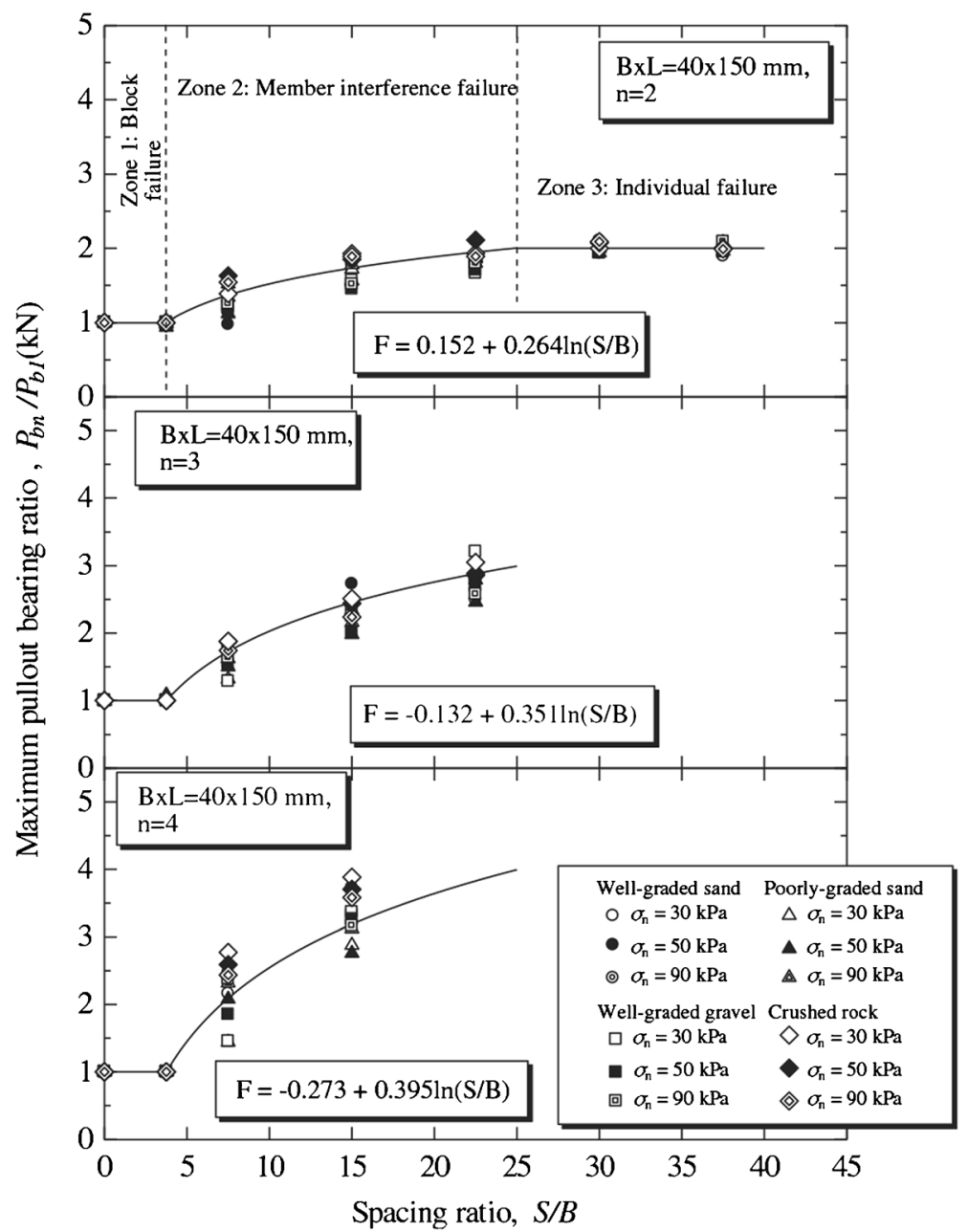

Fig. 22 Interference effect: measured and predicted $\mathrm{P}_{\mathrm{bn}} / \mathrm{P}_{\mathrm{b} 1}$ and $\mathrm{S} / \mathrm{B}$ relationship by Suksiripattanapong et al. [48]

pullout tests on several bioriented geogrids (tested in transversal direction), characterized by different spacing and thickness of the bearing members, by removing some transversal bars from the same specimens.

The main results are illustrated in Fig. 23 where the existence of an optimal spacing, $S$, which maximizes the peak pullout resistance, is emphasized.

Therefore, when the transverse bars spacing is below the "optimum" value, the pullout response is affected by the interference phenomena. On the other hand, when the transverse bars spacing is above the "optimum" value, the pullout resistance decreases because the number of bearing members that provides the bearing resistance is not the maximum number for that spacing $S$. These results clearly demonstrate the significant effect of the spacing between the transversal bearing elements on the peak pullout resistance of geogrids.

Therefore, the theoretical expressions, previously described, used to evaluate the pullout resistance and the soil-geosynthetic pullout interaction coefficient show 


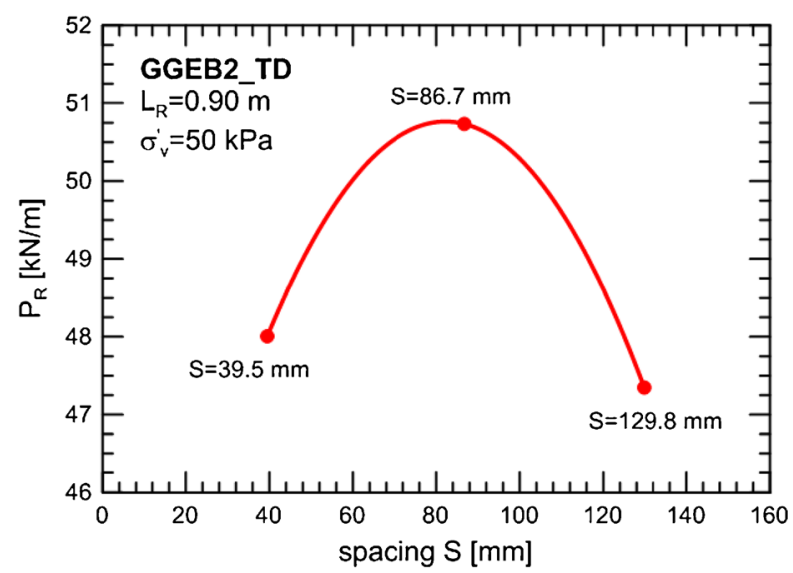

Fig. 23 Effect of the transverse bars spacing on peak pullout resistance for bioriented geogrid specimens [28]

different limitations. In particular, these equations do not take into account the real reinforcement geometry and extensibility, and the soil dilatancy effects that, as showed in the "Soil-Geosynthetic Interaction Under Monotonic Pullout Loading Conditions", strongly affect the pullout behavior.

Moraci and Gioffrè [7] proposed a simple method to predict the pullout resistance of geogrids embedded in compacted granular soils. The method is suitable for geogrids for which scale and interference effects are negligible. Moreover, the method is able to take into account the reinforcement extensibility and the soil dilatancy effects.

The proposed method is based on the evaluation of both frictional and bearing components of pullout resistance using the following equation:

$$
P_{R}=2 \cdot C_{\alpha S} \cdot \alpha_{S} \cdot L_{R} \cdot \sigma_{n}^{\prime} \cdot \tan \delta+n_{t} \cdot n_{t b} \cdot A_{b} \cdot \sigma_{b}^{\prime}
$$

Where $C_{\alpha S}$ is the reduction coefficient of geogrid area where skin friction develops, $\delta$ is the mobilized skin friction angle between soil and geogrid depending on soil dilatancy and reinforcement extensibility, $n_{t}=L_{R} / S$ is the number of geogrid bearing members, $n_{t b}$ is the number of nodes in a transversal element, $A_{b}=A_{t}+A_{r}$ is the area of each rib element (including the single node and the bar portion between two nodes) where the bearing resistance can be mobilized, and $\sigma_{b}^{\prime}$ is the bearing stress evaluated by equation according to Matsui et al. [41].

Moreover, the complex geometry of transverse bars was assumed equivalent to that one of a strip of uniform thickness.

The evaluation of the interaction factors is complex. In fact, $C_{\alpha S}$ depends on the extension of passive and active failure surfaces, and it was assumed equal to 1 in the absence of interference effect; $\delta$ depends on soil dilatancy and reinforcement extensibility; $\sigma^{\prime}{ }_{b}$ depends on soil dilatancy, reinforcement extensibility, and type of failure mechanism. In order to take into account the curvature of soil failure envelope, the value of peak shear strength angle was assumed variable with the applied effective vertical stress. 
Referring to the evaluation of the frictional component, based on experimental results, $\delta$ was assumed equal to a fraction of the mobilized soil shear strength angle depending on the type of geogrid. In order to evaluate the mobilized soil shear strength angle, the following assumptions, according to experimental results, can be made:

- For short reinforcements, the peak shear strength angle was used.

- For long reinforcements, the mean value between the peak and the constant volume shear strength angle was used; in residual condition, the constant volume shear strength angle was used.

Moreover, to evaluate the bearing component, the peak shear strength angle was used. Figure 24 shows a comparison between experimental (continuous and dotted curves) and theoretical (square, triangular, and circular points) results in terms of peak pullout resistance. It is possible to notice a good agreement between the theoretical method and experimental data. In Fig. 24, the horizontal line represents the value of geosynthetic failure obtained by wide-width tensile test carried out at the same displacement rate of pullout test.

Similar results were obtained also in terms of peak interface apparent coefficient of friction. In order to obtain the whole pullout curve, different authors [44, 49, 50] proposed to apply the stress transfer method.

The method proposed by Moraci et al. [49] consists in modeling the geogrid as a series of elements supported by discrete nonlinear springs, which represent the resistance of the soil in skin friction ( $\tau-d$ spring), and nonlinear springs at the transversal bar representing the bearing $\left(\sigma^{\prime} b^{-}-d\right)$ spring (Fig. 25).

The load transfer curves were evaluated experimentally by means of pullout tests performed on a HDPE geomembrane and on a HDPE extruded mono-oriented geogrid with isolated transversal bar by varying the applied vertical effective pressures. The proposed numerical method well predicts the experimental results for geogrids without interference and scale effects as showed in Fig. 26.
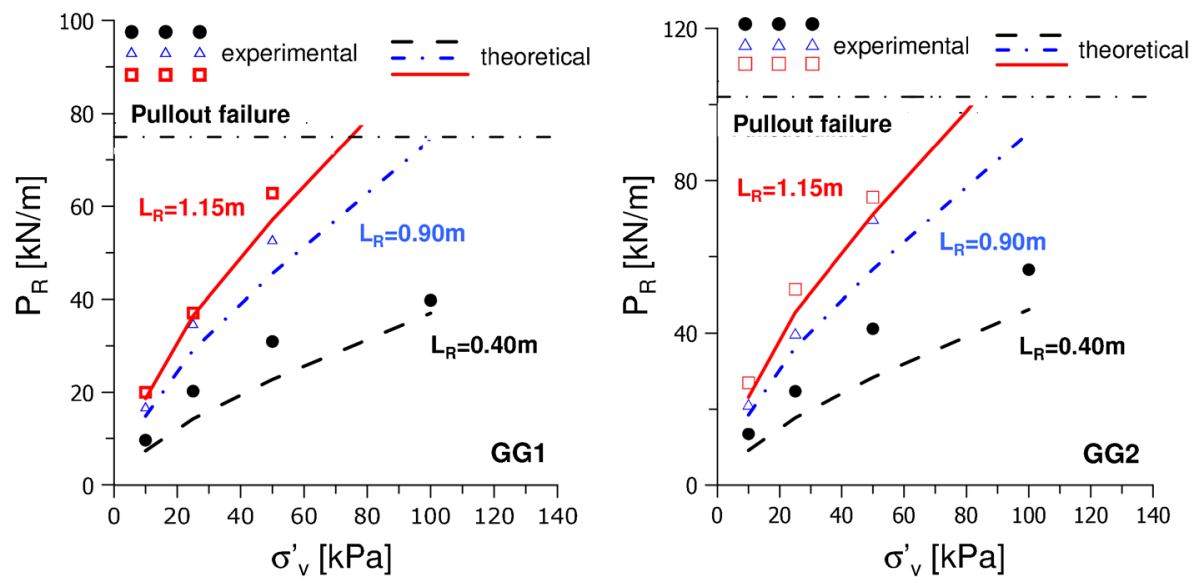

Fig. 24 Comparison between experimental and theoretical values of peak pullout resistance [7] 

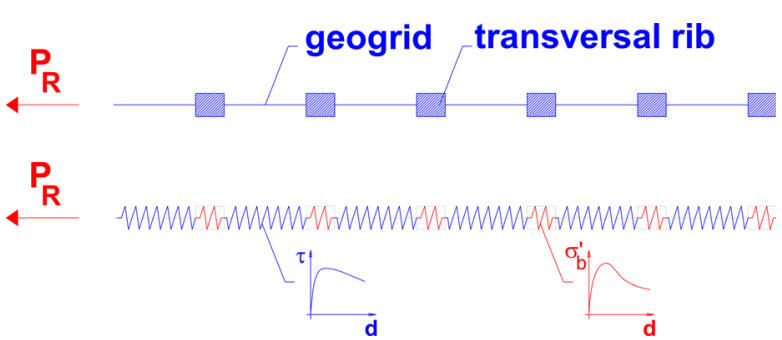

Fig. 25 Scheme of load transfer analysis [49]

Conclusions on Soil-Geosynthetic Interaction in Pullout Tests

Based on the considerations outlined in the previous paragraphs, the following conclusions can be drawn.

- The pullout behavior of geogrids embedded in granular soils depends on geotechnical characteristic of granular soils, reinforcement length, geometry and stiffness, and applied effective vertical stress.

- The pullout resistance and the mobilized interface apparent coefficient of friction depend on soil dilatancy and on reinforcement extensibility.

- The node iso-displacement curves obtained by means of pullout tests may be useful in the serviceability analysis performed using displacement methods.

- The application of cyclic tensile loads can produce a decrease of post-cyclic peak pullout resistance and of post-cyclic interface apparent coefficient of friction $\mu_{S / G S Y}$ compared to the values obtained in monotonic pullout tests. Therefore, in pseudostatic analysis design, the interface apparent coefficient of friction $\mu_{\mathrm{S} / \mathrm{GSY}}$ must be reduced with respect to the one used for static analysis.

- The analysis of pullout cyclic behavior can be performed according to the double graph approach.

- The theoretical methods well predict the experimental results for geogrids without interference and scale effects. These methods can be also used to evaluate the confined tensile resistance in pullout conditions and to evaluate both frictional and bearing components of pullout resistance.

Nevertheless, more studies are required in order to:

- Quantify the long-term interface apparent coefficient of friction (creep effects)

- Develop an optimum geometry that maximizes the geogrid pullout resistance

- Evaluate the influence of cyclic tensile load amplitude and frequency

- Evaluate the influence of reinforcement extensibility and soil dilatancy under cyclic loads

- Evaluate a criterion for the equivalent damage corresponding to a given number of cycles

- Evaluate the influence of tensile creep before the application of tensile cyclic loads

- Develop interface constitutive models under static and cyclic tensile loading conditions

- Include in the existing theoretical model the scale, interference, and long-terms effects 

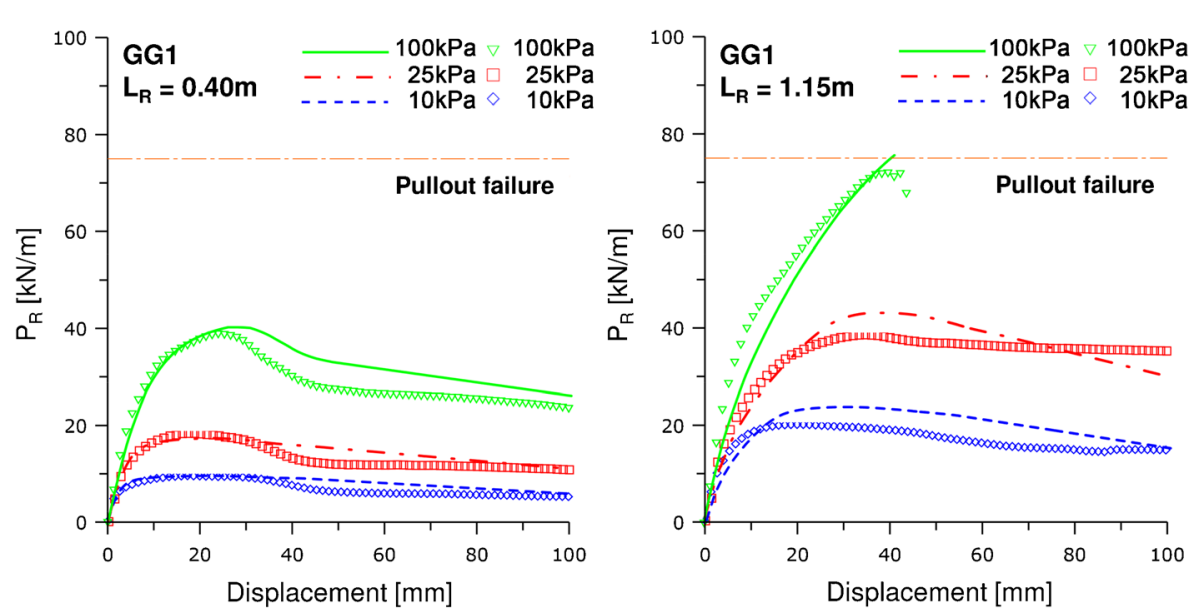

Fig. 26 Comparison of experimental (points) and numerical (lines) pullout curves [49]

\section{Direct Shear Tests}

Direct shear apparatus (DSA) tests have been extensively used to evaluate the soil shear strength parameters. Since 1990, DSA has been extended to determine the interface apparent friction between soils and reinforcing elements [51].

Geosynthetic-soil interface shear behavior depends on a large number of factors, related to the applied effective normal stress, geosynthetic type, geometry and stiffness, soil grain size distribution, soil plasticity, soil density, moisture content, specimen size, drainage conditions, displacement rate, magnitude of displacement, and other parameters $[52,53]$.

The direct shear test at soil-geosynthetic interfaces are generally performed according to three principal standards: the British standard BS 6906 [54], the EN ISO 129571 [55], and the ASTM D5321.08 [53].

Different large DSAs were developed by various researchers in order to study the soil-geosynthetic interaction behavior. The devices currently in use worldwide mainly differ for several factors that could affect the test results. Literature evidences $[52,56$, 57] show clearly a large degree of variability in published data due to the different direct shear apparatus used and to the different boundary and test conditions.

In the following paragraphs, the influence of the main factors affecting the direct shear test results is described. In particular, the effects of shear box sizes, of constraint imposed by the loading platen, of vertical load application system, of opening size between the two halves of the shear box, of support and test type, and of geosynthetics fixing system are discussed.

Factors Affecting Direct Shear Test Results

\section{Influence of the Shear box Size}

Many authors studied the influence of the box size (i.e., box length and box height in relation to the max/average soil particle diameter) on the ratio between the shear stress and the normal stress (or peak shear strength angle). 
The ASTM D5321.08 [53] standard suggests that the minimum shear box dimension should be greater than $300 \mathrm{~mm}$ (suggested also by the other standards and according to different researches); 15 times the $D_{85}$ of the coarse soil used in the test, or a minimum of 5 times the maximum opening size (in plan) of the tested geosynthetic. In addition, the depth of each shear box should be $50 \mathrm{~mm}$ or six times the maximum particle size of the tested coarse soil, whichever is greater.

Referring to DSA test with geogrids, the EN ISO 12957-1 [55] standard suggests that the minimum dimensions of the boxes should be such that at least two full longitudinal ribs and three transverse bars are contained within the length of both upper and lower boxes.

There are controversial issues regarding the influence of the shear box sizes on the direct shear test results. Generally, the obtained shear strength angle decreases with increasing box size until a limit box size value is reached at which the shear strength angle remains constant. This effect can be related to the volume available in the box for the shear zone $[58,59]$. In order to avoid box scale effect, the size of DSA box should be designed in order to enable the full propagation of the shear zone [60]. Therefore, the box dimensions depend on the soil grain size distribution and on geosynthetic type and geometry.

The interaction between soil and geogrid generally can be identified as the sum of three different mechanisms [1], soil shearing over the plane of the reinforcement area, soil shearing over soil through geogrid opening, and soil bearing on the transverse ribs area of the reinforcement.

Jewell et al. [1] state that in DSA tests, only the first two types of mechanisms can be mobilized at the geogrid-soil interface. A recent research performed by Liu et al. [61, 62] showed that also the passive mechanism may contribute to the shear resistance of sand-geogrid interfaces. Only if the passive effect of the transversal ribs is negligible (i.e., soil-geotextile), the upper limit of the thickness of the shear zone is as close as the alone soil-soil thickness one. Therefore, only in this case, the shear box design should be performed using the soil-soil interface literature results. Otherwise, also the geometrical characteristic of the geogrid can affect the DSA tests behavior.

Unreinforced DSA tests results on dense sand $\left(D_{50}=0.9 \mathrm{~mm}\right)$ performed by Jewell and Wroth [58] suggest a minimum ratio of shear box length with respect to average particle size equal to 50 . In order to allow the full propagation of the shear zone, Scarpelli and Wood [60] suggested a value of $100 * D_{50}$ for the box length.

Cichy et al. [63] carrying out stereo photogrammetry analysis on an interface between fine gravel and sand glued on a rigid plate found that the thickness of the shear zone is about $3 \div 6 * D_{50}$.

DeJaeger [64] showed that the thickness of the shear zone increases with increasing of grain angularity and particles size, and it is related with the failure strain. The author observed that the shear zone has a minimum thickness ranging from 5 to $14 \mathrm{~mm}$ for fine sand and from 14 to $22 \mathrm{~mm}$ for the coarse one (Fig. 27). The thickness of the shear zones corresponds to values ranging from 1 to $100 * D_{50}$.

DeJong et al. [65], using a microimages analysis system, stated that the maximum thickness of the shear zone varies from $8^{*} D_{50}$ for silica sand $\left(D_{50}=0.72 \mathrm{~mm}\right)$ to $12 * D_{50}$ for an artificial gradation of well-graded angular calcareous sand $\left(D_{50}=0.85 \mathrm{~mm}\right)$.

In order to study scale effects, Palmeira [66] and Palmeira and Milligan [67] carried out direct shear tests on dense sand $\left(D_{50}=0.80 \mathrm{~mm}\right)$ using shear boxes of different 


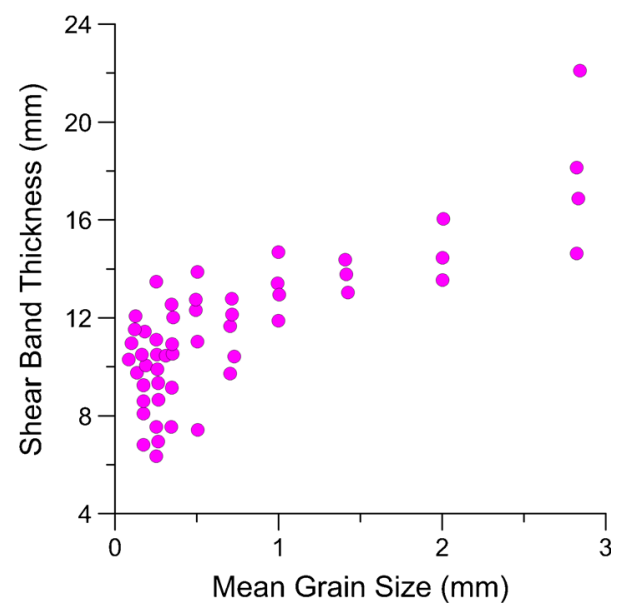

Fig. 27 Shear zone thickness as a function of the soil $D_{50}$ (modified from [64])

dimensions $(60 \times 60 \times 32 \mathrm{~mm}, 250 \times 150 \times 150 \mathrm{~mm}$, and $1,000 \times 1,000 \times 1000 \mathrm{~mm})$. The authors found that shear zone thickness, evaluated using a photographic technique, depends on box dimensions and it increases as shear box size increases (from about 9 to $100 \mathrm{~mm}$ ). Moreover, Palmeira and Milligan [68] using three different sands (with $D_{50}$ values of $0.4,0.8$, and $1.6 \mathrm{~mm}$ ) showed that the normalized shear zone thickness with respect to the soil specimen height $(t / H)$ decreases with the increasing of the $H / D_{50}$.

Stone and Wood [69] studying the effect of dilatancy in granular soils, taking into account soil particle size, suggested a minimum shear box length of about $176 * D_{50}$.

Cerato and Lutenegger [59] carried out direct shear tests on five different sands (varying $D_{\max }$ from 0.9 to $5 \mathrm{~mm}$ ) at three different relative densities using various shear box sizes $\left(60 \times 60,101.6 \times 101.6\right.$, and $\left.304.8 \times 304.8 \mathrm{~mm}^{2}\right)$. They demonstrated the important effects of box size on the constant volume shear strength angle and suggested to use a box length at least $50 * D_{\max }$ [58] and a box height greater than $6 * D_{\max }[70]$. Moreover, the authors stated that the influence of specimen size is also a function of sand type and relative density.

Zhang and Thornton [71] presented two-dimensional DEM simulations of direct shear tests. The authors suggested to use a shear box ratio $L / H$ below the value of 2 in order to obtain more reliable data.

In order to minimize the box scale effects, Wang and Gutierrez [72, 73], on the basis of DEM simulations, recommended to use, as optimal dimensions for DSA, a minimum value of 60 , for $L / D_{\max }$, a minimum value of 40 , for $H / D_{\max }$, and $L / H$ ranging from 1.5 to 2 .

Hsieh and Hsieh [74] carried out direct shear tests on sand-geomembrane interfaces. The authors recommended using a direct shear box with a minimum size of $300 \times$ $300 \mathrm{~mm}^{2}$.

Ingold (1984) carried out direct shear tests using different shear box dimensions $\left(60 \times 60 \mathrm{~mm}^{2}\right.$ and $\left.300 \times 300 \mathrm{~mm}^{2}\right)$ in which geotextile (bonded to a rigid base plate at the lower half of the shear box) was in contact with soil (coarse to medium sand in the upper half). The authors found that the interface shear strength decreases when the shear box's dimensions increase. 


\section{Influence of Boundary Condition on the Top Box}

Referring to the DSA currently used in the world, three different types of kinematic degrees of freedom at the top box (Fig. 28) can be recognized. The first type (type A), in which the top platen and the upper part of the shear box are independent of each other, allows the top platen to move vertically and to rotate freely [76]. The second type (type B) is characterized by a top platen securely fastened to the top half box (after applying the vertical stress) that allows to the two parts to move vertically or to rotate together [58]. The last type (type C) in which the upper box is prevented to move vertically or to rotate and the top platen moves independently, but it can also avoid to rotate $[77,78]$.

In a free top platen configuration (type A), the consequence of the application of the horizontal shear stress is the formation of an anticlockwise moment on the upper platen which increases the nonuniformity of the vertical contact stress distribution. In order to maintain equilibrium, a counteracting clockwise moment must be arisen [79]. The tilting also causes an undesirable variation of soil density, which further accentuates the vertical stress nonuniformity.

In order to reduce the rotation in type A apparatus, Lings and Dietz [80] used a pair of "wings," attached to the sides of the upper frame, to allow also the application of the load near the center of the shear box.

Jewell [79] showed how the symmetrical direct shear test (type B) is an effective method for a more reliable measure of both friction and dilation angles. In fact, a better uniformity distribution of vertical stress at shearing plane can be achieved by firmly securing the rigid top loading plate to the top half of the apparatus (type B) so that the upper half moves as a unit during shear. Thus, fixed top platen eliminates the rotation in a direct shear test (Fig. 29).

When the upper shear box of the DSA is completely fixed (type C, the most common setup for large direct shear test), the vertical displacement is restricted, and the vertical shear stresses (due to grains relative movements) occur at the inner walls of

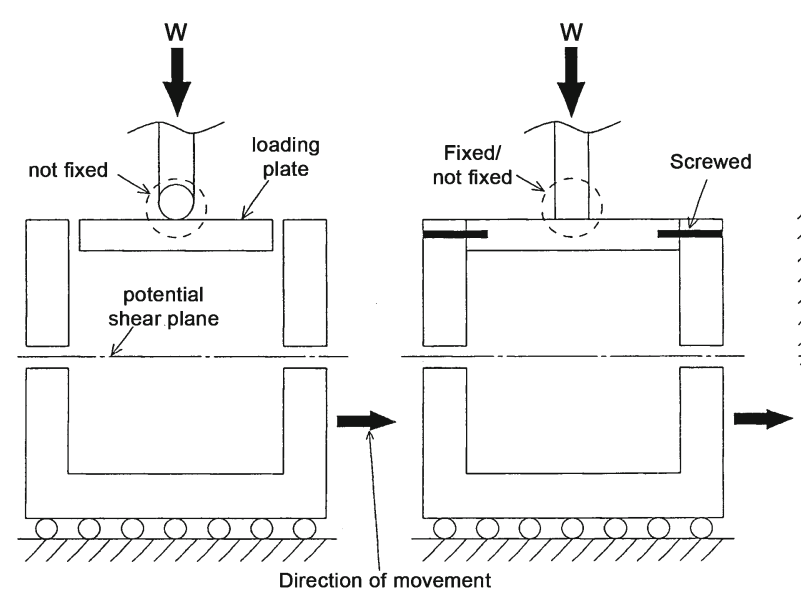

TYPE A

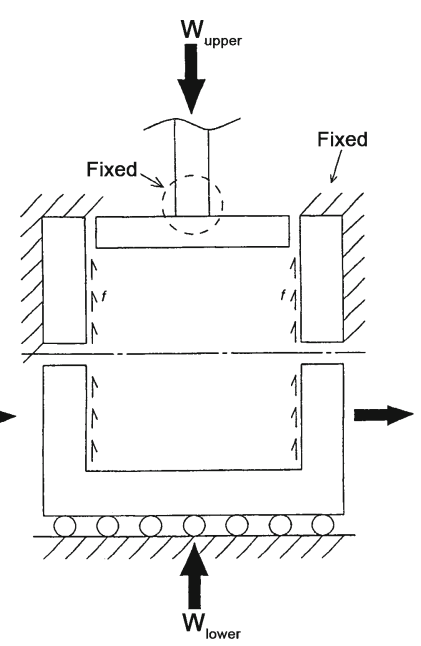

TYPE C

Fig. 28 DSA boxes currently in use [75] 


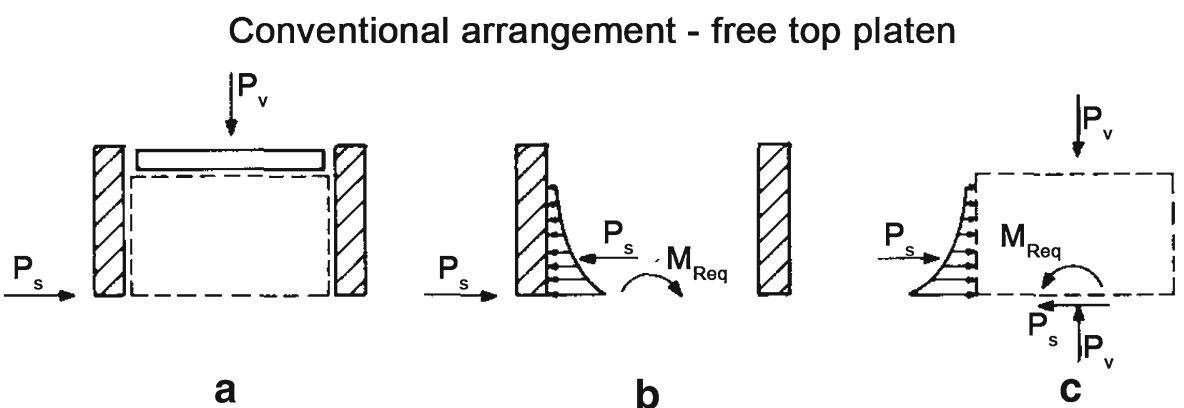

a

b

C

Improved arrangement - fixed top platen

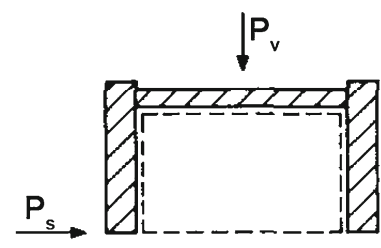

d

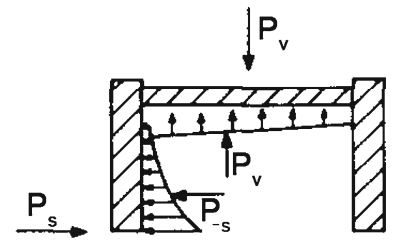

e

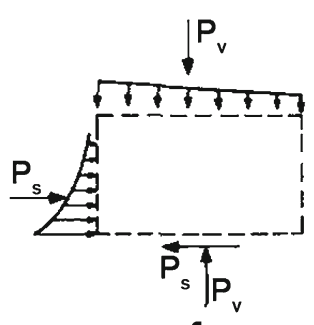

f

Fig. 29 DSA types A and B arrangements [79]

the upper box. This circumstance involves a nonuniformity distribution of vertical stress at shearing plane, and an average vertical stress reduction in the frictional shearing plane, with a considerable error especially if the inner walls are not enough lubricated.

Friction along the front side wall restricts soil dilation, then the normal stress on the shear plane increases and consequently increases the measured shear strength [10] (Fig. 30). Therefore, if the free vertical movement of the upper rigid part of the shear box is prevented during shearing and no correction of the applied vertical load is taken into account, the resulting shear strength can be either underestimated (contractive soils) or overestimated (dilatant soils) [81]. These effects could be avoided using the constant normal stiffness DSA. The ASTM [53] standard specifies that the horizontal force must be corrected as resulting from the internal resistance to the shear device.

In order to solve this problem, Stoewhase [82] proposed to measure the vertical load in the rigid half-box (Fig. 31). This solution, in which the frictional force was not measured directly but was computed as the difference between the applied load and the loads recorded on a reaction plate, was adopted in DIN 18 137-3 standard. A similar DSA device was recently proposed by Kostkanovà and Herle [81].

The ASTM D5321.08 [53] suggests that the normal stress load application device should be capable of applying and maintaining, for all the test duration, a constant uniform normal stress on the specimen. During DSA test, tilting of the load plates must be limited to $10 \mathrm{~mm}$ from the center to the edge of the plate. The BS EN ISO 129571:2005 [55] and the ASTM D5321.08 [53] standards state that the normal stress control have to be carried out with an accuracy of $\pm 2 \%$. The vertical stress can be applied by means of rigid top plate or flexible pressurized bag. 

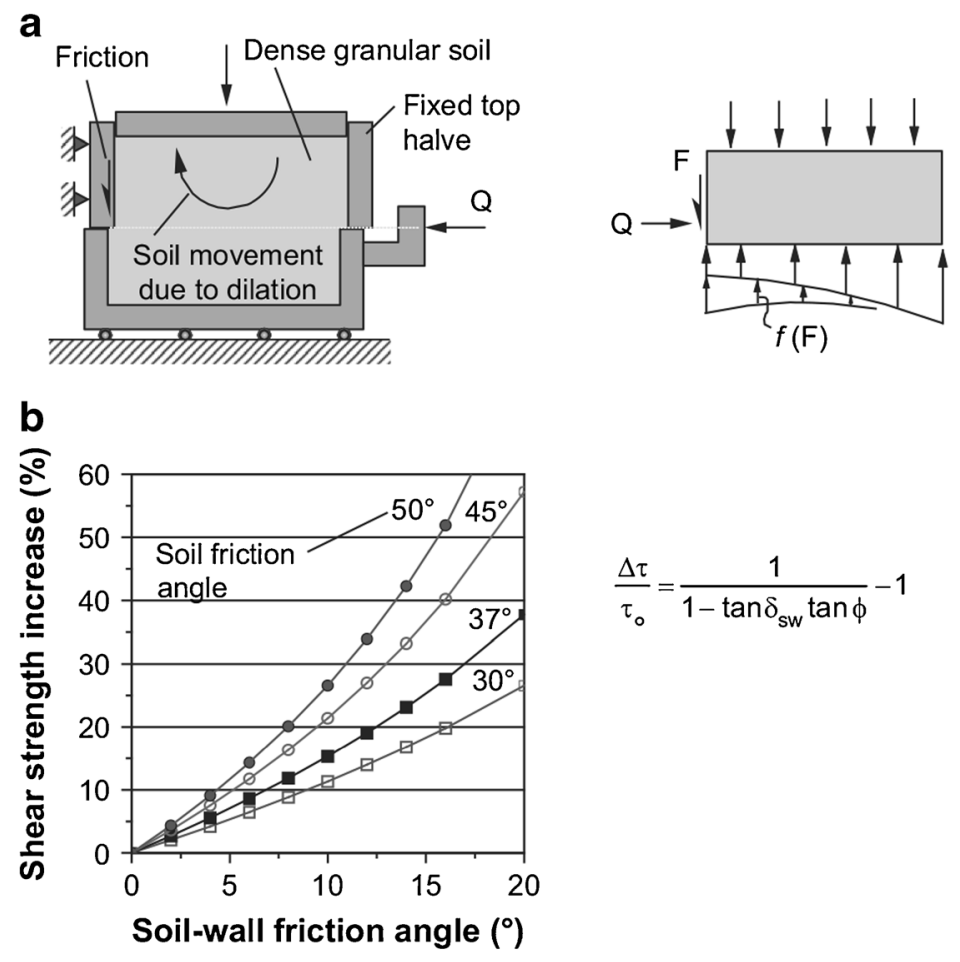

$$
\frac{\Delta \tau}{\tau_{\mathrm{o}}}=\frac{1}{1-\tan \delta_{\mathrm{sw}} \tan \phi}-1
$$
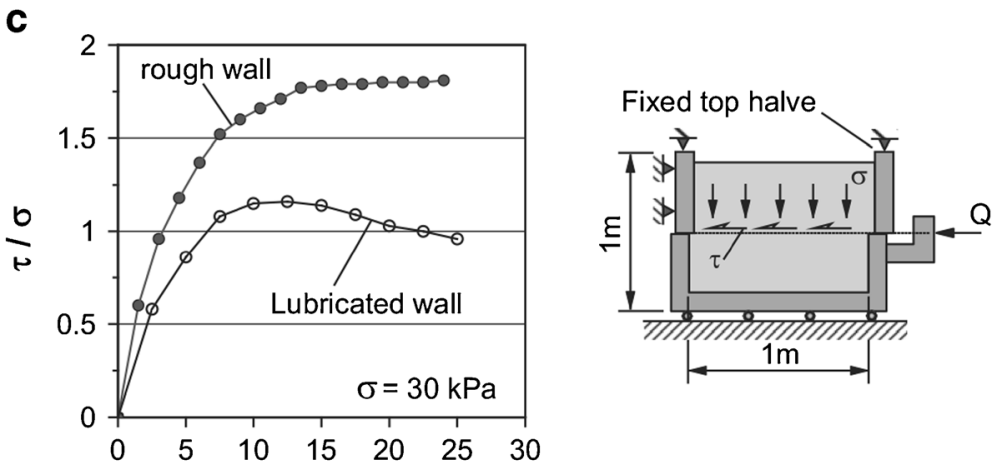

\section{Shear displacement $(\mathrm{mm})$}

Fig. 30 Influence of side friction in direct shear tests on dilative soils: a side friction mobilization, b estimate of shear strength increase due to side friction, and $\mathbf{c}$ influence of side friction in a large-scale direct shear test [10]

Gourc et al. [83] stated that if a rigid top plate is used to apply the vertical load, vertical stresses on horizontal plane are higher in the front area than in the rear area of the box. The use of a rubber bag, filled with air or water, on top implies that the pressure distribution along the sample is more uniform at any stage of the test [10]. The use of top flexible boundary has also the practical advantage to apply the vertical load without the more sophisticated and expensive jack on top of the shear box. On the other hand, using this system, it is impossible to perform the test at constant normal stiffness. 


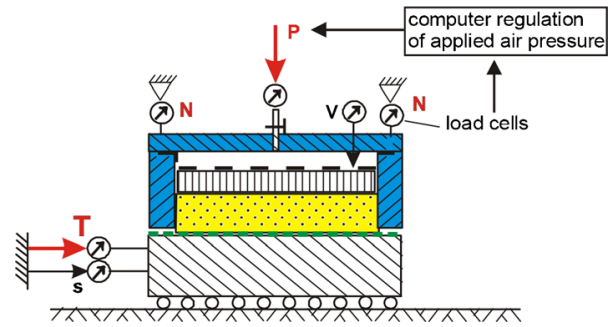

Fig. 31 DSA proposed by Stoewhase [82]

Gourc et al. [83] and Palmeira [10,66] found that the maximal shear stresses are higher in DSA tests performed with pressurized bag.

Hsieh and Hsieh [74] performed direct shear tests on sand-geomembrane interfaces, using different vertical load application systems (rigid plate and flexible plate). In this research, in order to measure the vertical pressure on the shearing surface, load cells were also used. The test results showed that the normal pressure distribution associated with the flexible load application device is quite uniform along the shear plane, while using a rigid load plate device, a not uniform pressure distribution was recorded (Fig. 32). The large differences measured by the authors are probably due to a poor lubrication of the internal side walls.

\section{Influence of Opening Size Between the Two Halves of Shear box}

If the vertical movement and/or the rotation of the upper box are not prevented, the opening size between the two halves of the shear box (gap) varies during test according to soil and geosynthetic characteristics; this involves the occurrence of many practical problems. Therefore, Shibuya et al. [75] suggested that this gap should be maintained at a constant value during the test.

The ASTM D5321.08 [53] standard recommends a gap large enough to prevent friction between the parts of the box but small enough to prevent the soil loss. The BS EN ISO 12957-1 [55] suggests a constant gap value equal to $0.5 \mathrm{~mm}$. The BS6906 [54] specifies that for soil-geosynthetic interfaces, the gap must be equal to $D_{85} / 2$ or $1 \mathrm{~mm}$ when using fine-grained soils.

Shibuya et al. [75] carried out DSA tests on sand (varying $D_{50}$ from 0.16 to $0.62 \mathrm{~mm}$ ) using different opening size between the two halves of the shear box. The authors found how the smaller opening size $(0.2 \mathrm{~mm})$ developed higher shear strength angles values compared with the ones obtained using higher gaps (Fig. 33). Nakamaru et al. [84] and Lings and Dietz [80] also found similar results.

Therefore, the full development of the shear zone is restricted if the size opening (gap) between the two halves of the shear box is smaller than the thickness of a free shear zone. This effect should be due to the restraint offered by the shear box itself. The effect of the stress release increases with the increase of the gap. Shibuya et al. [75] suggested to use a gap slightly larger than the thickness of a free shear zone, which is approximately $10 \div 20 * D_{50}$ according to Tatsuoka et al. [85].

Nevertheless, the use of a gap size equal to $10 \div 20 * D_{50}$, as proposed by Shibuya et al. [75], was not appropriate for coarse materials [86]. If the upper halves box is free 


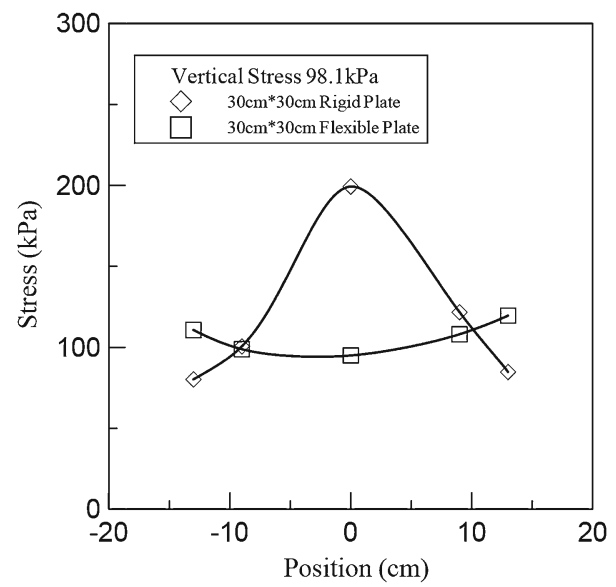

Fig. 32 Normal pressure distribution associated with flexible and rigid load application device [74]

to move vertically, the gap size must be measured after the soil consolidation due to the application of the vertical load.

A recent research developed by Kim et al. [87] studied the effect of the gap between the two halves of the shear box on the shear behavior using seven types of granular soils ( $D_{50}$ varying from 0.076 to $1.15 \mathrm{~mm}$ ), using a type $C$ of DSA. The authors found that the peak shear strengths decrease with the increase of the opening size results according to other researchers. Moreover, the authors introduced a useful graph that correlates the soil mean diameter $D_{50}$ with the limit opening sizes to be used in order to minimize the gap influence on the shear behavior (Fig. 34).

Lings and Dietz [80], to avoid the outflow of soil particles through the opening, proposed to use a 1.0-mm thick rubber at the gap. Also, Kim et al. [87] studied the

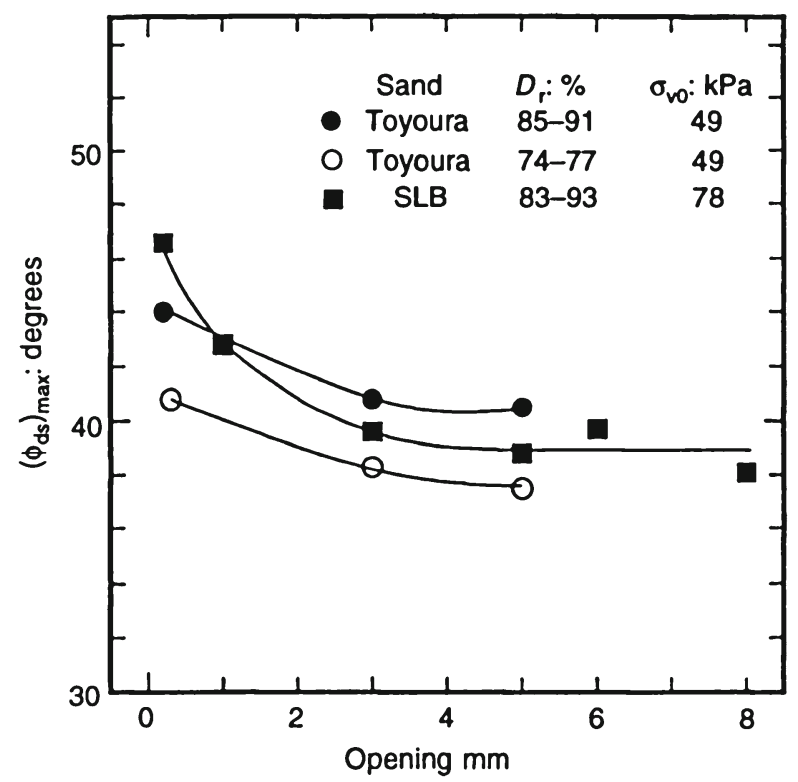

Fig. 33 Effect of gap on peak shear strength angle [75] 

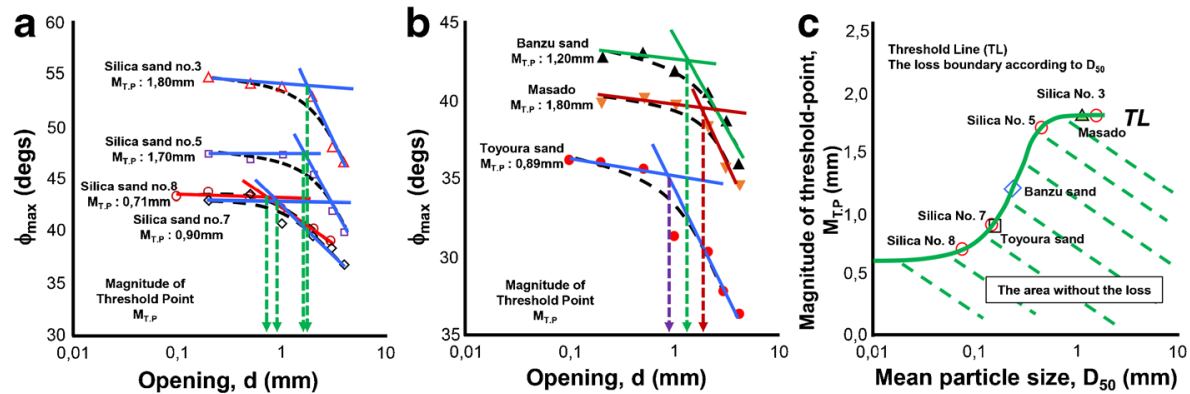

Fig. 34 Limit opening sizes to be used in order to minimize the gap influence on the direct shear test results [87]

effect on the shear strength and deformation behavior due to the application of a Teflon sheet for the opening.

\section{Influence of Specimen Support (Rigid Base or Soil) and of Test Type (Constant or Reduced-Area)}

The BS6906:1991, EN ISO 12957-1, and the ASTM D5321.08:2008 stated that direct shear tests with geosynthetic in contact with soil or other geosynthetic can be performed using both rigid or soil support. Moreover, the geosynthetic must be fixed (clamped or glued) to prevent relative displacement between specimen and support. Moreover, the EN ISO 12957-1 allows both constant and reduced-area test procedure discussed in the following.

The direct sliding resistance mobilized at soil-geogrid interface depends on the shear resistance of soil that slides over soil through the apertures of the geogrid and of soil sliding over the material of the geosynthetic. Then, to evaluate correctly the direct sliding apparent coefficient of friction, the test must be performed using a large direct shear apparatus with soil in the lower half of the box. In fact, for soil-geogrids interface, the mobilized friction with a smooth rigid support is much lower than one mobilized using a sand support [83]. Moreover, in the absence of an effective anchorage and support, slippage and distortion could occur during the shear displacement [88].

Actually, there are three different types of DSA in which the geosynthetic may be supported on a rigid base or on soil using constant or reduced area test procedure (Fig. 35). In particular, it is possible to perform direct shear tests using a lower box with the same size of the upper box filled with soil (Fig. 35a), with a larger lower box filled with soil (Fig. 35b), or consisting in a rigid block (Fig. 35c).

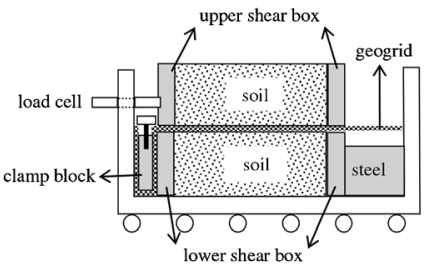

a

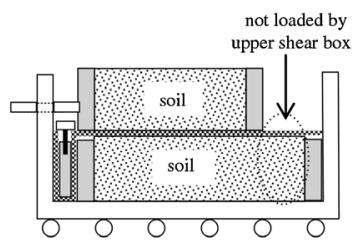

b

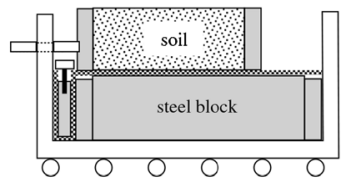

C

Fig. 35 Different set-ups of lower shear box, Liu et al. [62] 
Liu et al. [62] carried out large DSA tests in order to study the effect of the different setups of the lower box, showed in Fig. 35, on the soil-geogrid shear strength.

The reinforcement effect was evaluated by means of the coefficient $\alpha$ defined as the ratio between soil-geosynthetic interface shear strength $\left(\tau_{S / G S Y}\right)$ and soil internal shear strength $\left(\tau_{S / S}\right)$.

Ling et al. [62] found that the suitable condition was the one with the two halve boxes of the same dimension and filled with soil (Fig. 36). This conclusion was justified by the authors because in the soil support constant area test (Fig. 35b), the soil outside the loading area is always not confined and, consequently, it flows out of the lower half box. Lopes and Silvano [89] observed the same phenomenon (Fig. 37).

Likewise, it is clear, that the use of a rigid plate (Fig. 35c) in the lower half of the shear box does not allow the shear resistance mobilization of soil sliding over the soil through the openings of the geogrid.

Lopes and Silvano [89], in order to overcome the constant area test problems, proposed to use a reduced area shear-type test with a metallic box placed inside the lower half of the box. In a DSA test carried out without reinforcements, when the imposed horizontal displacement is large, there is the soil-metallic surface friction that contributes to the total mobilized shear strength that could influence the test results. The authors showed that, due to the low friction and to the small contact area between soilmetallic surface, the influence of soil-iron sheet friction in soil-soil direct shear results is negligible (Fig. 38).

Moreover, the same authors showed that the distribution of the pressure at the shearing plane along the interface length depends on the technique used to fix the geosynthetic specimen at the DSA. In particular, Lopes and Silvano [89], in order to achieve an adequate connection of the geotextiles, recommended the use of an aluminum oxide abrasive sheet glued over the rigid base (as suggested by the EN ISO 129571). In fact, for sand-geotextile interfaces, slippage and distortion could occur during relative shear displacement in the absence of an adequate anchorage system [88].

Soil-Geosynthetic Interaction in Direct Shear Tests: Experimental and Theoretical Studies

The direct shear test between soil and geosynthetic reinforcement is a common testing method to investigate the soil-geosynthetic interface shear strength and the apparent

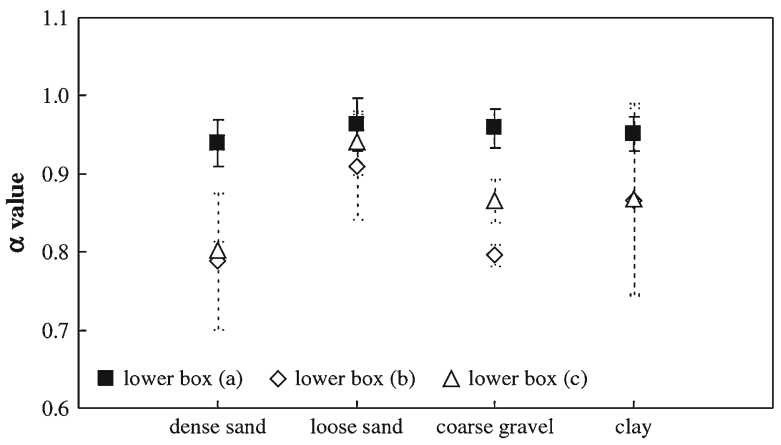

Fig. 36 Normalized interface shear strength coefficient $(\alpha)$ of soil/geogrid interfaces for different setups of lower shear box, Liu et al. [62] 


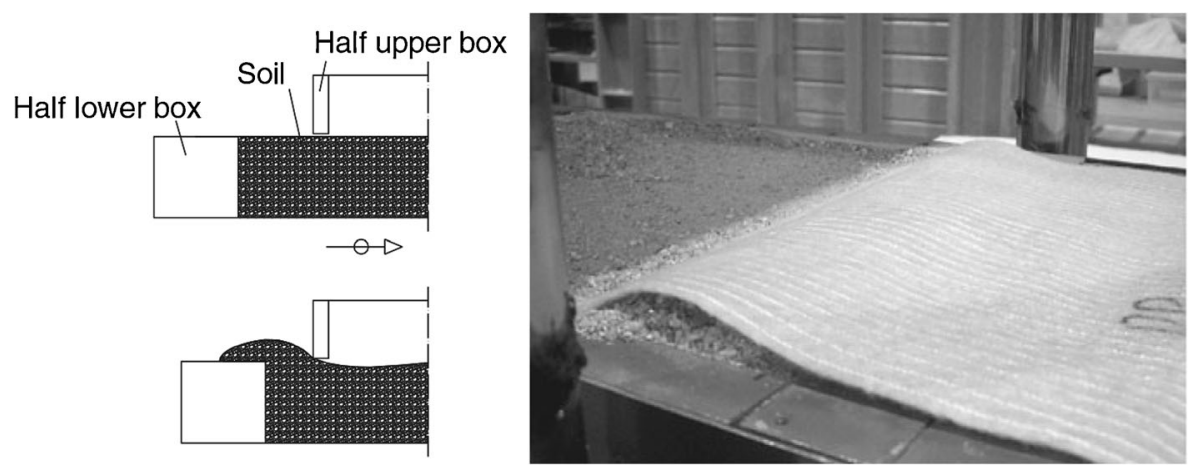

Fig. 37 Soil outside the loading area is always not confined and then it flows out of the lower half box [89]

coefficient of friction. As the type of the reinforcing material changes, the soilgeosynthetic interaction and the mechanisms in direct sliding condition change.

While for pullout mechanism, the passive pullout resistance against the transverse bearing members resistance has been recognized to provide the uppermost contribution to the overall pullout resistance at soil-geogrid interface $[7,8,10,28,38,90]$; the contribution to transverse ribs under direct shear mechanism is still an issue of scientific discussion. Jewell et al. [1] stated that the contribution to passive earth pressure, induced by the relative movement between the soil and the grid bearing members, is almost negligible for two important aspects. The first one is that the bearing stresses, mobilized against the opposite transversal ribs of the same opening mesh, could be balanced, in fact, the soil in the upper and lower halves of the grid apertures would shear in opposite directions. The second one is because, if the relative opening size with respect to soil particle ones is small, the rupture surface would occur above the top of grid, inside the soil, thus relative displacements between the soil contained in the grid apertures and the bearing ribs do not take place.

On the other hand, Bergado et al. [45] stated that the shear strength of the HDPE soil-geogrid interface could be greater than the soil one; therefore, they concluded that bearing resistance under direct shear mode might be mobilized.

A recent research conducted by Liu et al. [61, 62] was focused on clarifying the contribution of geogrid transverse bars to the shear strength at soil-geogrid interface under direct sliding conditions. The authors carried out DSA tests, using a large shear box to investigate the interface shear strength of different compacted soils in contact
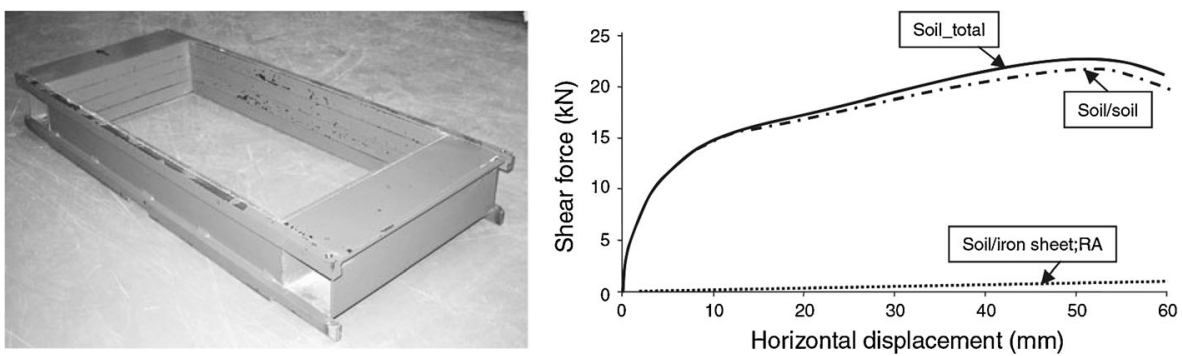

Fig. 38 Soil-metallic surface friction that contributes to the total mobilized shear strength in constant area direct shear tests 
with a geotextile and with different geogrids manufactured using the same raw material (Fig. 39).

Initially, DSA tests were performed at soil-soil interface to quantify the soil internal shear strength, and at sand-geotextile interface, in order to quantify the component of shear resistance due to the friction that develops between the soil and the solid geogrid surfaces. The result is that the shear strength on soil-geogrid interfaces is between the upper limit, that is the soil internal shear strength, and the lower limit, that is the soilgeotextile interface shear strength. The authors related this result to the interlocking effect due to the soil particles that penetrate through the geogrid apertures. The authors derived this consideration from the test results shown in Fig. 40, in particular, they assumed that the frictional resistant components are fully mobilized at small shear displacement and the bearing resistance is involved at larger displacements (Fig. 40).

The static direct shear test results, as already observed in CRD pullout tests, showed that direct sliding coefficients of interaction for dense granular soil-geogrid interface depend on the effective confining pressure [61, 88, 91-94], and they are higher at lower stress levels due to dilatancy effects.

Moreover, the normalized interface direct shear strength coefficient $\alpha$ obtained by Liu et al. [61, 62] (Fig. 41) is comparable with experimental results obtained by other researches [95-98], in which its value for granular material in contact with different geogrids changes from 0.90 to 1.12 .

The first theoretical study on soil-geosynthetic interaction under direct shear condition was conducted by Jewell et al. [1]. According to the authors, the basic equation for direct sliding resistance of soil/geogrid interface can be expressed in terms of two contributions as follows: the shear resistance mobilized at soil-solid grid surface areas and the shear resistance mobilized at soil--soil interface.

$$
L_{R} \cdot W_{R} \cdot \sigma_{n}^{\prime} \cdot f_{d s} \cdot \tan \phi_{d s}^{\prime}=L_{R} \cdot W_{R} \cdot \sigma_{n}^{\prime} \cdot\left[\alpha_{d s} \cdot \tan \delta+\left(1-\alpha_{d s}\right) \tan \phi_{d s}^{\prime}\right]
$$

Where $f_{d s}$ is the interface coefficient of direct sliding, $\phi^{\prime}{ }_{d s}$ is the soil friction angle in direct shear, $\delta$ is the soil-geogrid skin friction angle, and $\alpha_{d s}$ is the fraction of geogrid surface area that is solid and in contact with soil.

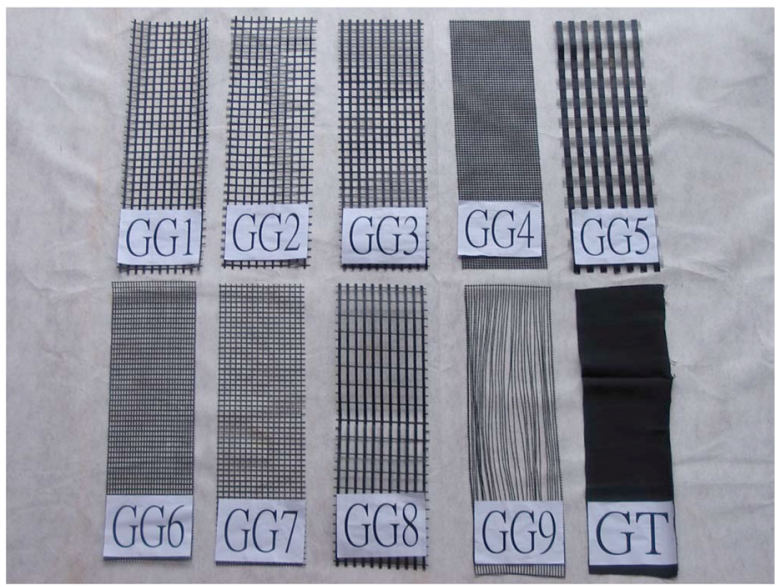

Fig. 39 Geosynthetics used, Liu et al. [61, 62] 

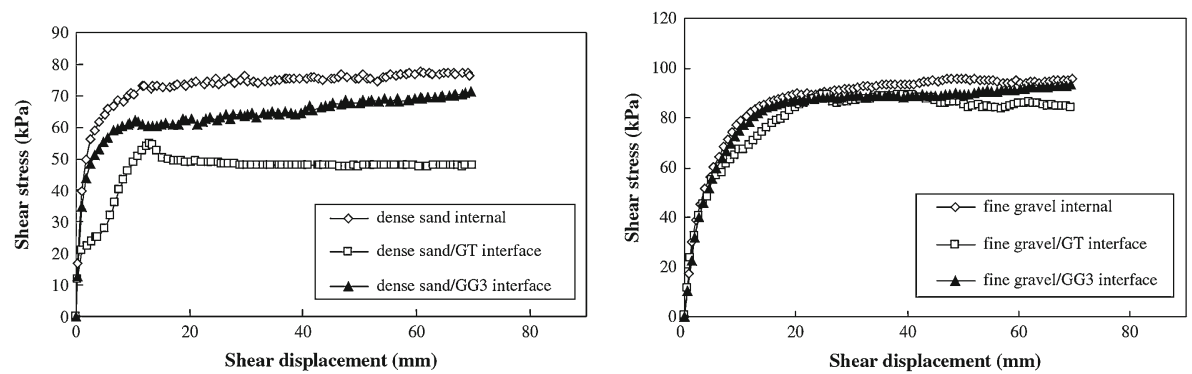

Fig. 40 Stress-strain behavior of different soil-soil, soil-GT, and soil-GG interfaces under the same normal pressure [61, 62]

From Eq. (10), it is possible to obtain the Jewell's theoretical interface coefficient of direct sliding $f_{d s}$ as follows:

$$
f_{d s}=1-\alpha_{d s}\left(1-\frac{\tan \delta}{\tan \phi_{d s}^{\prime}}\right)
$$

It is important to observe that the parameter $\alpha_{d s}$ also depends on the soil grain size distribution and on geogrid opening sizes as, qualitatively, showed in Fig. 42 [1].

In the limit case in which the soil particle size is similar to grid opening size, the failure zone is forced away from the grid plane so the shear resistance would be equal to the full shear resistance of the soil, therefore $\alpha_{d s}=0$ and $f_{d s}=1.00$.

On the other hand, in the extreme case in which the soil particles size are too large to penetrate the grid openings, these remain directly on the grid plane surface and the shear resistance is due to the contact between themselves and the plane grid surface. In this case, and for geotextiles in which the soil geotextile skin friction is the only interaction mechanism, the parameter $\alpha_{d s}=1$ resulting in a reduction of the direct sliding coefficient to $f_{d s}=\tan \delta / \tan \phi^{\prime}{ }_{d s}$.

The previous theoretical approach proposed by Jewell et al. [1] was adopted by Liu et al. [61, 62] as a basis for the analysis of the direct shear test results. The authors introduced, for different soil/geogrid interface, a normalized interface shear strength
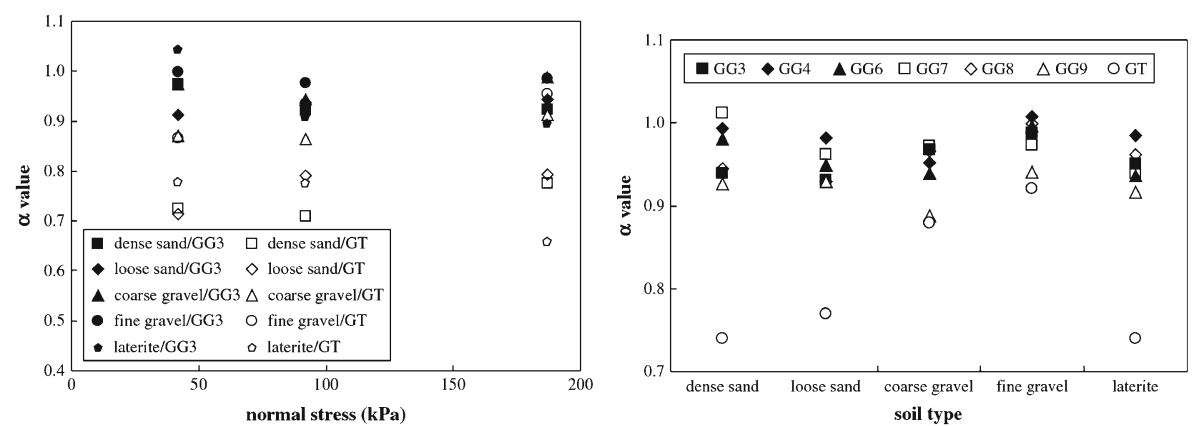

Fig. 41 Soil-geogrid normalized interface direct shear strength coefficient $(\alpha)$ for different soils and geogrids at different applied vertical effective stresses [62] 


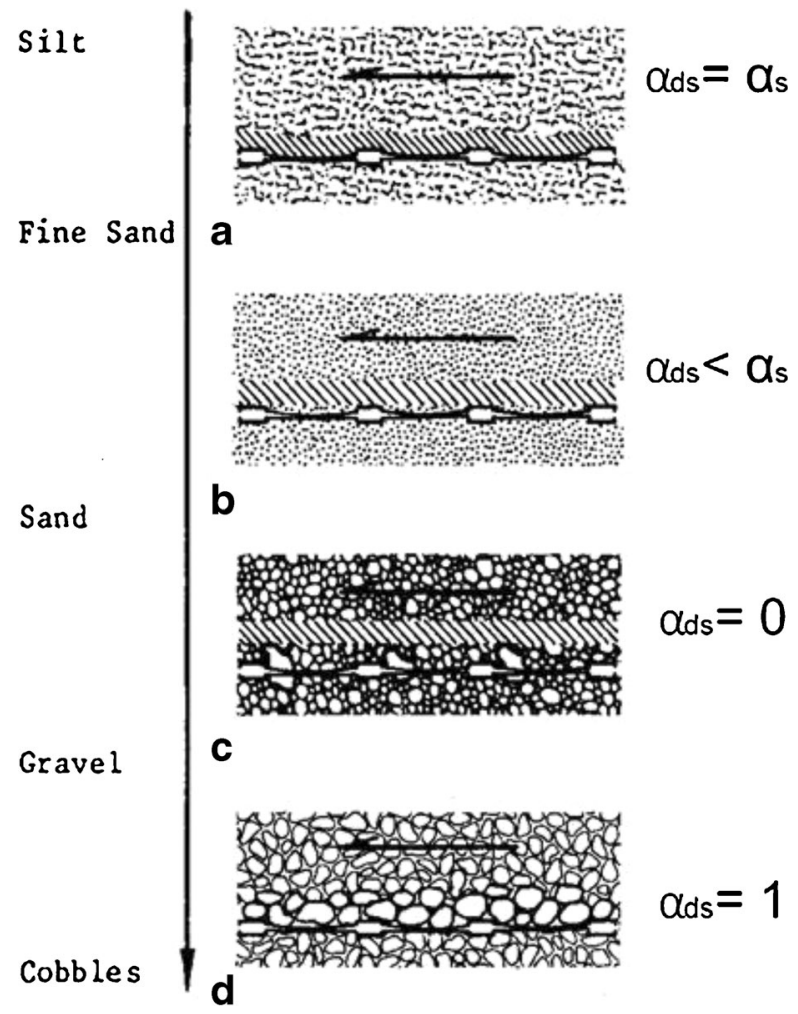

Fig. 42 Qualitative rang of variation of $\alpha_{\mathrm{ds}}$ as function of soil grain size distribution and geogrid opening size [1]

coefficient $\alpha$ defined as the ratio by soil-geosynthetic interface shear strength and soil internal shear strength as follows:

$$
\alpha=\left(\frac{\tau_{S / G S Y}^{\max }}{\tau_{S / S}^{\max }}\right)
$$

Where $\tau^{\max }{ }_{S / G S Y}$ is the peak shear strength at soil geosynthetic interface and $\tau^{\max }{ }_{S / S}$ is the soil peak shear strength obtained by means of direct shear tests.

It is possible to observe that $\alpha$ is equal to $f_{d s}$ according to the Eq. 10 as follows:

$$
\alpha=\left(\frac{\tau_{S / G S Y}^{\max }}{\tau_{S / S}^{\max }}\right)=\frac{f_{d s} \cdot W_{R} \cdot L_{R} \cdot \sigma_{n}^{\prime} \cdot \tan \phi^{\prime}}{W_{R} \cdot L_{R} \cdot \sigma_{n}^{\prime} \cdot \tan \phi^{\prime}}=f_{d s}
$$

The authors compared the values of $\alpha$, obtained by means of the experimental results, with the theoretical values of $f_{d s}$, obtained with the expression of Jewell (Fig. 43). They found that the interface direct shear strength predicted by Jewell equation does not well predict the measured values, especially when the ratio between geogrid opening size and soil average diameter is greater than 100 or smaller than 1 . Moreover, the magnitude of the predicted direct shear strength is generally smaller than the measured value. Therefore, the authors assumed that an additional mechanism, due 

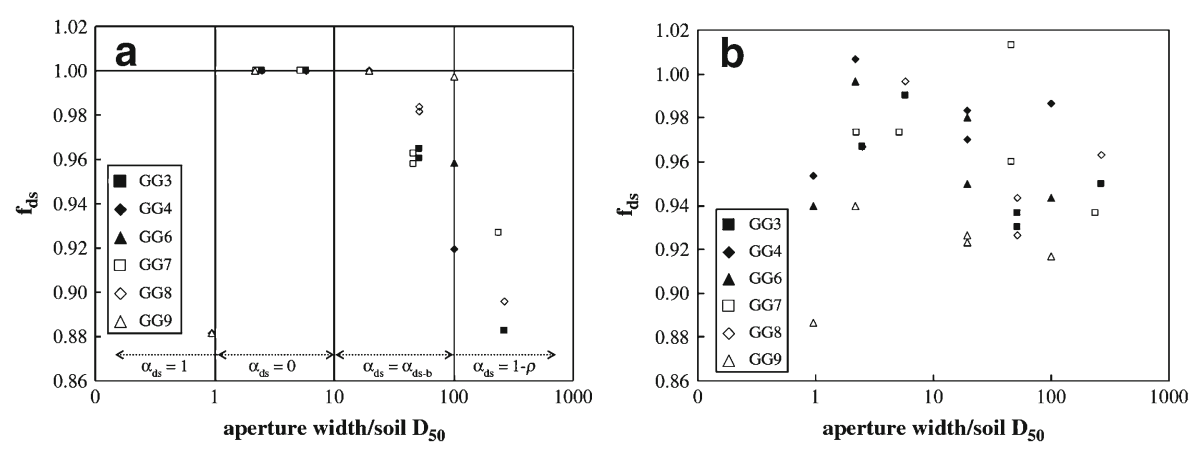

Fig. 43 Interface coefficient of direct sliding for different soil-geosynthetic interfaces: a Jewell theoretical expression and;b experimental values [62]

to bearing stress provided by transverse ribs, should contribute to the shear resistance of sand-geogrid interfaces.

Liu et al. [62] propose a simple equation to model the overall shear resistance of the soil/geogrid interface under direct shear mode as follows:

$$
\tau_{S / G G}^{\max }=\alpha_{d s} \cdot \tau_{S / G S Y}^{\max }+\left(1-\alpha_{d s}\right) \cdot \tau_{S / S}^{\max }+\tau_{\text {bearing }}^{\max }
$$

Where $\tau_{S / G G}^{\max }$ is the overall peak shear strength at soil-geogrid interface, and $\tau_{\text {bearing }}^{\max }$ is the peak shear strength provided by transverse bearing members; the others parameters were previously defined.

Consequently, the bearing resistance contribution ratio $\left(\beta^{*}\right)$ was defined as the ratio between the peak shear strength provided by transverse bearing members and the overall shear resistance at soil-geogrid interface as follows:

$$
\beta^{*}=\frac{\tau_{\text {bearing }}^{\max }}{\tau_{S / G G}^{\max }}=\frac{\tau_{S / G G}^{\max }-\alpha_{d s} \cdot \tau_{S / G S Y}^{\max }-\left(1-\alpha_{d s}\right) \cdot \tau_{S / S}^{\max }}{\tau_{S / G G}^{\max }}
$$

The authors determined the values of $\beta^{*}$ using Eq. 14 and the experimental results (Fig. 44).

It is important to notice that the passive resistance contribution is negligible for the geogrid GG9, for which all the transverse bars were removed. These results showed that transverse ribs provide a passive resistance contribution. Therefore, in addition to the shear resistance components, sand internal, and sand-geogrid skin friction, the passive resistance, induced by transverse ribs, provides an additional contribution to the shear strength of sand-geogrid interfaces under direct shear mode.

A limitation of the predicted passive resistance contribution by Eq. 14 is due to $\beta^{*}$ that becomes negative in some cases. The authors attributed this result to the interference phenomena that occur when the transverse bearing members are too close. Moreover, the authors found that the bearing resistance contribution ratio $\beta^{*}$ varies with the soil-geogrid interface studied. In particular, higher values of $\beta^{*}$ were obtained for geogrids in contact with soil with particle size smaller than the geogrid opening size, while smaller values of $\beta^{*}$ were determined when the geogrids were in contact with gravelly soil with particle size larger than the geogrid opening size. In general, the authors recorded that the bearing resistance contribution ratio was about 0 $10 \%$ of the overall interface shear strength. 


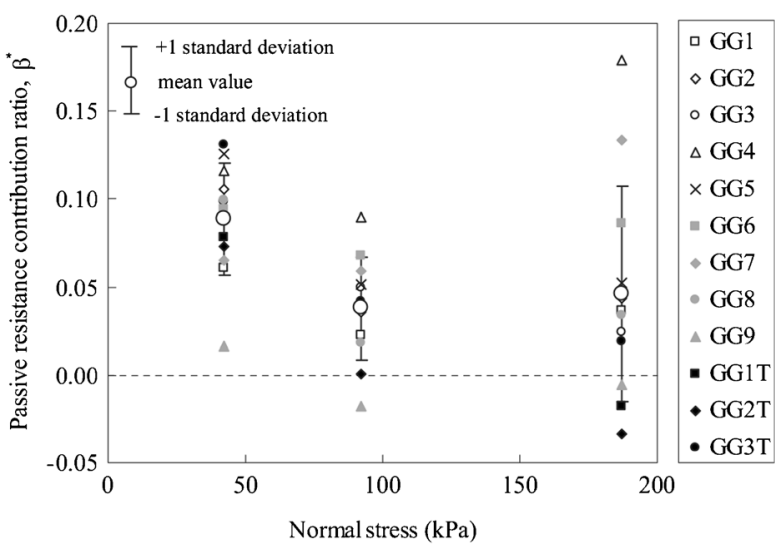

Fig. 44 Passive resistance contribution ratio for different sand-geogrid interfaces [62]

Only a few researches about soil-geosynthetic interface interaction under cyclic direct shear test are available in literature [91, 99].

Ling et al. [99] describe the direct shear interaction behavior of sand-clay mixture/ geogrid interfaces under monotonic and cyclic loading conditions. The cyclic direct shear tests were conducted on the soil alone and on the soil/woven geogrid interfaces at the same normal stresses of the monotonic tests. In the cyclic tests, a total of at least 15 loading cycles were applied under constant displacement and by controlling the shear stress at a level of 56-74 \% of the monotonic shear strength, applying a cyclic load amplitude between 30 and $40 \%$ of the cyclic strength for the soil/geogrid interface. The results, in the test condition used in the research, showed that the strength of soil/geogrid interfaces was not significantly affected by cyclic loadings (Fig. 45).

Vieira et al. [91] studied the behavior of a silica sand/high strength geotextile interface under monotonic and cyclic loading conditions. The cyclic direct shear tests were performed under load and under displacement control. The failure of the interface was detected by the decrease of the shear stress, for an imposed displacement, with the number of cycles.

For the load-controlled cyclic direct shear tests, the imposed shear stress semiamplitude ranged from approximately $20 \%$ of the maximum shear stress reached under monotonic loading $\left(\tau_{\max }\right)$ to the interface failure with increments of $10 \%$ of

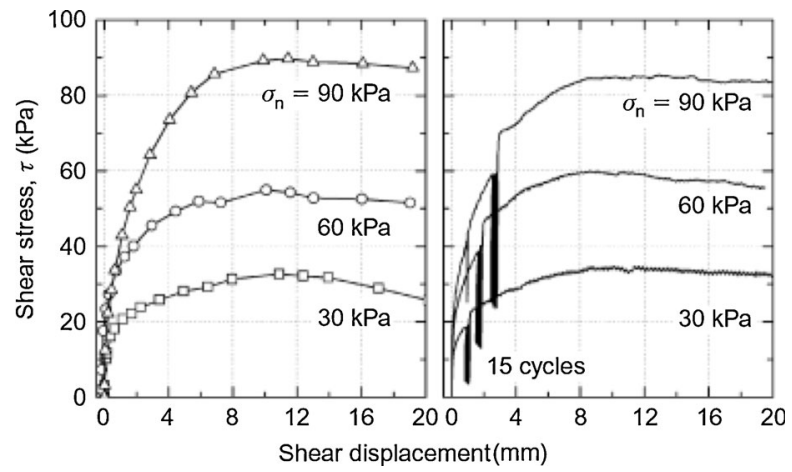

Fig. 45 Shear stress-displacement behavior of soil-geogrid interface, Ling et al. [99] 
$\left(\tau_{\max }\right)$. The failure of the interface was detected when the shear displacements, for an imposed shear stress, increased strongly with the number of cycles.

The applied normal stress, the vertical movements of the loading plate, the shear displacements (imposed in the displacement-controlled tests or resulting in the load controlled tests), and the horizontal shear stresses (resulting in the displacementcontrolled tests or imposed in the load-controlled tests) were recorded.

The test results showed that the interface shear stiffness increased with the number of loading cycles, whereas the damping ratio tended to decrease. The variation of these parameters after 10 cycles was slight (Fig. 46).

Moreover, the authors studied the effect of cyclic loading comparing the DSA results obtained by monotonic tests carried out on virgin specimens with the results of displacement- or load-controlled cyclic tests and with the results after that the interface failure by cyclic loading (Fig. 47a, b). In both cases, the test results analysis leads to similar conclusions: the cyclic loading did not lead to peak shear strength degradation if the cyclic strength of the interface was not reached previously. However, the post-cyclic shear strength for large displacements exhibited an important decrease.

\section{Conclusions on Soil-Geosynthetic Interaction in Direct Shear Test}

On the base of the considerations outlined in the previous paragraphs, the following conclusions can be drawn.

- The test boundary conditions may affect the test results, particularly for small shear boxes.

- The direct shear tests can be used to evaluate the interface shear strength if large shear boxes are used.

- The soil-geosynthetic interface shear strength depends on the applied vertical stress, on the geogrid opening, with respect to the soil particle average size, and on the thickness of bearing members.

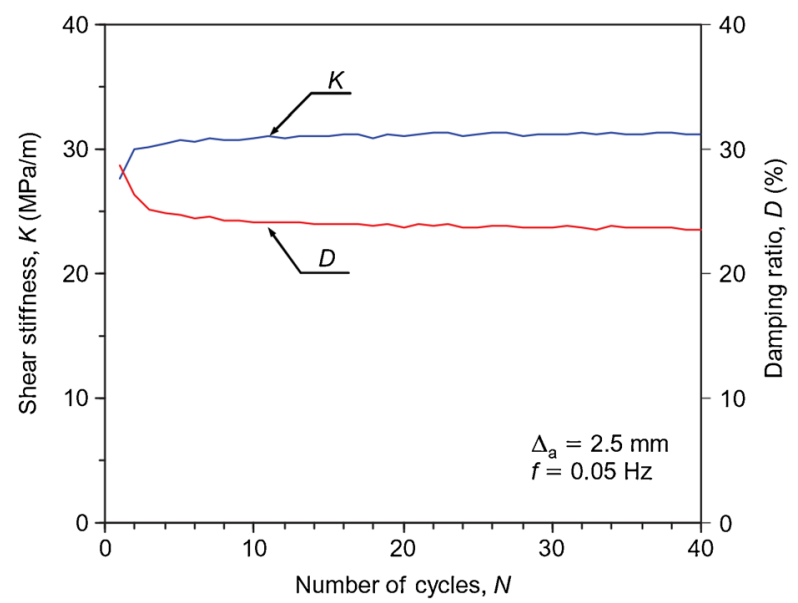

Fig. 46 Variation of shear stiffness and damping ratio with the number of cycles $( \pm \Delta a=2.5 \mathrm{~mm}, f=0.05 \mathrm{~Hz})$, Vieira et al. [91] 

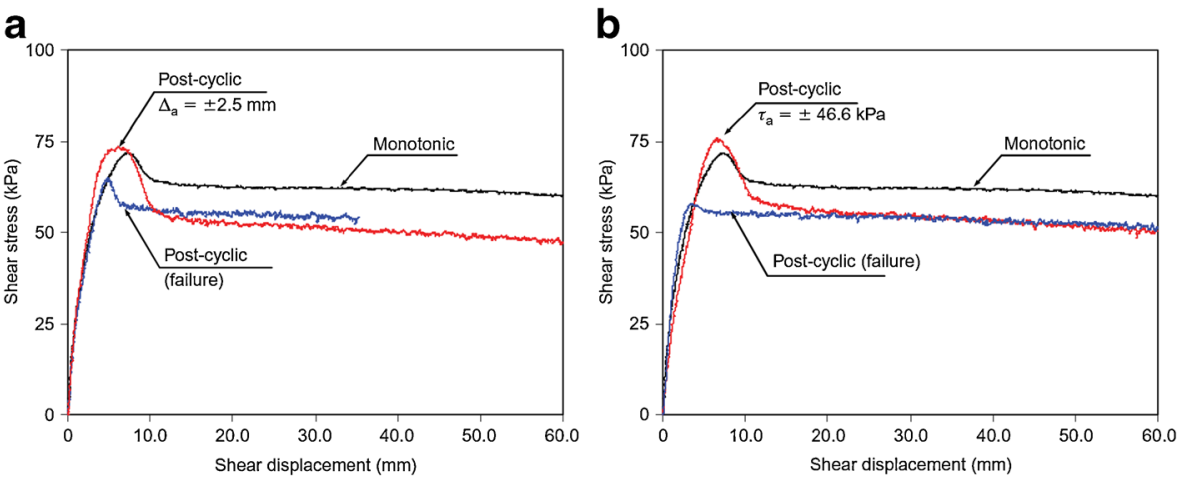

Fig. 47 Effect of cyclic loading on the interface shear strength for a displacement-controlled cyclic direct shear tests (after $\Delta a= \pm 2.5, f=0.05 \mathrm{~Hz})$ and $\mathbf{b})$ load-controlled cyclic direct shear tests $\left(\operatorname{after} \pm \tau_{a}=46.6 \mathrm{kPa}, f=\right.$ $0.05 \mathrm{~Hz})$. Vieira et al. [91]

- The conventional equations proposed to predict the sand-geogrid interface shear strength generally predict values that are smaller than the measured ones.

- The passive resistance induced by transverse ribs provides an additional contribution to the shear strength of sand-geogrid interfaces under direct shear mode.

Nevertheless, more studies are required to improve the existing theoretical model in order to evaluate this passive resistance and to include reinforcement extensibility and soil dilatancy effects.

Further studies are also required in order to evaluate the effects of reinforcement geometry and stiffness, of soil dilatancy, of cyclic tensile loading, of reinforcement in plane anisotropy, and on the restrained dilatancy on soil geosynthetic interaction in direct shear conditions.

\section{Inclined Plane Tests}

\section{Introduction}

In geotechnical applications such as geosynthetic liner systems on slopes of landfill sites either at the cap cover and on dams and riverbanks, an in-depth knowledge of the friction behavior of both soil-geosynthetic and geosynthetic-geosynthetic interfaces is required. The correct assessment of the interface shear properties between soils and geosynthetics or between different types of geosynthetics is an important issue considering the fact that interfaces with low in-plane shear resistance act as potential failure planes. If the stability of composite systems is not properly addressed, failure can occur. For example, failures of cover soils on geosynthetic layers in slopes of waste disposal areas, reservoirs, and ponds have been reported in the literature $[10,100,101]$.

The inclined plane test is the most appropriate tool [84, 102-106] for the characterization of the interaction between soil-geosynthetic and geosynthetic-geosynthetic at low normal stress typically found in such applications. 
A typical device, schematized in Fig. 48, is composed of an upper box sliding along an inclined support (a lower box or a plane). The test consists in studying the sliding behavior of the upper box while the inclination of the plane continuously increases.
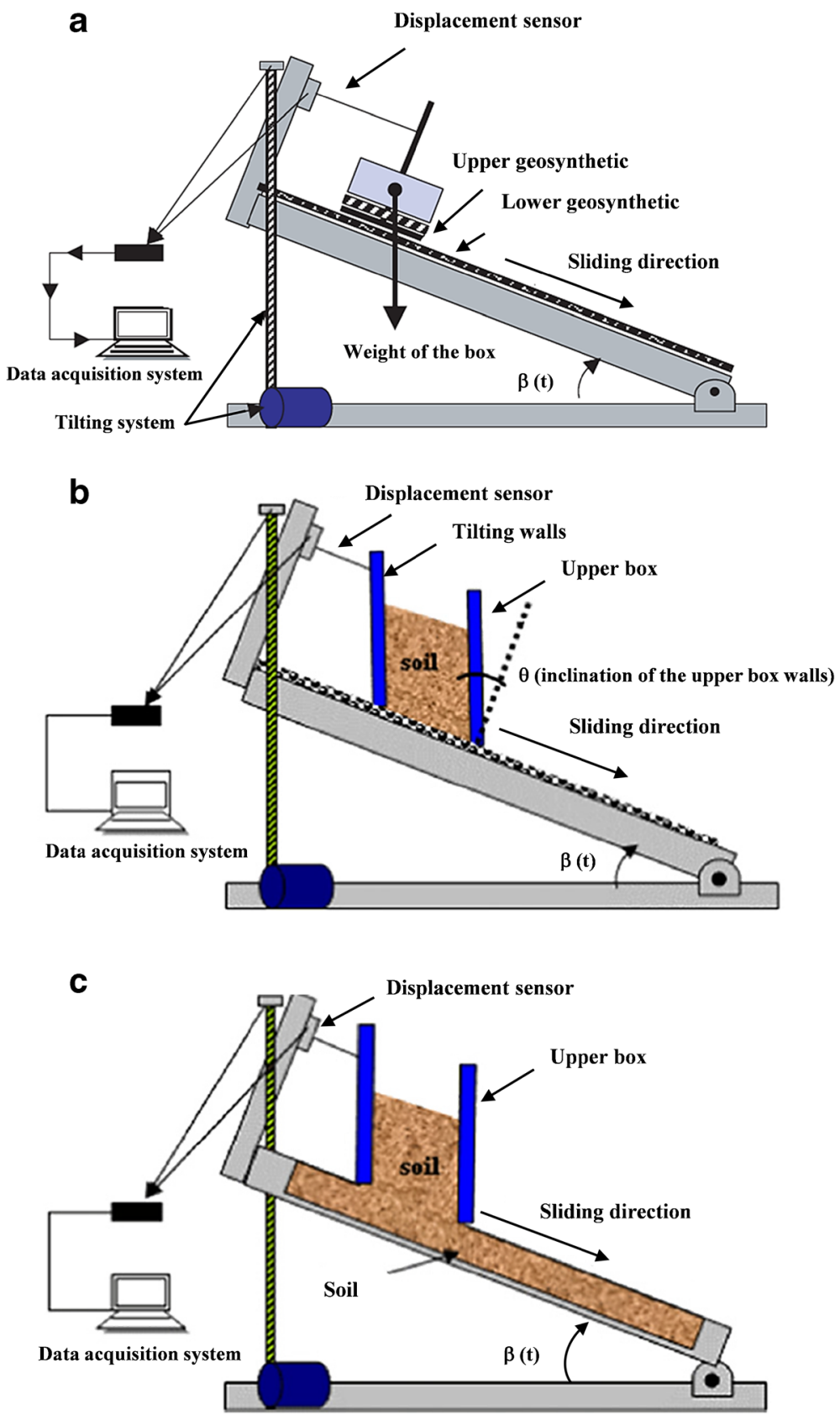

Fig. 48 Inclined plane device at different test configurations: a geosynthetic-geosynthetic interface, b soilgeosynthetic interface, and $\mathbf{c}$ soil-soil interface (after Pitanga et al. [106] and Reyes Ramirez and Gourc [105]) 
Several works on inclined plane test (tilting table or ramp test) can be found in literature $[10,83,84,102,104-113]$. In these works, despite the test is based on simple geometrical and mechanical concepts, variations between testing equipment can be found regarding apparatus arrangement, testing methodology, results interpretation, and experimental conditions.

The first studies [83, 84, 102, 103, 105, 109] on the inclined plane, mainly investigated the experimental condition of the test, the possibility of testing different types of interfaces, the selection of the direct shear or tilting test in function of the application, and the classification of these tests as index or performance tests.

Subsequently, the attention of researchers focused on the in-depth investigation of the test by redefining the following:

- The procedure (taking into account the influence of some experimental parameters)

- The interpretation of the test results (considering the current kinematic conditions during the entire test)

- Alternative approaches of testing in order to simulate additional conditions (i.e., testing multiple layers during a single experiment, abrasion tests, and creep tests) existing in the field.

Factors Affecting Inclined Plane Results

A review of the studies reported in literature highlighted the influence of some experimental parameters in the determination of the interface shear strength such as follows:

- Upper and lower box dimensions

- Spacing between upper box and lower specimen

- Nonuniformity of normal stress distribution

- Plane inclination rate

The influence of each parameter is discussed in the following.

\section{Box Dimensions}

The inclined plane can be used to perform tests on soil-geosynthetic, geosyntheticgeosynthetic, and soil-soil interfaces. Therefore, the dimensions of the boxes, especially when testing interfaces involving the soil, should take into account the need of a contact surface ensuring a representative tested interface, the need to minimize edge effects, and the difficulties of placing a large volume of soil. In literature, the interface area of the specimens varies from 0.005 [110] to $2.304 \mathrm{~m}^{2}$ [104], depending on the considered interface.

Izgin and Wasti [102], comparing interface shear strength values of smooth and rough geomembranes in contact with soil, obtained that a minimum area of $0.4 \mathrm{~mm}^{2}$ is required to have representative specimens for similar materials.

According to the EN ISO 12957-2 [55], for the upper box, the minimum dimensions are $L_{U}=0.30 \mathrm{~m}$ (length along the displacement direction) and $B_{U}=0.30 \mathrm{~m}$ (width), 
while for the lower support, they are $L_{L}=0.40 \mathrm{~m}$ and $B_{L}=0.325 \mathrm{~m}$. It is worth noting that the upper box dimensions are coincident with those encountered in large-scale direct shear devices and smaller dimensions of the upper box when testing geosynthetic interfaces can be still representative.

\section{Spacing Between Upper Box and Lower Sample}

To avoid friction between the upper box and the lower surface (geosynthetic or compacted soil), a spacing ( $s$ ) between the upper box and lower layer is necessary. The European Standard (ISO 12957-2 [55]) suggests $s=5 \mathrm{~mm}$, but some tests carried out firstly by Gourc et al. [83] and subsequently by Pitanga et al. [106], varying the spacing from 1 to $10 \mathrm{~mm}$, showed that the ideal spacing was equal to $6.5 \mathrm{~mm}$.

\section{Normal Stress Distribution}

In literature, inclined plane tests were performed at different normal stress levels ranging between 1.1 [109] to $50 \mathrm{kPa}$ [102] even if it is typically carried out at $5 \mathrm{kPa}$.

As in other types of tests, the dimensions of the box used to confine the soil in inclined plane tests influence the normal stress distribution on the tested interface. In particular, the effective normal stress acting on the interface decreases $\left(\sigma^{\prime}{ }_{v}=\sigma^{\prime}{ }_{0} \cos \beta\right)$ as the plane inclination $\beta$ increases $[83,104,109]$. The level of nonuniformity of the normal stress distribution along the interface is directly proportional to the tilting angle and to the height of the box center-mass, and inversely proportional to the box length. In order to limit the uneven shear stress along the interface tested, Palmeira et al. [104] suggested large box dimensions while Gourc et al. [83] adopted the use of inclined walls of the upper box especially when testing soil-geosynthetic interfaces. Thus, the front and rear sides of the upper box are kept parallel, and their inclination is predetermined through preliminary tests in order to be close to the vertical during the sliding phase. To determine the walls inclination, preliminary tests are required. In particular, they indicate that, for the tests with resulting angles between 20 and $35^{\circ}$, the walls should be fixed to $27^{\circ}$, while for angles higher than $35^{\circ}$, the walls can have angles equal to $40^{\circ}$.

The effectiveness of both solutions was verified by Palmeira et al. [104]. In their study, numerical analyses of inclined plane tests using the computer code PLAXIS was performed considering different lengths $(0.5,2$, and $10 \mathrm{~m})$ and thickness of the soil box at various plane inclinations. The numerical analysis results reported in Fig. 49 in terms of normal stress versus normalized interface length (i.e., where the normalization refers to the ratio $h / L$ with $h$ upper box height and $L$ upper box length) showed that the difference between maximum and minimum normal stress values increases considerably as the length of the upper box is reduced, while adopting inclined walls as suggested by Gourc et al. [83], a uniform stress distribution is obtained.

\section{Plane Inclination Rate}

In general, during the test, the plane inclination is increased at a constant rate ranging, depending on the work considered, from 0.0033 to $6.5 \%$ sec. The influence of the plane inclination rate, $d \beta / d t$, was investigated in literature by Izgin and Wasti [102] 

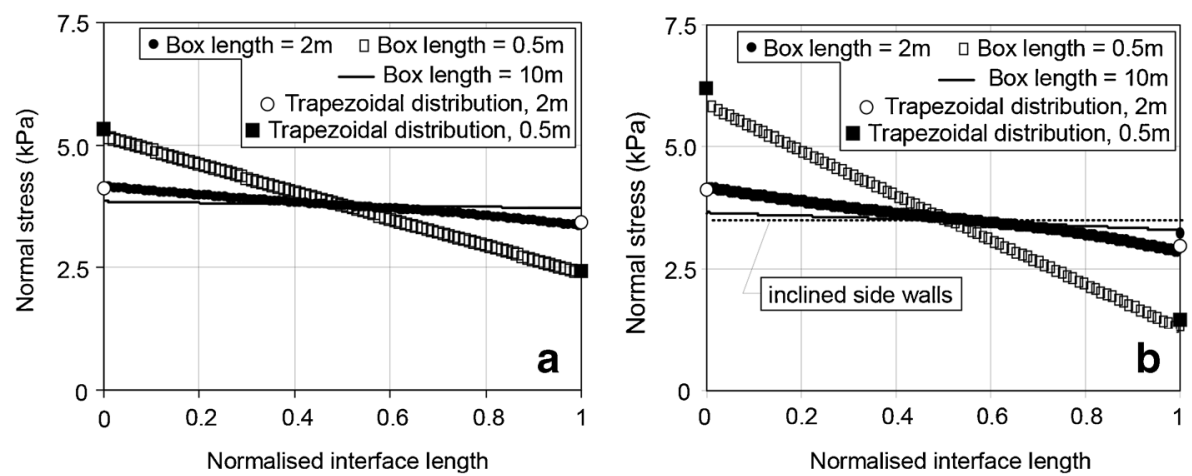

Fig. 49 Normal stress distribution along the interface at $15^{\circ}$ (a) and $25^{\circ}$ (b) of plane inclinations (after Palmeira et al. [104])

performing tests at rising speeds of $1,1.65$, and $6.5 \%$ and found no significant effect of the speed on test results. Further researches conducted by Reyes-Ramirez et al. [114] for a range of rates between 0.58 to $3.08 \% \mathrm{~min}$ demonstrated that the plane inclination speed has no significant effect on test results.

The European Standard EN ISO 12957-2 [55] establishes that, during the test, the plane inclination, $\beta$, must be increased at a constant low rate $d \beta / d t=3.0 \pm 0.5 \% \mathrm{~min}$.

Test Interpretation and Procedures

Due to the various characteristics of inclined plane equipment available in literature, some differences in performing the test and interpreting the results were observed.

Some studies consider the interface shear strength angle as the angle corresponding to the inclination of the plane at which the box slides [102, 103, 109]. Gourc et al. [83] and Lalarakotoson et al. [84] differentiate the interface shear strength angle corresponding to the beginning of the slide with respect to that at failure (i.e., when the upper box arrives at the end of the plane). Finally, in some researches [104, 107, 115], the interface shear strength properties were assessed in terms of tensile load exerted on the geosynthetics and of the upper box displacement versus the plane inclination.

In this contest, the European Standard [55] tried to homogenize the procedure and the result interpretation describing the method and the shear strength angle determination. As other studies underlined [106, 108, 116] the interpretation of test results according to EN ISO 12957-2 [55], here defined as "Standard Procedure," does not consider the actual kinematic conditions existing during the test. Therefore, alternative procedures were proposed by Gourc and Reyes Ramirez [116] and Briançon et al. [108], here called "Displacement Procedure" and "Force Procedure," respectively.

\section{The Standard Procedure (European Standard EN ISO 12957-2. 2005)}

The European Standard [55] proposes an interpretation of the test here called "Standard Procedure." According to this standard, the interface shear strength angle, $\phi_{\text {stan }}$, is evaluated at the plane inclination angle $\beta_{50}$ corresponding to a displacement of $50 \mathrm{~mm}$ 
of the upper box. The conventional upper box displacement, $u=50 \mathrm{~mm}$, was chosen because results obtained by testing the same interfaces at different European laboratories (experimental program: CEN-Interlab) showed for these values, satisfying results in terms of repeatability [83].

The standard interface shear strength angle, $\phi_{\text {stan }}$, is calculated considering a static equilibrium along the plane direction as follows:

$$
\begin{gathered}
W \cdot \sin \beta_{50}-N \cdot \tan \phi_{s \tan }=0 \\
W \cdot \cos \beta_{50}=N
\end{gathered}
$$

Where $N$ is the reactive force balancing the normal component of the weight, $W$, of the upper box.

The value of $\phi_{\text {stan }}$ is obtained by combining Eqs. 16 and 17 to yield the following:

$$
\tan \phi_{s \tan }=\tan \beta_{50}
$$

Since the standard interface shear strength angle, $\phi_{\text {stan }}$, is evaluated during the upper box sliding, the static interpretation is not fully correct and shear strength angle could be overestimated in many cases [117].

\section{Displacement Procedure}

The standard apparatus is not capable of allowing large displacements and does not provide the possibility of assessing the upper box motion during the sliding. Gourc and Reyes Ramirez [116], modifying a standard inclined plane device, proposed an interpretation of test results, here called "Displacement Procedure," taking into account the acceleration of the upper box $\left(a_{b o x}\right)$ during the sliding. Therefore, since the sliding rate of the upper box could be significant during the motion, the mechanical equilibrium analysis must be conducted using a dynamic approach.

In the Displacement procedure, three main phases can be recognized as follows:

- Phase 1 (static phase): the upper box is practically motionless (the displacement of the upper box is equal to zero) over the inclined plane until a critical angle, $\beta_{0}$, corresponding to the beginning of the sliding, is reached

- Phase 2 (transitory phase): with increasing inclination beyond $\beta_{0}$, the upper box moves downward, and the acceleration $a_{b o x}$ of the upper box increases

- Phase 3 (nonstabilized sliding phase): at $\beta=\beta_{s}$, the upper box undergoes nonstabilized sliding at an increasing speed (constant acceleration $a_{\text {const }}$ ), even if the plane inclination is held constant at $\beta_{s}$.

To summarize, $\beta_{0}$ is defined as the plane-inclination angle at the static limit of equilibrium and $\beta_{S}$ is the inclination angle at which a constant acceleration is achieved (phase 3 ).

The typical inclined plane test results are plotted in terms of upper box displacement, $u$, versus the plane inclination angle, $\beta$, as shown in Fig. 50. In particular, the analysis of various displacement $(u)$-inclination $(\beta)$ diagrams, highlights that phase 2 may be mainly classified into two types as follows: 

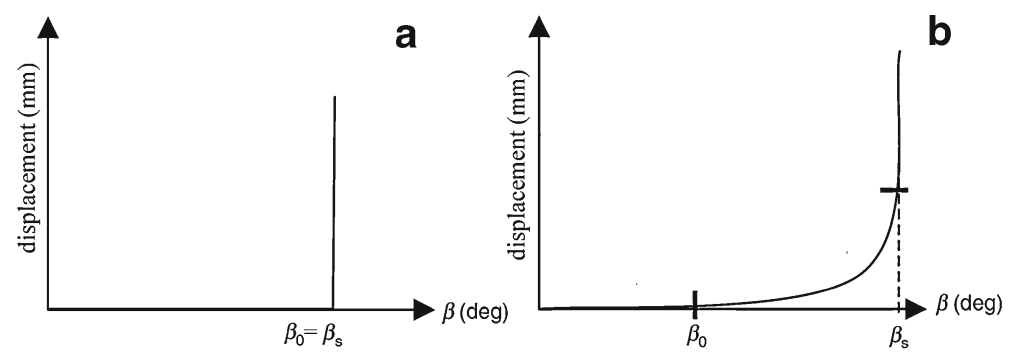

Fig. 50 Different mechanisms of sliding observed in the inclined plane test: a sudden sliding and $\mathbf{b}$ gradual sliding (modified from Gourc and Reyes Ramirez [116])

- $\quad$ Sudden sliding: abrupt displacement of the upper box under nonstabilized sliding with a nearly nonexistent phase $2\left(\beta_{0} \sim \beta_{s}\right)$, and

- Gradual sliding: displacement $u$ increases with inclination $\beta$, progressively

For the phase 3, taking into account the dynamic conditions of the upper box during the sliding, a constant acceleration, $a_{\text {const }}$, can be defined approximating the motion as uniformly accelerated. Therefore, the standard relations (Eqs. 15 and 16) are replaced with Eqs. 19 and 20 as follows:

$$
\begin{gathered}
W \cdot \sin \beta_{s}-N \cdot \tan \phi_{s}=W \cdot \frac{a_{\text {const }}}{g} \\
W \cdot \cos \beta_{s}=N
\end{gathered}
$$

The value of the actual shear strength angle, $\phi_{s}$, in place of $\phi_{\text {stan }}$, is similarly obtained by combining Eqs. 19 and 20 to give the following:

$$
\tan \phi_{s}=\tan \beta_{s}-\frac{1}{\cos \beta_{s}} \cdot \frac{a_{\text {const }}}{g}
$$

Where $a_{\text {const }}\left(\mathrm{m} / \mathrm{s}^{2}\right)$ corresponds to the constant acceleration of the upper geosynthetic component of the interface during the nonstabilized sliding phase and $g$ $\left(\mathrm{m} / \mathrm{s}^{2}\right)$ corresponds to the acceleration due to the gravity.

The principal limitation encountered in the application of this procedure is the acceleration assessment for those interfaces showing a gradual sliding behavior [106, 118].

\section{Force Procedure}

To overcome the problems related to the "Displacement Procedure," Briançon et al. [108] proposed the "Force Procedure." This method consists in determining the interface shear strength angle by measuring the force required to restrain the upper box above a limiting value of the sliding displacement $u_{\text {lim }}$.

Therefore, to apply this method, the inclined plane device is equipped with a force sensor, fixed to the device frame, and linked to the upper box by means of a loose cable (Fig. 51). Upon reaching a predetermined value, $u_{\text {lim }}$, of the upper box displacement corresponding to an inclination $\beta=\beta_{\text {lim }}$, the cable is stretched and the force $F(\beta)$ required to restrain the upper box is measured [108]. 


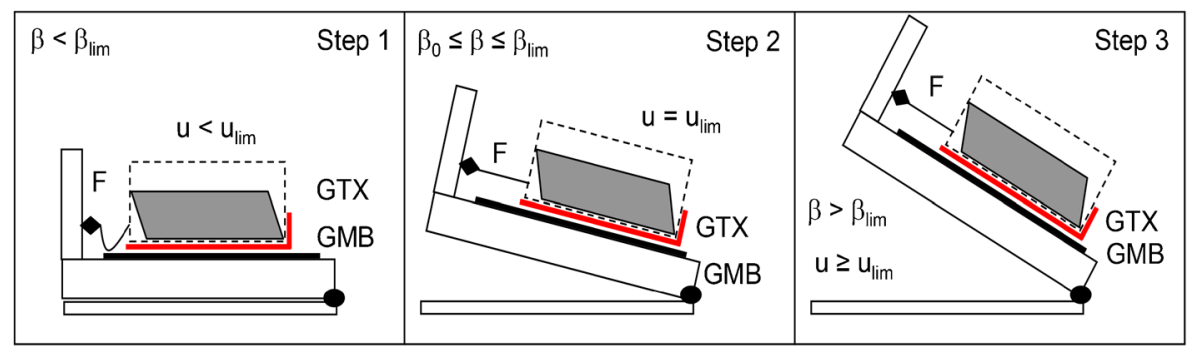

First step

Second step

Third step

Fig. 51 Schematization of the different steps during the "Force Procedure" (after Briançon et al. [108])

Following this procedure, three main steps can be identified as follows:

- Step 1 corresponds to the static state of the upper box with respect to the lower plane during the tilting process $\left(\beta<\beta_{0}\right)$.

- Step 2 corresponds to the transitory state; the upper box slides, gradually or suddenly, until the cable is stretched $u=u_{\text {lim }}$ and $\beta_{0}<\beta<\beta_{\text {lim }}$.

- Step 3 corresponds to the stretched condition of the cable after the sliding; here, the variation of $F(\beta)$ is monitored during the continuous tilting process $\left(\beta>\beta_{\text {lim }}\right)$. The upper box can be considered to be in a static state with respect to the lower box if the elongation of the cable under the tensile force $F$ is neglected.

During step 2, as the acceleration $a_{b o x}$ is generally not measured, only two different values of the interface shear strength angles corresponding to the step 1 (where $F(\beta)=0$ ) and step $3(F(\beta)>0$ ) are calculated considering a static and a pseudo-static conditions:

$$
\begin{gathered}
W \cdot \sin \beta-N \cdot \tan \phi-F(\beta)=0 \\
W \cdot \cos \beta=N \\
\tan \phi=\frac{W \cdot \sin \beta-F(\beta)}{W \cdot \cos \beta}
\end{gathered}
$$

Where $W$ is the total weight of the upper box and $F(\beta)$ is the force required to restrain the upper box.

When the plane exceeds the inclination necessary to fully mobilize the interface shear strength angle, the force $F(\beta)$ becomes proportional to $\beta$ in such a way that $\tan \phi$ does not vary further. After stabilization, the constant value of the shear strength angle is indicated as $\phi_{\text {lim }}$.

Soil-Geosynthetic and Geosynthetic-Geosynthetic Interaction in Inclined Plane Tests

The inclined plane test is able to simulate the interface response of geosynthetic liner systems on slopes. For this reason, researches often study the interaction between both soil-geosynthetic and geosynthetic-geosynthetic interfaces. 
In literature, especially before the European standardization, the incline plane test was conducted with various testing methods and result interpretations. An in-depth bibliographical analysis was carried out on the testing methods and on the main findings about the interface shear strength assessment by means of the incline plane apparatus.

\section{Inclined Plane Versus Direct Shear Test}

Firstly, in order to validate the test, several investigations drew a parallel study between the inclined plane and the shear box test results [83, 84, 102, 105, 109, 116] conducted both on soil-geosynthetic and geosynthetic-geosynthetic interfaces.

Girard et al. [109] studied a failure that occurred in a lining system at Aubrac Dam (France) along a PVC geomembrane-needle-punched geotextile interface through the inclined plane and the direct shear tests. The authors reported an overestimation of the direct shear test results compared with those obtained through the inclined plane and with those determined by the back-analysis of the failure. Similar conclusions were drawn by Giroud et al. [119] using an inclined plane as well as direct shear tests on the rough geomembrane-hard geonet and rough geomembrane-nonwoven geotextile interfaces. The normal stresses applied in both devices were between 25 and $160 \mathrm{kPa}$ in the direct shear test and of $0.7 \mathrm{kPa}$ in inclined plane tests. Test results were consistent for the hard geonetrough geomembrane interface, while the comparison between rough geomembraneneedle-punched nonwoven geotextile interface yielded quite dissimilar results.

Izgin and Wasti [102] compared inclined plane tests with direct shear tests equipped with boxes of different dimensions (from 0.12 to $0.6 \mathrm{~m}^{2}$ ) under a normal stress level ranging from 5 to $50 \mathrm{kPa}$, with $\sigma^{\prime}{ }_{v}=14-200 \mathrm{kPa}$. The tests were carried out on soil (Ottawa sand)-HDPE smooth and rough geomembrane interfaces considering the sliding angle (i.e., the slope of the inclined board at which the box slides) as the main parameter of the test. They concluded that the direct shear test overestimates the interface shear strength angle; furthermore, they noted higher discrepancy if the small size box dimensions are considered. Wasti and Özdüzgün [103] extended the work of Izgin and Wasti [103], assessing the shear strength properties of geotextilegeomembrane interfaces at both devices. They observed that the interface shear behavior and the agreement between the results of direct shear box and inclined plane tests depend on the type of interface. For smooth geomembrane-geotextile interfaces, a good agreement of test results was found. Conversely, for rough geomembrane-geotextile interfaces, direct shear tests predicted interface shear strengths significantly higher than those of inclined plane tests as a result of large adhesion intercept values in direct shear envelopes.

Gourc et al. [83] performed a series of inclined plane and direct shear tests on several types of geomaterials (soils and geosynthetics) under the European project for standardization (CEN-Interlab). They evaluated the influence of some experimental parameters (i.e., box dimensions, tilting walls, fixation of specimens, placing, and compaction of soil) and after, they compared the results obtained from testing the standard sand EN206/196 in contact with (HDPE and PVC) geomembranes, nonwoven needlepunched polyester, and woven geotextiles and geogrids (with thick and with flat ribs) using the two different devices. The interpretation of test results was based on two interface shear strength angles: $\phi_{0}$, defined by the following conditions: the differential ratio $\mathrm{du} / \mathrm{d} \beta$ greater than two for more than three datasets and $\phi_{f}$,corresponding to the 
angle of the slippage without interruption up to the end of allowed displacement. A good agreement between inclined plane and direct shear test results was observed (difference lower than $10 \%$ ) if the variation of normal stress level is taken into account.

Similar conclusions were found by Lalarakotoson et al. [84] investigating the shear strength at the interface between dense $(D r=0.85)$ and loose $(D r=0.2)$ sands (EN206/ 196) in contact with different geosynthetics (i.e., HDPE smooth and textured geomembranes, with woven and nonwoven geotextiles, and with geogrids). The shear strength is considered as purely frictional with no cohesive component and the interpretation of test results is conducted taking into account two main angles: $\phi_{g p}$, maximum shear strength angle representing the maximum friction resistance obtained for a given $\sigma^{\prime}{ }_{v}$ value (calculated during slip applying static equilibrium); $\phi_{g r}$, residual shear strength angle after slip for the same $\sigma^{\prime}{ }_{v}$ value.

A completely different sliding behavior was observed by testing interfaces involving loose and dense sands (Fig. 52). Independently on the geosynthetic tested, the interfaces involving the loose sand showed a stick-slip behavior (Fig. 52), while a continuous slip was observed when a dense sand was tested (Fig. 52). These interface behaviors (in particular the stick-slip) can be observed more easily in the inclined plane than in the direct shear box test because of the different test kinematics.

Reyes Ramirez and Gourc [105] extended the previous research work, performing inclined plane and direct shear tests on geosynthetic-geosynthetic interfaces. The materials tested involved a HDPE grid-type geospacer in contact with a nonwoven geotextile and a PP and HDPE smooth geomembranes, respectively. Assuming the threshold angle $\phi_{g g}$ (with $\phi$ value corresponding to $\tau_{l i m} / \sigma^{\prime}{ }_{v}=\tan \phi$ for an upper box displacement equal to 10,50 , and $100 \mathrm{~mm}$ ), as the critical angle determined with the inclined plane test, they found a drop in the shear strength angle passing from the inclined plane to the direct shear test results. This difference was attributed to the increase in normal stress acting on the interface.

\section{Inclined Plane Test: Testing Methods, Results Interpretation, and Parameters Assessed}

After the validation of the inclined plane test, researchers focused the attention on improving test method [106-108, 116], the assessment of the results [104, 107], and the analysis of the influence of other factors (i.e., presence of reinforcement, dry and wet
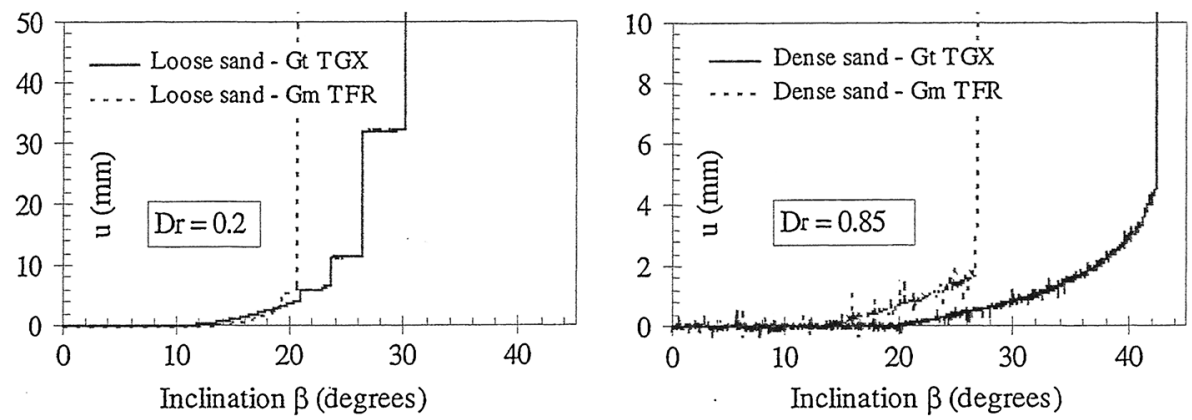

Fig. 52 Typical behavior obtained according to sand density: a nonwoven geotextile and smooth geomembrane in contact with loose sand and $\mathbf{b}$ nonwoven geotextile and smooth geomembrane in contact with dense sand (after Lalarakotoson et al. [84] 
conditions, creep, abrasion, and temperature) in shear strength evaluation $[105,107$, $112,113,115]$.

Briançon et al. [107] used a large inclined plane apparatus capable to perform tests under dry and wet conditions. Three different testing methods were developed in this study. These methods involved (i) the measurement of the upper box displacement as the plane is inclined (test described in the standards), (ii) the monitoring of the upper box displacement and of the tensions exerted on the geosynthetics (fixed to the lower box) in relation to the slope of the plane, and (iii) the analysis of the force required to hold back the upper box as the plane is inclined. The interfaces tested included soilgeotextiles (different types), geotextile-geomembrane (HDPE smooth and rough), and soil-geomembrane. The results obtained with such apparatus were validated by the authors in comparisons with results from large field experiments. Furthermore, it was found that the presence of water can decrease the friction angle and the reduction strictly depends on the interface investigated (in the case of geosynthetic-geosynthetic interface, the difference was about $1^{\circ}$ ).

Palmeira et al. [104] presented theoretical and experimental investigations on the use of a large ramp test apparatus to study the interaction between soil and geosynthetics and between different layers of geosynthetics. In this study, the soils tested were a fine and a coarse sand and clayey soil, while several types of geosynthetics were used involving nonwoven and woven geotextiles, geogrids, geonets, and PVC and HDPE smooth and rough geomembranes. The tests were carried out in a diverse manner with respect to those presented in literature. In fact, the lower specimen, usually fastened to the plane, was just laid on the ramp (preliminary tests to investigate the friction between the lower specimen and the ramp were conducted) and connected to a load cells through the clamps. In order to investigate the effect of multiple geosynthetic layers in contact with soil, different geosynthetics were placed on the lower specimen, and, through load cells, the tensile load mobilized at each geosynthetics was measured. The upper box was generally filled with soil; just in one configuration, a geosynthetic was fastened under the box. The displacement transducer monitored the upper box displacement and the test finished when the complete slide of the box along the ramp accomplished. Hence, the interface properties were expressed in terms of tensile load of the geosynthetic and considering the upper box displacement versus the plane inclination.

The principal findings of this study are (i) the shear strength angles between geosynthetics that occurred first along the weakest interface usually represented by geosynthetic-geosynthetic contact; (ii) in terms of displacement, tests with the fine sand yielded greater box displacements and geosynthetic forces at failure (Fig. 53a, b) than those observed in tests with the coarse sand (Fig. 53c, d); (iii) the presence of a geotextile layer between a geogrid and a geomembrane increased the box displacements, but caused a reduction of the geomembrane tensile force of $30 \%$ in comparison to the situation without the geotextile; (iv) the sequence of slippage along interfaces in tests with multiple geosynthetic layers influenced the magnitude and the variation of tensile forces in the underlying geomembrane layer.

Using the same large-scale inclined plane device, Palmeira and Viana [115] presented an experimental investigation on the use of geogrids buried in cover soils of slopes. The tests involved the use of geogrids with several values of tensile stiffness and bearing capacity (number of bearing members) installed at different elevations above 

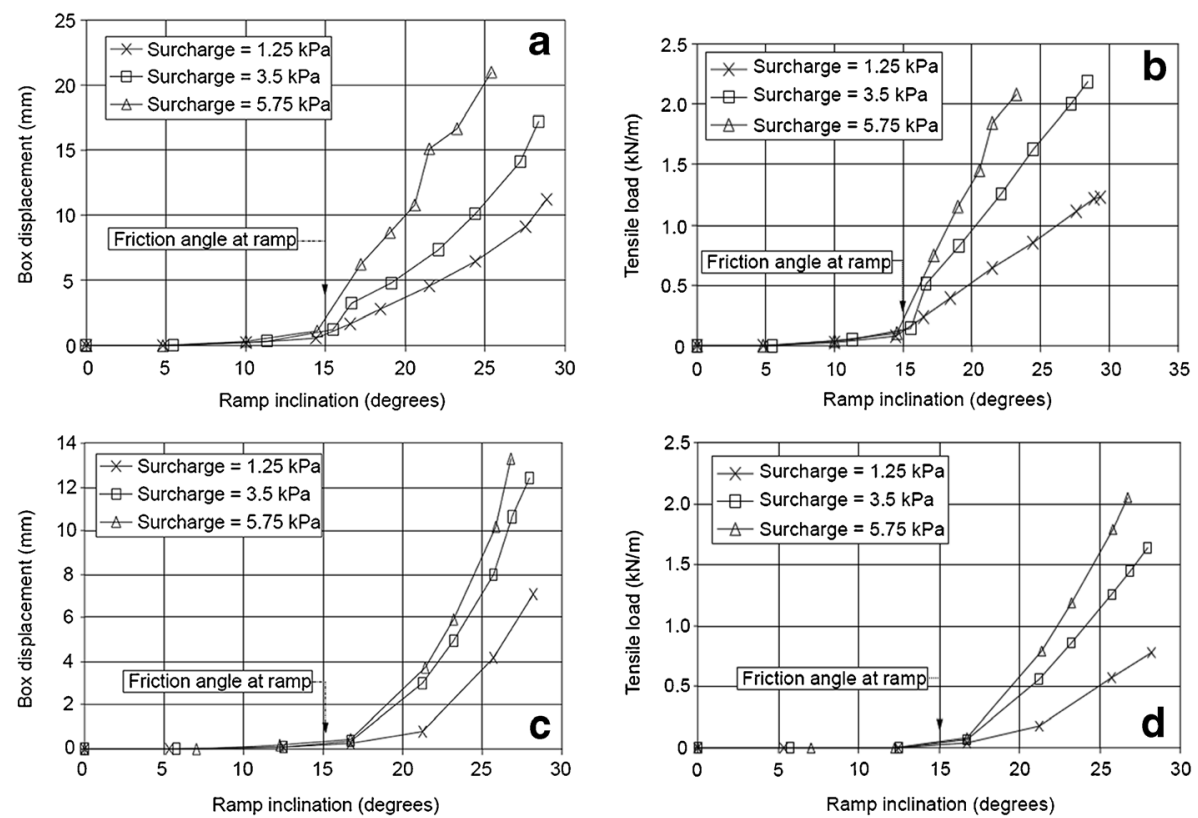

Fig. 53 Box displacement and tensile loads for tests with woven geotextile in contact with fine sand (a, b) and coarse sand $(\mathbf{c}, \mathbf{d})$ (after Palmeira et al. [104])

the geomembrane representing always the lower layer (Fig. 54a). Furthermore, the influence of the use of a geotextile layer on the geomembrane on the behavior of the system was also assessed being this solution commonly adopted to minimise damages on the geomembrane. The results showed in Fig. 54b refer to the following cases: a cover soil (coarse sand) on a geomembrane (smooth HDPE), a cover soil reinforced by a geogrid (in polyester with apertures $20 \mathrm{~mm} \times 20 \mathrm{~mm}$, thickness of $1.1 \mathrm{~mm}$, and a tensile stiffness of $200 \mathrm{kN} / \mathrm{m}$ ) installed at its mid-height, and also a situation with the reinforced cover soil on a geomembrane protected by a geotextile. The variation of box displacement versus ramp inclination showed in Fig. 54b reveals that the presence of a geogrid in the cover soil increased markedly the ramp inclination at failure and the arrangement with the geogrid, and the geotextile provided a less deformable system reducing the tensile forces mobilised in the geomembrane. In conclusion, as reported by Palmeira [10], the presence of the reinforcement layer in the cover soil can allow higher slope inclinations or, for the same inclination of an unreinforced system, the presence of the reinforcement can provide additional safety against cover soil sliding on the geomembrane. Furthermore, they found that the optimum elevation, $y$, of the geogrid layer above the geomembrane is of the order of one third of the cover soil thickness.

Due to a reduction of the upper box dimensions with respect to those described by the European Standard [55], Gourc and Reyes Ramirez [116] detailed the upper box sliding behavior and proposed a new interpretation of test results taking into account the dynamic conditions during the upper box slide (as described in Displacement Procedure). Therefore, the static and the dynamic shear strength angles were determined for interfaces involving dense and loose sands (Leucate) in contact with smooth HDPE geomembrane, and HDPE geospacer in contact with smooth HDPE geomembrane and with a nonwoven geotextile, respectively. In particular, focusing 


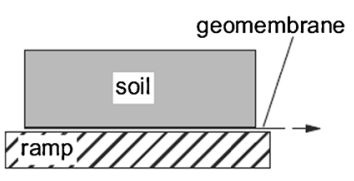

(1)

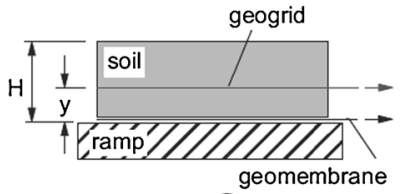

(2)

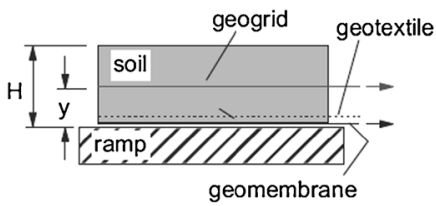

(3)

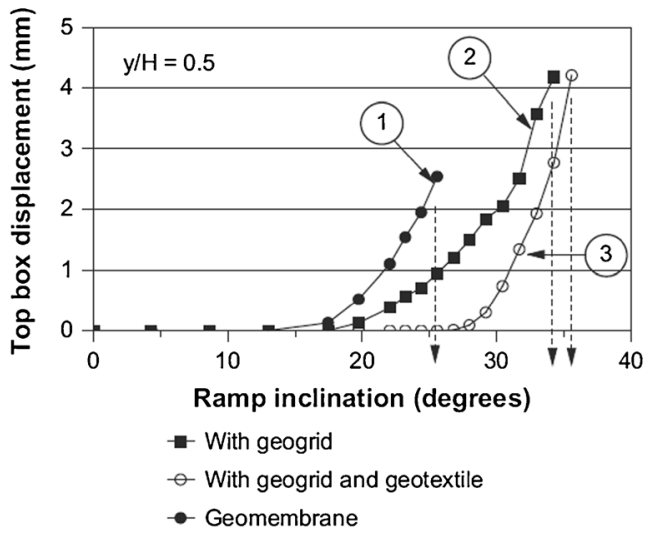

Fig. 54 Effect of the presence of reinforcement on cover soil stability (after Palmeira and Viana, [115])

the attention on sand-geomembrane interfaces, a sudden sliding behavior was found testing loose and dense soils (Fig. 55). Test results indicate a decrease of $\phi_{0}$ with the decrease of sand density and a dynamic interface shear strength angle, $\phi_{s}$, lower than the static one. Comparing the dynamic interface shear strength angles, $\phi_{s}$, provided by testing the two types of sand density, very close values are obtained. These results indicate that during the sliding, the sand at the interface experiences disturbance to its structure, and its mass density most likely decreases close to the critical mass density

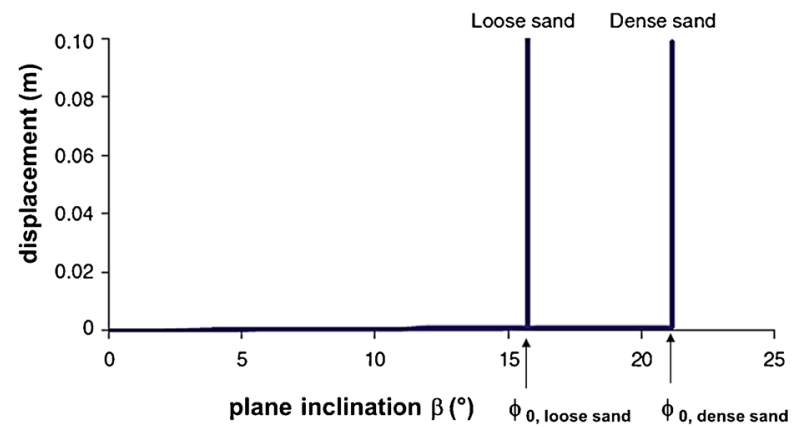

Fig. 55 Inclined plane tests on sand-geosynthetic interfaces for two sand densities, loose $(D r=20 \%)$ and dense $(D r=85 \%)$ [116] 

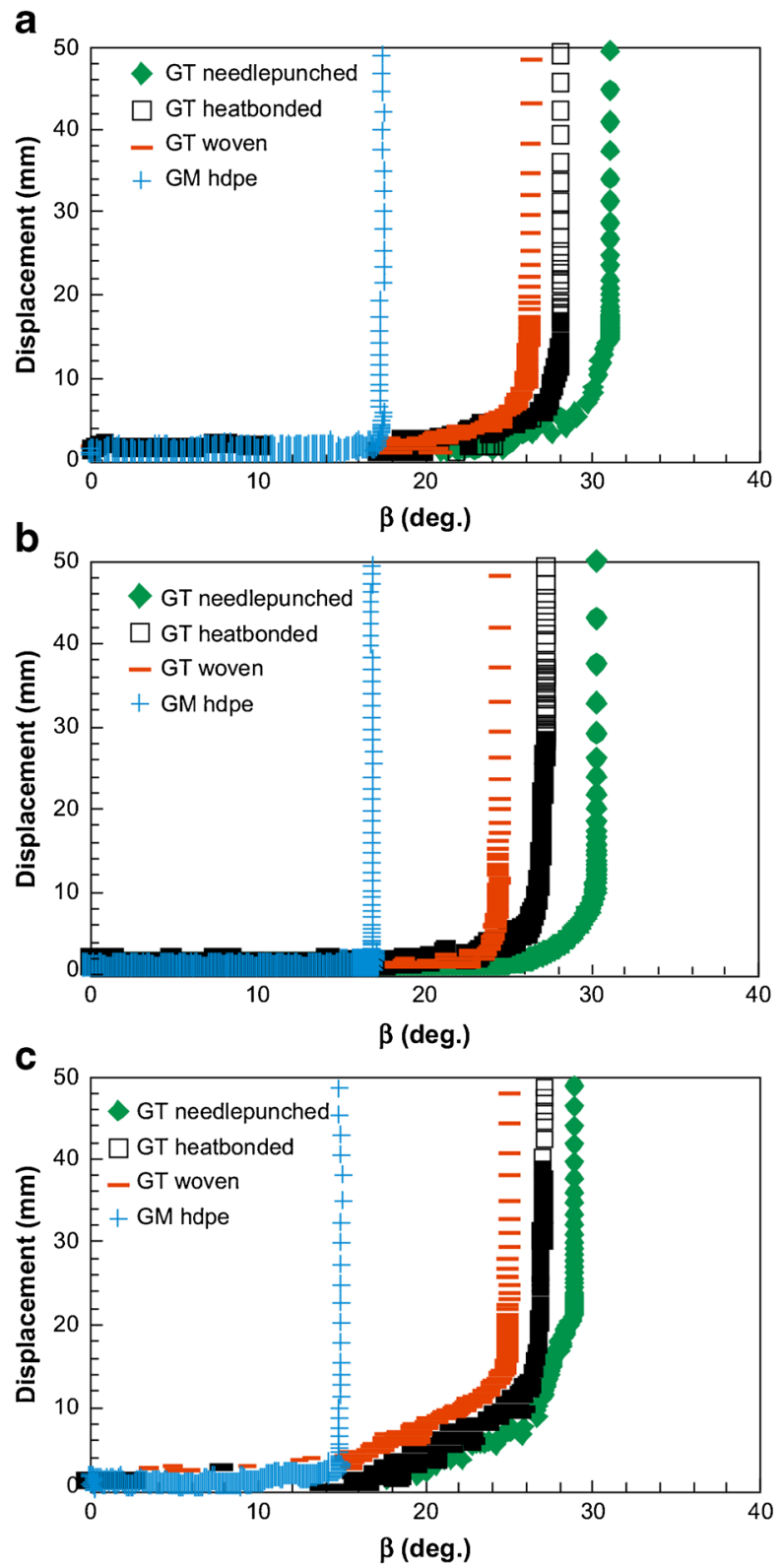

Fig. 56 Inclined plane tests for compacted soil-geotextile interfaces: $\mathbf{a} \sigma^{\prime}{ }_{0}=2.8 \mathrm{kPa}, \mathbf{b} \sigma^{\prime}{ }_{0}=5.9 \mathrm{kPa}$, and c $\sigma_{0}^{\prime}=10.4 \mathrm{kPa}$ (after Pitanga et al. [106])

corresponding to the residual friction in a conventional direct shear test. On the other hand, values of $\phi_{s}$, are poorly affected by the soil density during the dynamic phase because of the particle arrangement due to the dynamic effect. Finally, comparing $\phi_{0}$ values with the peak shear strength angles obtained in shear box tests, very close values were noticed. 

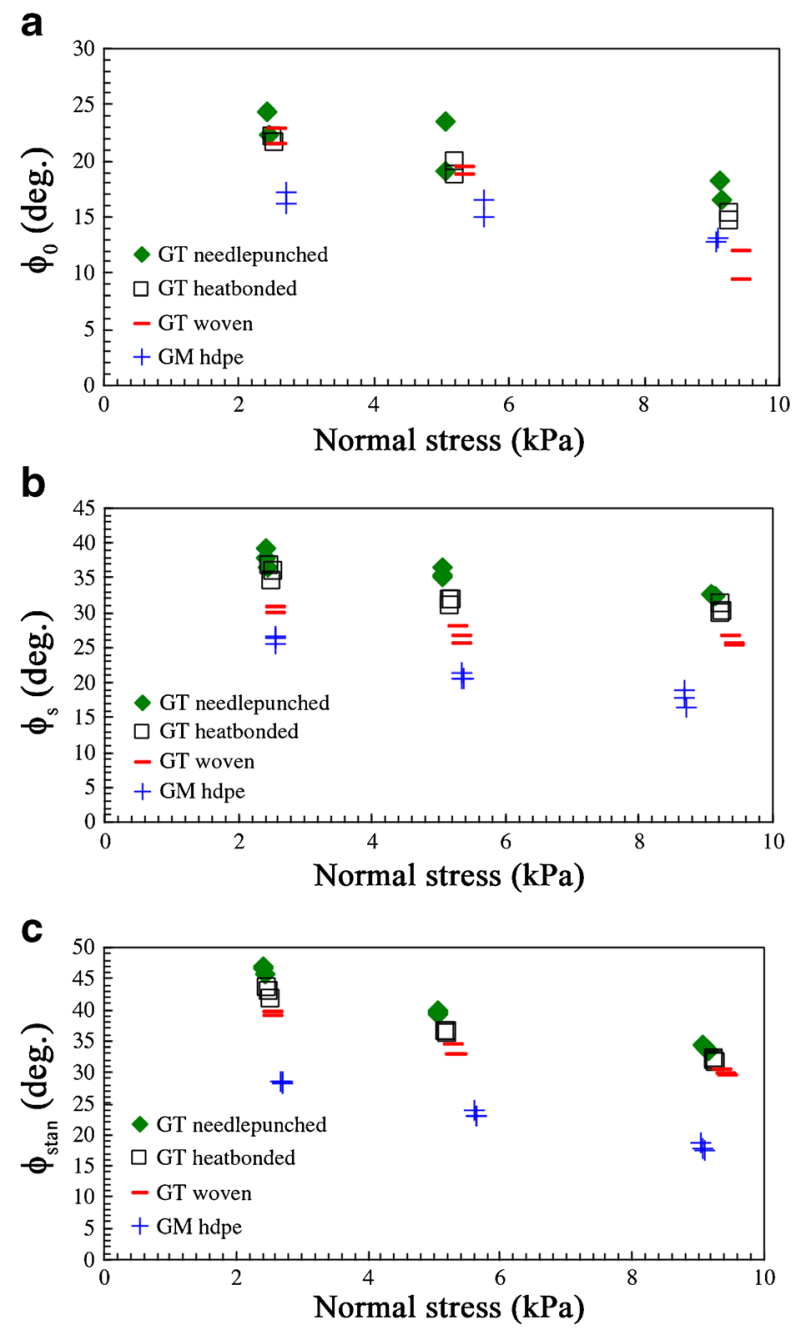

Fig. 57 Inclined plane tests results for compacted soil-geotextile interfaces versus the normal stress: a $\phi_{0}, \mathbf{b}$, $\phi_{S}$, and $\mathbf{c} \phi_{\text {stan }}$ (after Pitanga et al. [106])

Pitanga et al. [106] extended the study of Gourc and Reyes Ramirez [116] considering the interface behavior between different geosynthetic materials (comprising geotextile, reinforced geomat (geotextile+geomat), and geomembrane) and compacted soils (silty sand). In this set of tests, the soil-geosynthetic interaction was characterized for all the interfaces by a "gradual sliding" behavior. Figure 56 illustrates the typical trend of soil-geotextile interfaces at different normal stress ranging from 2.8 to $10.4 \mathrm{kPa}$. The resulting interface shear strength angles with respect to the normal stress were also schematized in Fig. 57.

The main findings of this study are as follows: (i) the shear strength angles tend to decrease significantly with normal stress, (ii) the mode of sliding leads to the different mechanical properties of the interface; as a first approximation, gradual and sudden sliding were compared to the strain hardening and the strain softening behavior observed in direct shear tests. 
Furthermore, it was noticed that, in some cases, when testing compacted soil with geosynthetics, failure primarily occurred throughout the cover soil instead of between interfaces. For the first time, some tests were performed to characterize the soil-soil interface showing that the shear zone enters in the layer of the soil support (upper box) and it is not limited to the interface.

Recently, Monteiro et al. [112] presented the results of incline plane and direct shear tests conducted on different geomembrane products (PVC and smooth and textured HDPE) in contact with a sandy soil prepared at various degrees of saturation. The results presented show that the interface shear strength angle between soil and geomembranes is insensitive to the variation of the soil degree of saturation. A progressive interface failure mechanism was observed in the tests with PVC geomembrane due to the more extensible nature of this type of geomembrane. The largest values of interface shear strength angles were obtained, as expected, with the textured HDPE geomembrane, whereas similar lower values were obtained with the smooth PVC and HDPE geomembranes.

Finally, the inclined plane test enables the acquisition of much more complete information than the merely threshold shear strength angle. In light of this, the effect of creep [105], of the surfaces abrasion [118], and of temperature on the determination of shear strength angles can be assessed.

\section{Conclusions on Soil-Geosynthetic and on Geosynthetic-Geosynthetic Interaction in Inclined Plane Test}

The inclined plane tests are easy to perform and useful to study the stability of liner systems under low normal stress. In fact, the inclined plane test is able to properly model the sliding mechanisms of liners on slopes.

This test allows the assessment of much more complete information than the merely interface shear strength angle. The inclined plane test provides static and dynamic evaluation of the interface behavior using displacement and force test procedures; it was also found that the interface shear strength depends on the current kinematic conditions. During the inclined plane test, it is possible to evaluate the effect of some factors such as creep, surfaces abrasion, and temperature.

The tests can also be employed to assess the effectiveness of cover soil reinforcement, the influence of water flow on the stability of composite systems, and the interface interaction of multilayer systems reproducing similar field conditions.

\section{References}

1. Jewell, R.A., Milligan, G.W.E., Sarsby, R.W., Dubois, D.: Interaction between soil and geogrids Telford, T. (ed.) Prooceedings of the Conference on Polymer Grid Reinforcement in Civil Engineering. 1984, pp. 18-30

2. ASTM D6706-01: Standard test method for measuring geosynthetic pullout resistance in soil. In: ASTM (ed.) Annual Book of ASTM Standards. American Society for Testing and Materials, (2001)

3. Moraci, N., Montanelli, F.: Analisi di prove disfilamento di geogriglie estruse installate in terreno granulare compattato (Evaluation of pullout behaviour of geogrids embedded in compacted granular soils). Rivista Italiana di Geotecnica (Italian Geotechnical Journal), (4), 5-21 (2000)

4. Palmeira, E.M., Milligan, G.W.E.: Scale and other factors affening the results of pull-out tests of grid buried in sand. Geotechnique 39(3), 511-524 (1989) 
5. Wilson-Fahmy, R.F., Koerner, R.M.: Finite element modelling of soil-geogrid interaction with application to the behavior of geogrids in a pullout loading condition. Geotext. Geomembr. 12(5), 479-501 (1993)

6. Carrubba, P., Montanelli, F., Moraci, N.: Long-term behaviour of an instrumented wall reinforced with geogrids. In: 2nd European Conference on Geosynthetics, Bologna, Italy, October 2000

7. Moraci, N., Gioffrè, D.: A simple method to evaluate the pullout resistance of extruded geogrids embedded in a compacted granular soil. Geotext. Geomembr. 24(3), 116-128 (2006)

8. Moraci, N., Recalcati, P.: Factors affecting the pullout behaviour of extruded geogrids embedded in compacted granular soil. Geotext. Geomembr. 24(4), 220-242 (2006)

9. Sugimoto, M., Alagiyawanna, A.M.N., Kadoguchi, K.: Influence of rigid and flexible face on geogrid pullout tests. Geotext. Geomembr. 19(5), 257-277 (2001)

10. Palmeira, E.M.: Soil-geosynthetic interaction: modelling and analysis. Geotext. Geomembr. 27, 368390 (2009)

11. Farrag, K., Morvant, M.: Effect of clamping mechanism on pullout and confined extension tests. ASTM STP1379-EB Grips, Clamps, Clamping Techniques, and Strain Measurement for Testing of Geosynthetics, 89-96 (2000).

12. Johnston, R.S., Romstad, K.M.: Dilation and boundary effects in large scale pull-out test. In: XIII International Conference on Soil Mechanics and Foundations Engineering New Delhi, India (1994)

13. Chang, D.T.-T., Chang, F.C., Yang, G.S., Yan, C.Y.: The influence factors study for geogrid pullout test. ASTM STP1379-EB Grips, Clamps, Clamping Techniques, and Strain Measurement for Testing of Geosynthetics, 14 (2000).

14. Hayashi, S., Alfaro, M.C., Watanabe, K.: Dilatancy effects of granular soil on the pullout resistance of strip reinforcement. In: International Symposium on Earth Reinforcement, Fukuoka, Kyushu, Japan, November 1996, pp. 39-44

15. Lopes, M.L., Ladeira, M.: Influence of confinement, soil density and displacement rate on soil-geogrid interaction. Geotext. Geomembr. 14, 543-554 (1996)

16. Cazzuffi, D., Moraci, N., Calvarano, L.S., Cardile, G., Gioffrè, D., Recalcati, P.: European experience in pullout tests: Part 2-the influence of vertical effective stress and of geogrid length on interface behaviour under pullout conditions. Geosynthetics 32(2), 40-50 (2014)

17. Johnston, R.S., Romstad, K.M.: Dilation and boundary effects in large scale pull-out tests. In: 12th International Conference on Soil Mechanics and Foundation Engineering, Rio De Janeiro, Brasil 1989, pp. $1263-1266$

18. Raju, D.M.: Monotonic and cyclic pullout resistance of geosynthetic. Ph.D., University of British Columbia (1995)

19. Bolt, A.F., Duszynska, A.: Pull-out testing of geogrid reinforcements. In: 2nd European Conference on Geosynthetics, Bologna, Italy, October 2000

20. Farrag, K., Acar, Y.B., Juran, I.: Pull-out resistance of geogrid reinforcements. Geotext. Geomembr. 12(2), 133-159 (1993)

21. Lopes, M.L., Ladeira, M.: Role of specimen geometry, soil height and sleeve length on the pull-out behaviour of geogrids. Geosynth. Int. 3(6), 701-719 (1996)

22. Raju, D.J., Lo, S.C.R., Fannin, R.J., Gao, J.: Design and interpretation of large scale laboratory pullout tests. In: 7th Australia-New Zealand Conference on Geomechanics, Adelaide, Australia 1996, pp. 151156

23. Hayashi, S., Shahu, J.T., Watanabe, K.: Effect of restrained dilatancy on pullout resistence of strip reinforcement. In: Geosynthetics Asia '97, Bangalore, India, 26-29 November 1997, pp. 39-44

24. Moraci, N., Romano, G., Montanelli, F.: Interface pullout behaviour of geogrids embedded in compacted granular soils. In: Vanicek (ed.) XIIIth European Conference on Soil Mechanics and Geotechnical Engineering, Prague, Czech Republic, 25-28 August 2003, pp. 837-841

25. Moraci, N., Cardile, G.: The use of pullout test results in the serviceability limit states design of earth reinforcement structures. In: GeoAfrica, Cape Town, 2-5 September 20092009

26. Moraci, N., Cardile, G.: Influence of cyclic tensile loading on pullout resistance of geogrids embedded in a compacted granular soil. Geotext. Geomembr. 27, 475-487 (2009)

27. Moraci, N., Cardile, G.: Deformative behaviour of different geogrids embedded in a granular soil under monotonic and cyclic pullout loads. Geotext. Geomembr. 32, 104-110 (2012)

28. Cazzuffi, D., Calvarano, L.S., Cardile, G., Moraci, N., Recalcati, P.: European experience in pullout tests: The influence of geogrid's geometry and structure on interface behaviour. Geosynthetics 29(5), 42-51 (2011) 
29. Gourc, J.P., Ratel, A., Delmas, P.: Design of fabric retaining walls: the displacement method. In: 3rd International Conference on Geotextiles, Vienna, Austria 1986, pp. 289-294, 1067-1072

30. Hanna, T.H., Touahmia, M.: Comparative Behaviour of Metal and Tensar Geogrid Strip Under Static and Repeated Loading. In: Geosynthetic 91, Atlanta 1991, pp. 575-585

31. Yasuda, S., Nagase, H., Marui, H.: Cyclic pull-out test of geogrids in soils. In: International Symposium on Earth Reinforcement Practice, Fukuoka, Japan 11-13 November 1992 1992, pp. 185-190

32. Raju, D.J., Fannin, J.: Monotonic and cyclic pull-out resistance of geogrids. Geotechnique 47(2), 331337 (1997)

33. Raju, D.J., Fannin, J.: Load-strain-displacement response of geosynthetic in monotonic and cyclic pullout. Can. Geotech. J. 35, 183-193 (1998)

34. Mayer, N., Nernheim, A., Kohler, U.: Geosynthetic-soil interaction under cyclic loading. In: 3rd European Geosynthetics Conference, Munich, Germany, 01-03 March 2004, pp. 635-639

35. Nernheim, A.: Interaktionsverhalten von Geokunststoff und Erdstoff bei statischen und zyklishen Beansprungen. Phd Thesis, TU Clausthal (2005)

36. Min, Y., Leshchinskyb, D., Ling, H.I., Kaliakin, V.N.: Effects of sustained and repeated tensile loads on geogrids embedded in sand. Geotech. Test. J. 18(2), 204-225 (1995)

37. Moraci, N., Cardile, G.: Cyclic pullout behaviour of extruded geogrids. In: 4th European Conference on Geosynthetics - Eurogeo4, Edinburgh, Scotland, 7-10 September 2008

38. Jewell, R.A.: Reinforcement bond capacity. Geotechnique 40(3), 513-518 (1990)

39. Peterson, L.M., Anderson, L.R.: Pullout Resistance of Welded Wire Mats Embedded in Soil. In., p. 106. Hilfiker Company, (1980)

40. Bergado, D.T., Chai, J.C.: Pullout force/displacement relationship of extensible grid reinforcements. Geotext. Geomembr. 13, 295-316 (1994)

41. Matsui, T., San, K.C., Nabeshima, Y., Amin, U.N.: Bearing mechanism of steel grid reinforcement in pullout test. In: International Symposium on Earth Reinforcement, Fukuoka, Kyushu, Japan, November 1996, pp. 101-105

42. Zhou, J., Chen, J.-F., Xue, J.-F., Wang, J.-Q.: Micro-mechanism of the interaction between sand and geogrid transverse ribs. Geosynth. Int. 19(6), 426-437 (2012)

43. Jewell, R.A.: Soil reinforcement with geotextile. CIRIA Thomas Telford, London (1996)

44. Palmeira, E.M.: Bearing force mobilisation in pull-out tests on geogrids. Geotext. Geomembr. 22(6), 481-509 (2004)

45. Bergado, D.T., Shivashankar, R., Alfaro, M.C., Chai, J.-.C., Balasubramaniam, A.S.: Interaction behaviour of steel grid reinforcements in a clayey sand. Geotechnique 43(4), 589-603 (1993)

46. Dyer, M.R.: Observations of the stress distribution in crushed glass with applications to soil reinforcement. Ph.D. Thesis, University of Oxford (1985)

47. Milligan, G.W.E., Earl, R.F., Bush, D.I.: Observations of Photo-Elastic Pullout Tests on Geotextiles and Geogrids. In: 4th International Conference on Geotextiles, Geomembranes and Related Products 1990, pp. 747-751

48. Suksiripattanapong, C., Horpibulsuk, S., Chinkulkijniwat, A., Chai, J.C.: Pullout resistance of bearing reinforcement embedded in coarse-grained soils. Geotext. Geomembr. 36, 44-54 (2013)

49. Moraci, N., Cardile, G., Gioffrè, D.: A theoretical method to predict the pullout behaviour of extruded geogrids embedded in granular soils. In: 5th International Symposium on Earth Reinforcement,

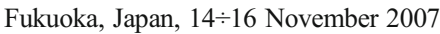

50. Teixeira, S.H.C., Bueno, B.S., Zornberg, J.G.: Pullout Resistance of Individual Longitudinal and Transverse Geogrid Ribs. Journal of Geotechnical and Geoenvironmental Engineering, 37-50 (2007).

51. Hausmann, M.R.: Engineering principles of ground modification. McGraw Hill, (1990)

52. Dixon, N.: Soil-geosynthetic interaction: interface behaviour. In: Proceedings, 9th International Conference on Geosynthetics, Guaruja, Brazil, May 23rd-27th 2010, pp. 563-582. International Geosynthetics Society

53. ASTM: Standard Test Method for Determining the Coefficient of Soil and Geosynthetic or Geosynthetic and Geosynthetic Friction by the Direct Shear Method. In, vol. D 5321. American Society for Testing and Materials, Philadelphia, (2008)

54. BS: Methods of test for geotextiles. Determination of sand-geotextile frictional behaviour by direct shear. In, vol. 6906 Part 8. British Standards Institution, (1991)

55. BS-EN-ISO: Geosynthetics - Determination of friction characteristics. Part 1 - Direct Shear tests. In, vol. 12957-1. British Standards Institution, (2005)

56. Baxter, D.J., Dixon, N., Fleming, P.R., Cromwell, K.: Refining shear strength characteristic value using experience. Geotech. Eng. 161, 247-257 (2008) 
57. Dixon, N., Jones, D.R.V., Fowmes, G.J.: Interface shear strength variability and its use in reliabilitybased landfill stability analysis. Geosynth. Int. 13(1), 1-14 (2006)

58. Jewell, R.A., Wroth, C.P.: Direct shear tests on reinforced sand. Geotechnique 37(1), 53-68 (1987)

59. Cerato, B., Lutenegger, A.J.: Specimen size and scale effects of direct shear box tests of sands. Geotech. Test. J. 29(6), 1-10 (2006)

60. Scarpelli, G., Wood, D.M.: Experimental observations of shear band patterns in direct shear tests. In: Vermeer, P.A., Luger, H.J. (eds.) IUTAM Symposiumon Deformation and Failure of Granular Materials, Delft, Netherlands 1982, pp. 473-484

61. Liu, C.-N., Zornberg, J.G., Chen, T.-.C., Ho, Y.-.H., Lin, B.-.H.: Behavior of geogrid-sand interface in direct shear mode. J. Geotech. Geoenviron. 135(12), 1863-1871 (2009)

62. Liu, C.-N., Ho, Y.-.H., Huang, J.-W.: Large scale direct shear tests of soil/PET-yarn geogrid interfaces. Geotext. Geomembr. 27, 19-30 (2009)

63. Cichy, W., Boulon, M., Desrues, J.: Etude experimentale stereophotogrammetrique des interfaces solsfondations a la boite de cisaillement direct. In: Flavigny, E., Cordary, D. (eds.) 4eme Coloque FrancoPolonais de Mecanique des Soils Appliquee Grenoble (France), September 1987, pp. 311-325

64. DeJaeger, J.: Influence of Grain Size and Shape on the Dry Sand Shear Behaviour. In: 13th International Conference on Soil Mechanics and Foundation Engineering 1994, pp. 13-16

65. DeJong, J.T., Randolph, M.E., White, D.J.: Interface load transfer degradation during cyclic loading: a microscale investigation. Soils Found. 43(4), 81-93 (2003)

66. Palmeira, E.M.: The study of soil-reinforcement interaction by means of large scale laboratory tests. Ph.D., University of Oxford (1987)

67. Palmeira, E.M., Milligan, G.W.E.: Scale effects in direct shear tests on sand. In: Proc. 12th ICSMFE, Rio, Brazil 1989, vol. 17, pp. 739-742

68. Palmeira, E.M., Milligan, G.W.E.: Large scale direct shear tests on reinforced soil. Soils Found. 229(1), 18-30 (1989)

69. Stone, K.J.L., Muir Wood, D.: Effects of dilatancy and particle size observed in model tests on sand. Soils Found. 32(4), 43-57 (1992)

70. ASTM: Standard Test Method for Direct Shear Test of Soils Under Consolidated Drained Conditions. In, vol. D 3080. American Society for Testing and Materials, Philadelphia, (1990)

71. Zhang, L., Thornton, C.: A numerical examination of the direct shear test. Geotechnique 4, 343-354 (2007)

72. Wang, J., Dove, E., Gutierrez, S.: Discrete-continuum analysis of shear banding in the direct shear test. Geotechnique 57(6), 513-526 (2007)

73. Wang, J., Gutierrez, S.: Discrete element simulations of direct shear specimen scale effects. Geotechnique 60(5), 395-409 (2010)

74. Hsieh, C., Hsieh, M.W.: Load plate rigidity and scale effects on the frictional behavior of sand/geomembrane interfaces. Geotext. Geomembr. 21, 25-47 (2003)

75. Shibuya, S., Mitachi, T., Tamate, S.: Interpretation of direct shear box testing of sands as quasi-simple shear. Geotechnique 47(4), 769-790 (1997)

76. Skempton, A.W., Bishop, A.W.: The measurement of the shear strength of soils. Geotechnique 2, 188192 (1950)

77. Mikasa, M.: New direct shear test apparatus. In: 15th Annual Convention Japanese Soc. Civ. Engrs, Tokyo (1960), pp. 45-48

78. Takada, N.: Mikasa's direct shear apparatus, testing procedures and results. Geotech. Test. J. 16(3), 314 322 (1993)

79. Jewell, R.A.: Direct shear tests on sand. Geotechnique 39(2), 309-322 (1989)

80. Lings, M.L., Dietz, M.S.: An improved direct shear apparatus for sand. Geotechnique 4, 245-256 (2004)

81. Kostkanovà, V., Herle, L.: Measurement of wall friction in direct shear tests on soft soil. Acta Geotech. 7, 333-342 (2012)

82. Stoewahse, C.: Ermittlung des Reibungsverhaltens von Geokunststoffen und Erdstoffen im Rahmenschergerät. In: Publications Institute for Soil Mechanics and Foundation Engineering, vol. 56. Hanover University, (2001)

83. Gourc, J.P., Lalarakotoson, S., Müller-Rochholtz, H., Bronstein, Z.: Friction measurements by direct shearing or tilting process-Development of a European standard. In: 1st European Conference on Geosynthetics - EUROGEO 1, Maastricht, The Netherlands (1996), pp. 1039-1046

84. Lalarakotoson, S., Villard, P., Gourc, J.P.: Shear strength characterization of geosynthetic interfaces on inclined planes. Geotech. Test. J. 22, 284-291 (1999)

85. Tatsuoka, F., Nakaumura, S., Huang, C.-.C., Tani, K.: Strength anisotropy and shear band direction in plane strain tests in sand. Soils Found. 30(1), 35-54 (1990) 
86. Simoni, A., Houlsby, G.T.: The direct shear strength and dilatancy of sand-gravel mixtures. Geotech. Geol. Eng. Geol. 24, 523-549 (2006)

87. Kim, B.-S., Shibuya, S., Park, S.-W., Kato, N.: Effect of opening on the shear behavior of granular materials in direct shear test. KSCE J. Civ. Eng. 16(7), 1132-1142 (2012)

88. Lee, K.M., Manjunath, V.R.: Soil-geotextile interface friction by direct shear tests. Can. Geotech. J. 37, 238-252 (2000)

89. Lopes, M.L., Silvano, R.: Soil/geotextile interface behaviour in direct shear and pullout movements. Geotech. Geol. Eng. 28, 791-804 (2010)

90. Calvarano, L.S., Cardile, G., Moraci, N., Recalcati, P.: The influence of reinforcement geometry and soil types on the interface behaviour in pullout conditions. In: 5th European Conference on Geosynthetics Eurogeo 5, Valencia, Spain (2012), pp. 708-714

91. Vieira, C.S., Lopes, M.L., Caldeira, L.M.: Sand-geotextile interface characterisation through monotonic and cyclic direct shear tests. Geosynth. Int. 20(1), 26-38 (2013)

92. Athanasopoulos, G.A.: Results of direct shear tests on geotextile reinforced cohesive soil. Geotext. Geomembr. 14, 619-644 (1996)

93. Jones, V., Russel, D., Dixon, N.: Shear strength properties of geomembrane/geotextile interfaces. Geotext. Geomembr. 16, 45-71 (1998)

94. Chu, L.-M., Yin, J.-.H.: Comparison of interface shear strength of soil nails measured by both direct shear box tests and pullout tests. Journal of Geotechnical and Geoenviromental Engineering 131(9), 1097-1107 (2005)

95. Cancelli, A., Rimoldi, P., Togni, S.: Frictional characteristics of geogrids by means of direct shear and pullout tests. In: International Symposium on Earth Reinforcement Practice, Kyushu, Japan (1992), pp. 29-34

96. Bergado, D.T., Chai, J.C., Abiera, H.O., Alfaro, M.C., Balasubramaniam, A.S.: Interaction between cohesive-frictional soil and various grid reinforcements. Geotext. Geomembr. 12(4), 327-349 (1993)

97. Cazzuffi, D., Picarelli, L., Ricciuti, A., Rimoldi, P.: Laboratory investigations on the shear strength of geogrid reinforced soils. ASTM Spec. Tech. Publ. 1190, 119-137 (1993)

98. Abu-Farsakh, M.Y., Coronel, J.: Characterization of cohesive soil-geosynthetic interaction from large direct shear test. In: 85th Transportation Research Board Annual Meeting, Washington D.C. (2006)

99. Ling, H.I., Wang, J.G., Leshchinsky, D.: Cyclic behaviour of soil-structure interfaces associated with modular-block reinforced soil-retaining walls. Geosynth. Int. 15(1), 14-21 (2008)

100. Blight, G.E.: Failures during construction of a landfill lining: a case analysis. Waste Manag. Res. 25, 327-333 (2007)

101. Wu, W., Wang, X.T., Aschauer, F.: Investigation on failure of a geosynthetic lined reservoir. Geotext. Geomembr. 26, 363-370 (2008)

102. Izgin, M., Wasti, Y.: Geomembrane-sand interface frictional properties as determined by inclined board and shear box tests. Geotext. Geomembr. 16(4), 207-219 (1998)

103. Wasti, Y., Özdüzgün, Z.B.: Geomembrane-geotextile interface shear properties as determined by inclined board and direct shear box tests. Geotext. Geomembr. 19, 45-57 (2001)

104. Palmeira, E.M., Lima, N.R.J., Mello, L.G.R.: Interaction between soils and geosynthetic layers in largescale ramp tests. Geosynth. Int. 9, 149-187 (2002)

105. Reyes Ramirez, R., Gourc, J.P.: Use of the inclined plane test in measuring geosynthetic interface friction relationship. Geosynth. Int. 10(5), 165-175 (2003)

106. Pitanga, H.N., Gourc, J.P., Vilar, O.M.: Interface shear strength of geosynthetics: evaluation and analysis of inclined plane tests. Geotext. Geomembr. 27, 435-446 (2009)

107. Briançon, L., Girard, H., Poulain, D.: Slope stability of lining systems - experimental modeling of friction at geosynthetic interfaces. Geotext. Geomembr. 20, 147-172 (2002)

108. Briançon, L., Girard, H., Gourc, J.P.: A new procedure for measuring geosynthetic friction with an inclined plane. Geotext. Geomembr. 29(5), 472-482 (2011)

109. Girard, H., Fischer, S., Alonso, E.: Problems of friction posed by the use of geomembranes on dam slopes - examples and measurements. Geotext. Geomembr. 9, 129-143 (1990)

110. Ling, H.I., Burke, C., Mohri, Y., Matsushima, K.: Shear strength parameters of soil-geosynthetic interfaces under low confining pressure using a tilting table. Geosynth. Int. 9(4), 373-380 (2002)

111. Lopes, P.C., Lopes, M.L., Lopes, M.P.: Shear behaviour of geosynthetics in the inclined plane testinfluence of soil particle size and geosynthetic structure. Geosynth. Int. 8(4), 327-342 (2001)

112. Monteiro, C.B., Araújo, G.L.S., Palmeira, E.M., Cordão Neto, M.P.: Soil-geosynthetic interface strength on smooth and texturized geomembranes under different test conditions In: 18th International Conference on Soil Mechanics and Geotechnical Engineering, Paris, France, 02-06 September 2013, pp. 3053-3056 
113. Pitanga, H.N., Gourc, J.P., Vilar, O.M.: Enhanced measurement of geosynthetic interface shear strength using a modified inclined plane device. Geotech. Test. J. 34(6), 10 (2011)

114. Reyes Ramirez, R., Gourc, J.P., Billet, P.: Influence of the friction test conditions on the characterization of the geosynthetics interfaces. In: Delmas, Gourc, Girard (eds.) 7th International Conference on Geosynthetics, Nizza, France, 22-27 September 2002, pp. 591-594

115. Palmeira, E.M., Viana, H.N.: Effectiveness of geogrids as inclusions in cover soils of slopes of waste disposal areas. Geotext. Geomembr. 21, 317-337 (2003)

116. Gourc, J.P., Reyes Ramìrez, R.: Dynamics-based interpretation of the interface friction test at the inclined plane. Geosynth. Int. 11, 439-454 (2004)

117. Carbone, L., Briançon, L., Gourc, J.P., Moraci, N., Carrubba, P.: Geosynthetic interface friction using Force Procedure at the Tilting Plane. In: 5th European Conference on Geosynthetics - Eurogeo 5, Valencia, Spain (2012), pp. 93-98

118. Carbone, L., Gourc, J.P., Briançon, L., Moraci, N., Carrubba, P.: What value of interface friction to select for geosynthetic liner on landfill slopes? In: Geosynthetics 2013, Long Beach, USA (2013), pp. 636 644

119. Giroud, J.P., Swan, R.H., Richer, P.J., Spooner, P.R.: Geosynthetic landfill cap: laboratory and field tests, design and construction. In: 4th International Conference on Geotextiles, Geomembranes and Related Products, The Hague, The Netherlands, June 1990, pp. 493-498. BALKEMA 